\title{
Chemistry of the thermosphere and ionosphere
}

\author{
D. G. Torr and M. R. Torr \\ Space Physics Research Laboratory, University of Michigan, Ann Arbor, Michigan 48109, U.S.A. \\ National Institute for Telecommunications Research of the South African C.S.I.R., P.O. Box 3718, Johannesburg, \\ South Africa
}

(Received 29 May 1978)

\begin{abstract}
The ionosphere offers an excellent laboratory for the study of atomic and molecular processes. Densities are low, permitting highly reactive species to accumulate in measurable quantities. Temporal and spatial scales are large, and the solar energy source causes substantial departures from thermodynamic equilibrium. This laboratory has been exploited by the Atmosphere Explorer Program of NASA. Simultaneous measurements of a large number of interrelated atmospheric parameters to altitudes as low as $150 \mathrm{~km}$ have provided data that can be analyzed in a quantitative manner to derive precise rates, as functions of temperature, for many important chemical reactions, including the reactions of electronically or vibrationally excited metastable species. Analysis of AE results has provided new information on the photochemical role of $\mathrm{N}$ in the thermosphere; the rate coefficients for dissociative recombination of $\mathrm{NO}^{+}, \mathrm{O}_{2}{ }^{+}$and $\mathrm{N}_{2}^{+}$; reactions of $\mathrm{O}^{+}$with $\mathrm{N}_{2}, \mathrm{~N}_{2}^{+}$with $\mathrm{O}$, and $\mathrm{O}^{2+}$ with $\mathrm{O}$; and reactions of metastable ions, atoms, and molecules. The progress in our understanding of ionospheric chemistry during the last few years shows the power of space science measurement programs carefully designed to provide rigorous tests of quantitative theoretical predictions.
\end{abstract}

\section{INTRODUCTION}

The response of the atmosphere to solar radiation is complex. Figure 1 which depicts ROBLE's (1975) model of the thermosphere, illustrates the complexity of the interactions involved. Many of these have been explored or extensively surveyed, but it was only with the advent of multi-parameter and multisatellite measurement programs coupled with incoherent scatter radar measurements of aeronomic parameters and comprehensive laboratory studies of reaction rates that a detailed understanding of the mechanisms involved began to emerge. Results obtained from these studies over the past few years have impacted our understanding of nearly every major process which occurs in the thermosphere. In many cases new processes have been discovered, or old concepts have been discarded or significantly revised. The main reason for recent progress is a marked improvement in the quality of measurements made in aeronomy. On the Atmosphere Explorer satellites for example (cf. Dalgarno et al., 1973), many aeronomic parameters are measured simultaneously with accuracies better than $10 \%$. With this kind of data it has become possible to realize a long standing ambition of aeronomers to use the atmosphere as a laboratory. This review has been limited to results obtained from the Atmosphere Explorer program, which has constituted NASA's main thrust in thermospheric aeronomy during the 1970 s.

Figure 2 illustrates schematically the main processes which govern the balance of ionization in the thermosphere. Significant advances have been made during the last 5 years in quantitatively understanding the processes involved. We review the most significant of these below. Emphasis is placed on the identification of new processes, the determination of rate coefficients, and on the role played by metastable species in the chemistry of the ionosphere and thermosphere. We begin this discussion with recent developments in our knowledge of processes which produce ionization in the thermosphere.

\section{SOURCES OF IONIZATION}

\subsection{Photoionization}

The primary source of ionization in the thermosphere is photoionization of neutral atmospheric constituents by solar extreme ultraviolet radiation. An accurate knowledge of the solar EUV flux as a function of wavelength as well as the related absorption and ionization cross sections is needed to 


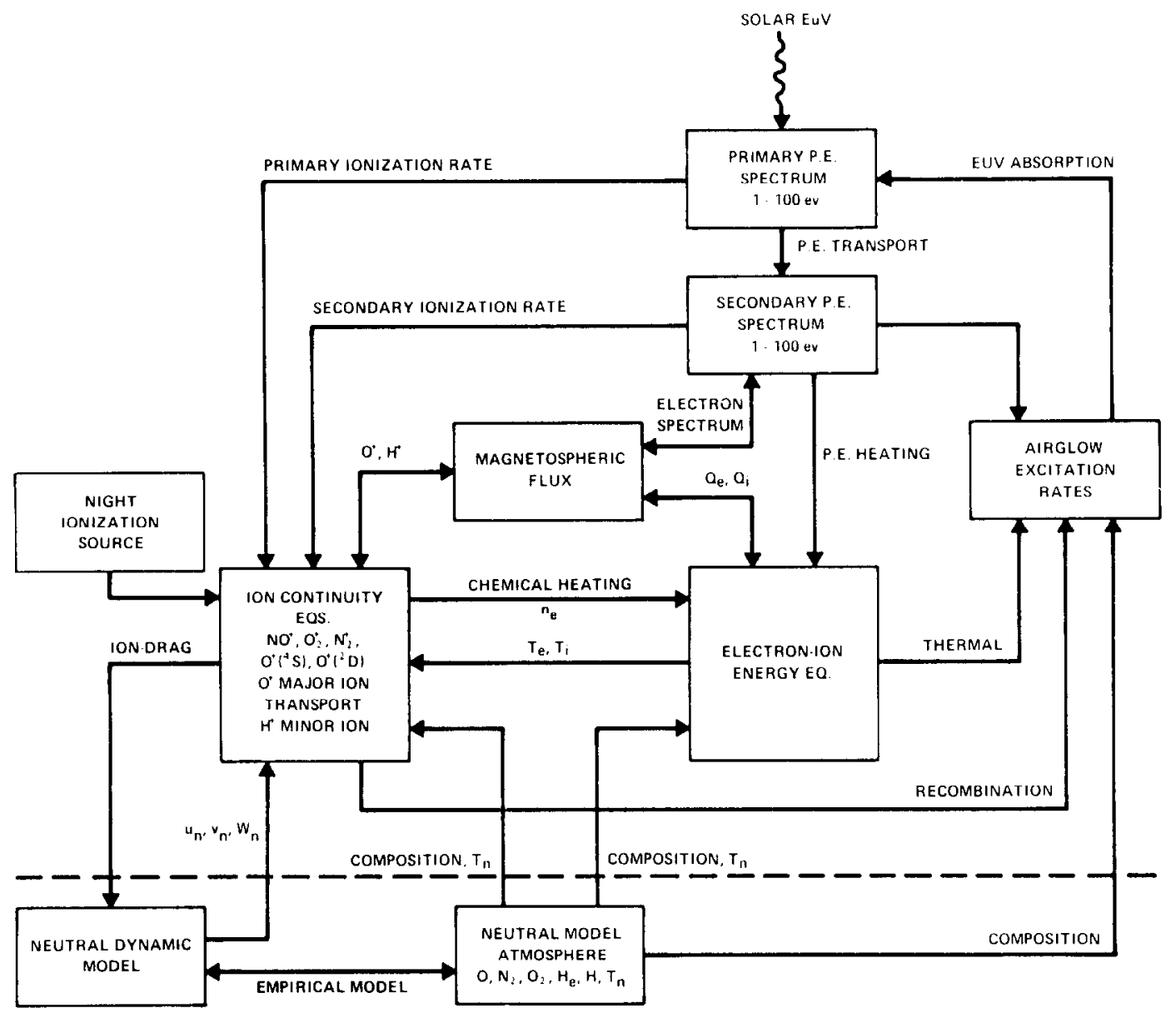

Fig. 1. Block diagram from ROBLE (1975) illustrating the various physical processes which influence the behavior of the ionosphere.

quantitatively model the ionosphere. The most comprehensive measurements of the solar EUV flux made to date are those of HinteregGer (1976). These measurements were made by the extreme ultraviolet spectrophotometers on the $\mathrm{AE}$ satellites (Hinteregger et al., 1973). Measurements have been made since December 1973. Tables of solar flux data have subsequently been published (HinTEREGGer, 1976; Heroux and HINTEREGGER, 1978; HiNTEREGGER et al., 1977) in the form of a summary reference spectrum. The complete reference spectrum tabulated at $\sim 1 \AA$ intervals comprises part of the on-line $\mathrm{AE}$ data base. Also available are factors for scaling selected wavelength ranges to reproduce the actual flux for any given day of the year for which measurements are available. These have been published for 1974 (HINTEREGGER et al., 1977).

It has become common practice for many years to scale the solar EUV flux according to variations in the solar $10.7 \mathrm{~cm}$ flux. Recent AE EUVS measurements indicate that this procedure is not justified. Hinteregger (1978a, b) has observed that the correlation between the EUV and $10.7 \mathrm{~cm}$ fluxes is deteriorating with the new solar cycle. The question arises as to whether the degradation in the correlation coefficient will affect neutral densities derived from atmospheric models which use the $10.7 \mathrm{~cm}$ flux as a solar index parameter. A comparison of measurements made by the $A E$ open source neutral mass spectrometer (NIER et al., 1973) with atomic oxygen densities derived from the MSIS model atmosphere of HEDIN et al. (1974, $1977 \mathrm{a}, \mathrm{b})$ indicates a disagreement which has increased over the last 2 years, i.e. 1976-77. [O] appears to be as low as $60 \%$ of the MSIS value at $300 \mathrm{~km}$ on some orbits.

The relative amplitude of the solar cycle variation in the EUV flux was about one fifth that of the $10.7 \mathrm{~cm}$ flux for solar cycle 20 (HinteregGer, 


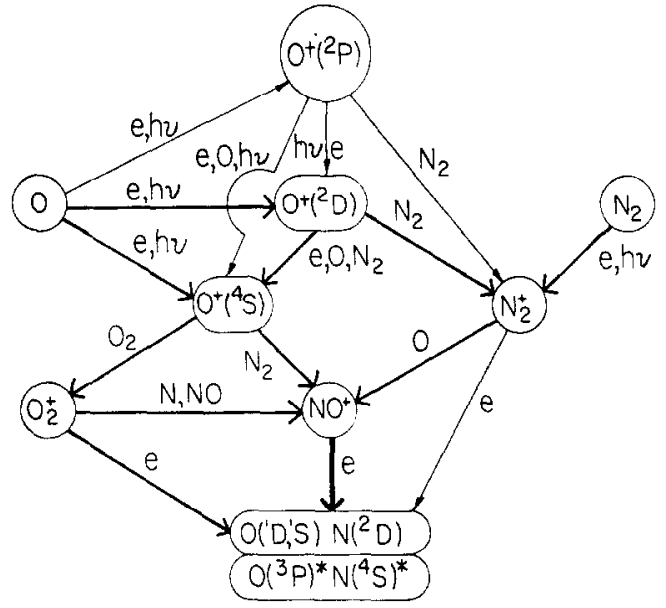

Fig. 2. Schematic illustration of the main processes which govern the balance of ionization in the thermosphere.

1978a). In the new cycle the EUV flux is higher than would be predicted using the $10.7 \mathrm{~cm}$ flux while optical depth measurements indicate that the increase in temperature, $T_{n}$, is smaller. HinTEREGGER (1978a) suggests that other sources of heat input must exist which are indirectly related to the $10.7 \mathrm{~cm}$ solar flux, since the latter currently provides a better index for modeling the neutral atmosphere than the direct measurements of the solar EUV flux. The $10.7 \mathrm{~cm}$ flux, however, should be used with caution in scaling tabulated reference values of the EUV flux, and in deriving neutral densities from atmospheric models until more data are available for cycle 21 .

Table 1a is a condensed version of HINTEREGGF.R's preliminary on-line AF. R74113 EUV reference spectrum which we have compiled in conjunction with OrsinI (1977). [The R74113 reference spectrum may be obtained from the National Space Science Data Center, Goddard Space Flight Center, Greenbelt, MD, U.S.A. In Table $1 \mathrm{~b}$ we present a recent update to $\mathrm{F} 74113$ published by Hinteregger (1978a).] Also included in Table 1a are absorption and ionization cross sections averaged over the same wavelength intervals. The original cross sections comprise part of the AE data basc, and are tabulated at the same wavelength intervals as the EUV fluxes given in HINTEREGGER's reference spectrum. The AE cross sections (which were compiled from many sources) will be published by KIRBY-DOCKEN et al. (1979).

We have compared production rates obtained with HiNTEREGGER's (1976) EUV fluxes and the cross sections of KIRBY-DOCKEN et al. (1978) with values derived using the data given in Table 1 . The agreement was excellent at altitudes above $150 \mathrm{~km}$. At altitudes below $150 \mathrm{~km}$ the attenuated fluxes differed by as much as $30 \%$ at large solar zenith angles.

\subsection{Photoelectron impact ionization}

The degradation of the primary photoelectrons ejected in the ionization of neutral constituents is a process of fundamental importance affecting the energetics of the thermosphere. Photoelectrons are a major source of heat and excitation, but only constitute about $25 \%$ of the total source of ionization.

The photoelectron flux has been calculated theoretically by numerous workers, and it has been measured experimentally. The most comprehensive set of measurements to date has been made with the AE photoelectron spectrometer (DoERING et al., 1973; Petersen et al., 1977). Theoretical results disagree with the $\mathrm{AE}$ data by a factor of 2 to 3. Initial calculations by VICTOR et al. (1976) were in agreement with measurements made by the AE$\mathrm{C}$ satellite. However, with the launch of AE-E in 1975 the AE-C measurements were subsequently revised and the conflict has not yet been resolved.

Experimenters and theoreticians agree on the shape of the energy spectrum, but disagree on the absolute magnitude by a factor of 2 to 3 . The results of VICTOR et al. (1976) are in harmony with the more recent and complete calculations of JASPerse (1978) and Prather et al. (1978). Recently, NAGY et al. (1977) derived results in harmony with the AE data. However, certain problems with one of the input parameters used has been identified which, if corrected, should bring the values of NAGY et al. into agreement with the other cited theoretical results. However, this will not resolve all the differences between NAGY et al. and the other theoreticians. Currently, the theoretical results of VICTOR et al. (1976) are in harmony with other measured geophysical quantities. For example, if the experimental values are correct, theoretical volume emission rates of several emissions would have to be increased significantly. These include the $7320 \AA \mathrm{O}^{+}\left({ }^{2} \mathrm{D}^{2} \mathrm{P}\right.$ ) emission (Rusch et al., 1977a), the $F$-region $5577 \AA \mathrm{O}\left({ }^{1} \mathrm{~S}\right)$ grecn linc (Frederick et al., 1976; Kopp et al., 1977a), the $3371 \AA \mathrm{N}_{2}$ second positive emission (KopP et al., 1977b). The theoretical fluxes of Victor et al. (1976) produce good agreement with the AE measurements of these emissions. An increase in the theoretical photoelectron flux of a factor of 2 to 3 would also detrimentally affect the heat balance studies of Hofry and Brace (1978). 
Table 1a. Solar flux and cross sections

\begin{tabular}{|c|c|c|c|c|c|c|c|c|}
\hline \multirow[b]{2}{*}{ Designation } & \multirow[b]{2}{*}{$\lambda, \AA$} & \multirow{2}{*}{$\begin{array}{l}\Phi / 10^{y} \\
\text { ph. } \mathrm{cm}^{-2} \mathrm{~s}^{-1}\end{array}$} & \multicolumn{3}{|c|}{$\begin{array}{l}\text { Total cross section } \\
\sigma_{\mathrm{eff}} \times 10^{18} \mathrm{~cm}^{2}\end{array}$} & \multicolumn{3}{|c|}{$\begin{array}{l}\text { Ionization cross sections } \\
\sigma_{\text {eff }} \times 10^{18} \mathrm{~cm}^{2}\end{array}$} \\
\hline & & & $\mathrm{O}^{\dagger}$ & $\mathrm{O}_{2}$ & $\mathrm{~N}_{2}$ & $\mathrm{O}^{\dagger}$ & $\mathrm{O}_{2}$ & $\mathrm{~N}_{2}$ \\
\hline 1. H Ly- $\alpha$ & 1025.7 & 2.65 & 0.00 & 1.60 & 0.00 & 0.00 & 1.00 & 0.00 \\
\hline 2. C II & 1010.2 & 0.11 & 0.00 & 1.40 & 0.00 & 0.00 & 1.30 & 0.00 \\
\hline 3. N III & 991.5 & 0.59 & 0.00 & 1.90 & 1.40 & 0.00 & 1.60 & 0.00 \\
\hline 4. Excl. 1, 2, 3 & $1027-990$ & 0.50 & 0.00 & 2.80 & 0.23 & 0.00 & 1.30 & 0.00 \\
\hline 5. C III & 977.0 & 4.40 & 0.00 & 21.80 & 68.10 & 0.00 & 1.90 & 0.00 \\
\hline 6. $\mathrm{HLy}-\gamma$ & 972.5 & 0.60 & 0.00 & 21.90 & 68.10 & 0.00 & 1.90 & 0.00 \\
\hline 7. Excl. 5,6 & $990-950$ & 0.26 & 0.00 & 23.10 & 45.00 & 0.00 & 1.90 & 0.00 \\
\hline 8. $\mathrm{HLy}-\delta$ & 949.7 & 0.30 & 0.00 & 30.10 & 7.16 & 0.00 & 2.30 & 0.00 \\
\hline 9. S VI & 944.5 & 0.13 & 0.00 & 23.40 & 39.80 & 0.00 & 2.40 & 0.00 \\
\hline 10. H Ly- $\varepsilon$ & 937.8 & 0.16 & 0.00 & 3.20 & 3.15 & 0.00 & 2.60 & 0.00 \\
\hline 11. S VI & 933.4 & 0.14 & 0.00 & 25.62 & 3.13 & 0.00 & 2.70 & 0.00 \\
\hline 12. H Ly-Z & 930.7 & 0.26 & 0.00 & 3.54 & 3.13 & 0.00 & 2.75 & 0.00 \\
\hline 13. Excl. 8-12 & $950-912$ & 0.12 & 0.00 & 18.20 & 35.74 & 0.00 & 2.70 & 0.00 \\
\hline 14. H Ly-con't. & $912-890$ & 4.40 & 2.96 & 12.50 & 46.00 & 2.96 & 3.40 & 0.00 \\
\hline 15. H Ly-con't. & $890-860$ & 3.80 & 3.00 & 10.30 & 44.30 & 3.00 & 3.20 & 0.00 \\
\hline 16. H Ly-con't. & $860-840$ & 1.10 & 3.04 & 15.10 & 19.50 & 3.04 & 4.30 & 0.00 \\
\hline 17. O II, III & $832-835$ & 0.63 & 3.07 & 24.00 & 0.00 & 3.07 & 6.50 & 0.00 \\
\hline 18. Excl. 17 & $840-810$ & 0.86 & 3.10 & 28.70 & 13.70 & 3.10 & 7.70 & 0.00 \\
\hline 19. & $810-796$ & 0.23 & 3.10 & 40.70 & 21.30 & 3.10 & 9.50 & 0.00 \\
\hline 20. OIV & 790.21 & 0.37 & 3.11 & 31.20 & 29.20 & 3.11 & 9.60 & 17.70 \\
\hline 21. OIV & 787.70 & 0.20 & 3.11 & 30.40 & 16.26 & 3.11 & 9.50 & 9.85 \\
\hline 22. $\mathrm{S} \mathrm{V}$ & 786.50 & 0.10 & 3.11 & 30.20 & 16.26 & 3.11 & 9.60 & 9.84 \\
\hline 23. $\mathrm{Ne}$ VIII & 780.30 & 0.22 & 3.12 & 28.60 & 24.70 & 3.12 & 10.00 & 15.14 \\
\hline 24. Excl. 20-23 & $796-780$ & 0.18 & 3.11 & 31.10 & 37.10 & 3.11 & 9.60 & 19.70 \\
\hline 25. Ne VIII & 770.40 & 0.28 & 3.12 & 24.90 & 9.72 & 3.12 & 9.60 & 6.60 \\
\hline 26. N III, IV & 764.60 & 0.16 & 3.13 & 22.70 & 35.50 & 3.13 & 8.50 & 23.40 \\
\hline 27. $\mathrm{OV}$ & 760.40 & 0.09 & 3.13 & 23.70 & 30.27 & 3.13 & 8.37 & 19.36 \\
\hline 28. Excl. $25-27$ & $780-760$ & 0.17 & 3.12 & 24.40 & 26.20 & 3.12 & 9.20 & 18.20 \\
\hline 29. & $760-740$ & 0.12 & 3.13 & 23.20 & 27.60 & 3.13 & 9.90 & 18.40 \\
\hline 30. & $740-732$ & 0.02 & 3.13 & 31.60 & 29.60 & 3.13 & 19.00 & 25.20 \\
\hline 31. O III & 703.40 & 0.07 & 7.23 & 31.80 & 26.34 & 7.23 & 18.00 & 20.80 \\
\hline 32. Excl. 31 & $732-700$ & 0.08 & 7.10 & 32.90 & 33.60 & 7.10 & 18.60 & 25.30 \\
\hline 33. N III & 685.70 & 0.07 & 7.36 & 26.25 & 26.25 & 7.36 & 18.43 & 21.62 \\
\hline 34. & $700-665$ & 0.07 & 7.35 & 26.20 & 31.20 & 7.35 & 22.30 & 25.60 \\
\hline 35. & $665-630$ & 0.04 & 9.90 & 25.30 & 25.00 & 9.90 & 21.00 & 20.70 \\
\hline 36. $\mathrm{OV}$ & 629.73 & 1.73 & 10.06 & 25.85 & 23.20 & 10.06 & 25.85 & 18.80 \\
\hline 37. $\mathrm{Mg} \mathrm{X}$ & 625.28 & 0.24 & 10.05 & 25.82 & 23.20 & 10.05 & 25.82 & 18.78 \\
\hline 38. $\mathrm{Mg} \mathrm{X}$ & 609.85 & 0.53 & 10.16 & 26.13 & 23.10 & 10.16 & 26.13 & 18.64 \\
\hline 39. Excl. 36-37 & $630-600$ & 0.02 & 10.11 & 25.86 & 23.18 & 10.11 & 25.86 & 18.70 \\
\hline 40. O III & 599.60 & 0.16 & 10.20 & 26.62 & 23.11 & 10.20 & 26.62 & 23.11 \\
\hline 41. He I & 584.33 & 1.27 & 10.24 & 22.01 & 23.11 & 10.24 & 22.01 & 23.11 \\
\hline 42. OIV & 554.51 & 0.72 & 10.24 & 25.56 & 24.74 & 10.24 & 25.56 & 24.74 \\
\hline 43. $\mathrm{He} \mathrm{I}$ & 537.03 & 0.14 & 10.20 & 25.20 & 25.30 & 10.20 & 25.20 & 25.30 \\
\hline 44. O III & 507.90 & 0.16 & 10.06 & 22.68 & 22.40 & 10.06 & 22.68 & 22.40 \\
\hline 45. SI XII & 499.27 & 0.10 & 10.00 & 22.05 & 21.98 & 10.00 & 22.05 & 21.98 \\
\hline 46. Excl. $39-44$ & $600-480$ & 0.47 & 10.04 & 22.73 & 22.64 & 10.04 & 22.73 & 22.64 \\
\hline 47. Nc VII & 465.22 & 0.27 & 9.71 & 20.39 & 21.84 & 9.71 & 20.39 & 21.84 \\
\hline 48. Excl. 46 & $480-460$ & 0.08 & 9.76 & 20.60 & 21.70 & 9.76 & 20.60 & 21.70 \\
\hline 49. & $460-435$ & 0.08 & 9.52 & 20.00 & 22.00 & 9.52 & 20.00 & 22.00 \\
\hline 50. & $435-400$ & 0.18 & 9.90 & 19.40 & 21.70 & 9.90 & 19.40 & 21.70 \\
\hline 51. $\mathrm{Mg}$ IX & 368.07 & 0.65 & 9.26 & 18.35 & 17.95 & 9.26 & 18.35 & 17.95 \\
\hline 52. Fe XVI & 360.76 & 0.32 & 9.15 & 18.12 & 17.36 & 9.15 & 18.12 & 17.36 \\
\hline 53. He II Ly- $\alpha$ & 303.78 & 7.70 & 8.40 & 16.00 & 11.61 & 8.40 & 16.00 & 11.61 \\
\hline 54. Excl. $50-52$ & $400-300$ & 0.41 & 8.72 & 17.38 & 15.00 & 8.72 & 17.38 & 15.00 \\
\hline 55. Fe XV & 284.15 & 0.21 & 8.03 & 14.80 & 10.58 & 8.03 & 14.30 & 10.58 \\
\hline 56. Excl. 54 & $300-280$ & 0.36 & 8.22 & 15.22 & 10.80 & 8.22 & 15.22 & 10.80 \\
\hline 57. Fe XIV & 274.24 & 0.30 & 7.81 & 14.09 & 10.28 & 7.81 & 14.09 & 10.28 \\
\hline 58. Fe XIV & 264.80 & 0.24 & 7.59 & 13.44 & 10.01 & 7.59 & 13.44 & 10.01 \\
\hline 59. Excl. 56-57 & $280-260$ & 0.57 & 7.77 & 13.95 & 10.11 & 7.77 & 13.95 & 10.11 \\
\hline 60. He II Ly- $\beta$. SI $\chi$ & 256.37 & 0.52 & 7.38 & 12.82 & 9.65 & 7.38 & 12.82 & 9.65 \\
\hline
\end{tabular}


Table 1a (continued)

\begin{tabular}{|c|c|c|c|c|c|c|c|c|}
\hline \multirow[b]{2}{*}{ Designation } & \multirow[b]{2}{*}{$\lambda, \AA$} & \multirow{2}{*}{$\begin{array}{c}\Phi / 10^{9} \\
\text { ph. } \mathrm{cm}^{-2} \mathrm{~s}^{-1}\end{array}$} & \multicolumn{3}{|c|}{$\begin{array}{c}\text { Total cross section } \\
\sigma_{\text {eff }} \times 10^{18} \mathrm{~cm}^{2}\end{array}$} & \multicolumn{3}{|c|}{$\begin{array}{l}\text { Ionization cross sections } \\
\sigma_{\text {eff }} \times 10^{18} \mathrm{~cm}^{2}\end{array}$} \\
\hline & & & $\mathrm{O}+$ & $\mathrm{O}_{2}$ & $\mathrm{~N}_{2}$ & $\mathrm{O}^{\dagger}$ & $\mathrm{O}_{2}$ & $\mathrm{~N}_{2}$ \\
\hline \multirow{18}{*}{$\begin{array}{l}61 . \text { Excl. } 59 \\
62 . \\
63 . \\
64 . \\
65 . \\
66 . \\
67 . \\
68 . \\
69 . \\
70 . \\
71 \\
72 \\
73 \\
74 . \\
75 \\
76 \\
77 \\
78 .\end{array}$} & $260-240$ & 1.27 & 7.28 & 12.40 & 9.48 & 7.28 & 12.40 & 9.48 \\
\hline & $240-220$ & 0.52 & 6.42 & 10.70 & 8.35 & 6.42 & 10.70 & 8.35 \\
\hline & $220-205$ & 0.29 & 6.14 & 9.30 & 7.20 & 6.14 & 9.30 & 7.20 \\
\hline & $205-190$ & 0.85 & 5.71 & 8.35 & 6.30 & 5.71 & 8.35 & 6.30 \\
\hline & $190-180$ & 1.00 & 5.29 & 7.50 & 5.60 & 5.29 & 7.50 & 5.60 \\
\hline & $180-165$ & 1.30 & 4.96 & 6.75 & 5.00 & 4.96 & 6.75 & 5.00 \\
\hline & $165-138$ & 0.27 & 4.30 & 5.32 & 3.80 & 4.30 & 5.32 & 3.80 \\
\hline & $138-103$ & 0.08 & 2.00 & 4.00 & 0.90 & 2.00 & 4.00 & 0.90 \\
\hline & $103-83$ & 0.19 & 0.70 & 1.40 & 0.55 & 0.70 & 1.40 & 0.55 \\
\hline & $83-62$ & 0.17 & 0.40 & 0.80 & 0.37 & 0.40 & 0.80 & 0.37 \\
\hline & $62-41$ & 0.11 & 0.22 & 0.44 & 0.18 & 0.22 & 0.44 & 0.18 \\
\hline & $41-31$ & $5.1(-3)^{*}$ & 0.10 & 0.20 & 0.07 & 0.10 & 0.20 & 0.07 \\
\hline & $31-22.8$ & $1.0(-2)$ & 0.045 & 0.09 & 1.00 & 0.045 & 0.09 & 1.00 \\
\hline & $22.8-15$ & $6.4(-3)$ & 0.35 & 0.70 & 0.36 & 0.35 & 0.70 & 0.36 \\
\hline & $15-10$ & $5.0(-5)$ & 0.135 & 0.27 & 0.15 & 0.135 & 0.27 & 0.15 \\
\hline & $10-5$ & $1.5(-4)$ & 0.037 & 0.075 & 0.045 & 0.037 & 0.075 & 0.045 \\
\hline & $5-3$ & $2.0(-6)$ & 0.006 & 0.012 & 0.0065 & 0.006 & 0.012 & 0.0065 \\
\hline & $3-1$ & $1.0(-3)$ & 0.001 & 0.002 & 0.0015 & 0.001 & 0.002 & 0.0015 \\
\hline \multicolumn{9}{|c|}{$\begin{array}{l}\begin{array}{l}*(-3)=\times 10^{-3} \\
+ \text { For: } 1 \AA \leq \lambda \leq 665 \AA \\
\sigma\left({ }^{4} S\right)=0.30 \times \sigma(\text { total }) \\
\sigma\left({ }^{2} D\right)=0.45 \times \sigma(\text { total }) \\
\sigma\left({ }^{2} P\right)=0.25 \times \sigma(\text { total })\end{array} \\
\text { The branching ratios for the }{ }^{4} \\
\text { ratios). }\end{array}$} \\
\hline \multirow{2}{*}{$\begin{array}{c}\text { Wavelength } \\
\text { range } \\
\AA\end{array}$} & \multicolumn{2}{|c|}{$\begin{array}{l}\text { Photon fluxes } \\
10^{9} \mathrm{ph} . \mathrm{cm}^{-2} \mathrm{~s}^{-1}\end{array}$} & Ratio & \multicolumn{2}{|c|}{$\begin{array}{c}\text { Energy fluxes } \\
10^{-3} \mathrm{erg} \mathrm{cm}^{-2} \mathrm{~s}^{-1}\end{array}$} & \multirow{2}{*}{$\begin{array}{l}\text { Ratio } \\
F / R\end{array}$} & \multicolumn{2}{|c|}{$\begin{array}{c}\text { Number of } \\
\text { entries }\end{array}$} \\
\hline & F74113 & R74113 & $F / R$ & F74113 & R74113 & & $F$ & $\mathbf{R}$ \\
\hline $50-150$ & 0.55 & 0.61 & 0.91 & 129 & 141 & 0.92 & 185 & 185 \\
\hline $150-250$ & 3.93 & 4.73 & 0.83 & 398 & 486 & 0.82 & 93 & 95 \\
\hline $250-350$ & 11.0 & 10,8 & 1.02 & 736 & 732 & 1.01 & 47 & 47 \\
\hline $350-450$ & 1.35 & 1.38 & 0.98 & 70 & 73 & 0.96 & 56 & 55 \\
\hline $450-550$ & 0.99 & 1.14 & 0.87 & 40 & 46 & 0.87 & 63 & 66 \\
\hline $550-650$ & 4.67 & 4.55 & 1.03 & 155 & 151 & 1.03 & 54 & 56 \\
\hline $650-750$ & 0.62 & 0.37 & 1.68 & 18 & 10 & 1.68 & 105 & 110 \\
\hline $750-850$ & 3.45 & 3.99 & 0.87 & 85 & 98 & 0.87 & 113 & 112 \\
\hline $850-950$ & 6.57 & 9.55 & 0.69 & 145 & 212 & 0.69 & 109 & 108 \\
\hline $950-1050$ & 13.9 & 13.1 & 1.06 & 275 & 259 & 1.06 & $\mathbb{1 1 0}$ & 108 \\
\hline $1050-1150$ & 3.75 & 4.95 & 0.76 & 68 & 89 & 0.76 & 105 & 106 \\
\hline $1150-1250$ & 264 & 283 & 0.93 & 4312 & 4622 & 0.93 & 105 & 105 \\
\hline $1250-1350$ & 16.5 & 19.7 & 0.84 & 250 & 298 & 0.84 & 109 & 108 \\
\hline $1350-1450$ & 17.8 & 18.7 & 0.95 & 252 & 264 & 0.95 & 104 & 103 \\
\hline $1450-1550$ & 45.4 & 52.6 & 0.86 & 599 & 688 & 0.87 & 104 & 103 \\
\hline $1550-1650$ & 95.5 & 104 & 0.91 & 1182 & 1295 & 0.91 & 108 & 104 \\
\hline $1650-1750$ & 355 & 363 & 0.98 & 4135 & 4221 & 0.98 & 105 & 106 \\
\hline $1750-1850$ & 961 & 924 & 1.04 & 10,564 & 10,164 & 1.04 & 103 & 103 \\
\hline $1850-1950$ & 1862 & 1872 & 0.99 & 19,411 & 19,516 & 0.99 & 100 & 100 \\
\hline
\end{tabular}

From Heroux and Hinteregger (1978).

Note: The intensities given in the wavelength bands include like intensities. This must be taken into account when scaling intensities. 
Table 1c. Solar UV reference spectrum F74113 for 23 April 1974

\begin{tabular}{|c|c|c|c|}
\hline \multirow[b]{2}{*}{ Wavelength, $\AA$} & \multirow[b]{2}{*}{ Ion } & \multicolumn{2}{|c|}{ Intensity incident on Earth } \\
\hline & & $10^{9}$ ph. $\mathrm{cm}^{-2} \mathrm{~s}^{-1}$ & $10^{-3} \mathrm{erg} \mathrm{cm}^{-2} \mathrm{~s}^{-1}$ \\
\hline $50-100$ & & 0.42 & 113 \\
\hline $100-150$ & & 0.15 & 24 \\
\hline $150-200$ & & 2.4 & 271 \\
\hline $200-250$ & & 1.6 & 139 \\
\hline 256.3 & He II, Si X & 0.46 & 36 \\
\hline 284.15 & Fe XV & 0.21 & 15 \\
\hline $250-300$ & & 2.3 & 166 \\
\hline 303.78 & He II & 6.9 & 450 \\
\hline $300-350$ & & 8.7 & 530 \\
\hline 368.07 & Mg IX & 0.65 & 35 \\
\hline $350-400$ & & 1.02 & 55 \\
\hline $400-450$ & & 0.39 & 18 \\
\hline 465.22 & NE VII & 0.29 & 12.4 \\
\hline $450-500$ & & 0.59 & 24 \\
\hline $500-550$ & & 0.49 & 19 \\
\hline 554.378 & OIV & 0.72 & 26 \\
\hline 584.33 & $\mathrm{He} \mathrm{I}$ & 1.3 & 44 \\
\hline $550-600$ & & 2.2 & 76 \\
\hline 609.76 & $\operatorname{MgX}$ & 0.53 & 17 \\
\hline 629.73 & OV & 1.6 & 50 \\
\hline $600-650$ & & 2.3 & 74 \\
\hline $650-700$ & & 0.11 & 3.2 \\
\hline 703.36 & O III & 0.36 & 10 \\
\hline $700-750$ & & 0.49 & 13.4 \\
\hline 765.15 & N IV & 0.17 & 4.4 \\
\hline 770.41 & $\mathrm{Ne}$ VIII & 0.26 & 6.7 \\
\hline 789.368 & OIV & 0.68 & 10.8 \\
\hline $750-800$ & & 1.8 & 46 \\
\hline $800-850$ & & 1.5 & 35 \\
\hline $850-900$ & & 3.5 & 78 \\
\hline $900-950$ & & 3.3 & 71 \\
\hline 977.02 & C III & 4.4 & 89 \\
\hline $950-1000$ & & 6.0 & 121 \\
\hline 1025.72 & H I & 3.5 & 68 \\
\hline 1031.91 & $\mathrm{OVI}$ & 2.1 & 40 \\
\hline $1000-1050$ & & 8.1 & 156 \\
\hline $1050-1100$ & & 2.9 & 52 \\
\hline $1100-1150$ & & 0.91 & 16 \\
\hline $1150-1200$ & & 4.4 & 74 \\
\hline 1215.67 & H I & 251 & 4100 \\
\hline $1200-1250$ & & 259 & 4200 \\
\hline $1250-1300$ & & 4.1 & 64 \\
\hline 1302.17 & OI & 1.10 & 17 \\
\hline 1304.86 & OI & 1.13 & 17 \\
\hline 1306.03 & O I & 1.23 & 19 \\
\hline 1334.53 & C II & 1.8 & 27 \\
\hline 1335.70 & C II & 2.5 & 37 \\
\hline $1300-1350$ & & 12.4 & 186 \\
\hline 1393.76 & Si IV & 1.3 & 19 \\
\hline $1350-1400$ & & 7.4 & 107 \\
\hline 1402.77 & SiIV & 0.91 & 12.9 \\
\hline $1400-1450$ & & 10.4 & 145 \\
\hline $1450-1500$ & & 16.2 & 218 \\
\hline 1548.19 & CIV & $\begin{array}{r}10.2 \\
3.8\end{array}$ & $\begin{array}{r}210 \\
49\end{array}$ \\
\hline $1500-1550$ & & 29 & 381 \\
\hline 1550.77 & C IV & 1.9 & 25 \\
\hline $1561.0 \S$ & C I & 2.5 & 32 \\
\hline $1550-1600$ & & 40 & 503 \\
\hline $1600-1650$ & & 56 & 681 \\
\hline 1657.28 & C I & 8.5 & 102 \\
\hline
\end{tabular}


Table 1c (continued)

\begin{tabular}{|c|c|c|c|}
\hline \multirow[b]{2}{*}{ Wavelength, $\AA$} & \multirow[b]{2}{*}{ Ion } & \multicolumn{2}{|c|}{ Intensity incident on Earth } \\
\hline & & $10^{9}$ ph. $\mathrm{cm}^{-2} \mathrm{~s}^{-1}$ & $10^{-3} \mathrm{erg} \mathrm{cm}^{-2} \mathrm{~s}^{-1}$ \\
\hline $1650-1700$ & & 130 & 1540 \\
\hline $1700-1750$ & & 225 & 2590 \\
\hline $1750-1800$ & & 357 & 3990 \\
\hline 1808.01 & Si II & 9.2 & 101 \\
\hline 1816.93 & & 14.2 & 155 \\
\hline 1816.45 & & 5.5 & 60 \\
\hline $1800-1850$ & & 604 & 6570 \\
\hline $1850-1900$ & & 777 & 8230 \\
\hline $1900-1940$ & & 829 & 8580 \\
\hline
\end{tabular}

From Heroux and Hinteregger (1978).

$\S$ From averaged weighted energy levels of the multiplet. Integrated intensity for the multiplet is given.

The full calculation of the photoelectron flux as a function of energy is tedious and for many problems it is adequate to scale the photoionization production rate to simulate the additional impact source. Currently, some differences exist between various groups concerning the values that should be adopted for these scaling factors. OpPENHEIMER et al. (1977a), using the electron impact cross sections compiled by G. Victor (which comprise part of the $\mathrm{AE}$ on line data base), derived the values given in Table 2. Also shown in Table 2 are values that have been adopted by D. TORR and TORR (1978). Their lower values for $\mathrm{O}^{+}$are based on airglow observations of $\mathrm{O}^{+}\left({ }^{2} D^{-}{ }^{2} P\right) 7320 \AA$ emission in the aurora which are significantly smaller than theoretical values derived using the AE cross sections compiled by G. VICTOR. Figure 3 shows the $7320 \AA$ auroral results of SwENSON (1976) and HAys et al. (1975). They used a combination of high altitude satellite measurements made with $\mathrm{AE}$ and low altitude rocket measurements made with the Michigan Airglow Payload to demonstrate that quenching could not account for the low observed $7320 \AA$ intensities. The effect of quenching at $220 \mathrm{~km}$ is small compared with $120 \mathrm{~km}$. Thus, the emission could only be uniformly reduced to match the measurements at both low and high altitudes if the source function is reduced. Whether the reason for this is due to a low cross section has not yet been established. Rusch et al. (1976, 1977a) studied the $7320 \AA$ dayglow on $\mathrm{AE}$ and found that the emission is consistent with the measured EUV fluxes of Heroux and Hinteregger (1978) if the photoelectron source is negligible. MERIWETHER et al. (1978) have drawn the same conclusion from ground based observations of the $7320 \AA$ emission. In the face of this conflict TORR and TORR (1978a) adopted intermediate values for electron impact $\mathrm{O}^{+}$

Table 2. Unattenuated photoionization frequencies $\left(\mathrm{s}^{-1}\right)$

\begin{tabular}{ccl}
\hline $\mathrm{O}+h \nu \rightarrow \mathrm{O}^{+}\left({ }^{4} \mathrm{~S}\right)+e$ & $1.39 \times 10^{-7 *}$ & OPPENHEIMER et al. $(1977 \mathrm{a})$ \\
$\mathrm{O}+h \nu \rightarrow \mathrm{O}^{+}\left({ }^{2} \mathrm{D}\right)+e$ & $9.6 \times 10^{-8 *}$ & OPPENHEIMER et al. $(1977 \mathrm{a})$ \\
$\mathrm{O}+h \nu \rightarrow \mathrm{O}^{+}\left({ }^{2} \mathrm{P}\right)+e$ & $5.6 \times 10^{-8 *}$ & OPPENHEIMER et al. $(1977 \mathrm{a})$ \\
$\mathrm{N}_{2}+h \nu \rightarrow \mathrm{N}_{2}^{+}+e$ & $3.1 \times 10^{-7 *}$ & OPPENHEIMER et al. $(1976)$ \\
$\mathrm{N}_{2}+h \nu \rightarrow \mathrm{N}^{+}+\mathrm{N}+e$ & $1 \times 10^{-7}$ & OPPENHEIMER et al. $(1977 \mathrm{a})$ \\
$\mathrm{N}_{2}+h \nu \rightarrow \mathrm{N}^{+}\left({ }^{1} \mathrm{~S}\right)+e$ & $3 \times 10^{-9}$ & BURNSIDE et al. $(1978)$ \\
$\mathrm{O}_{2}+h \nu \rightarrow \mathrm{O}^{+}+\mathrm{O}+e$ & $9.2 \times 10^{-8 *}$ & OPPENHEIMER et al. $(1977 \mathrm{a})$ \\
$\mathrm{O}_{2}+h \nu \rightarrow \mathrm{O}_{2}^{+}\left(X^{2} \pi_{\mathrm{g}}\right)+e$ & $2.4 \times 10^{-7 *}$ & OPPENHEIMER et al. $(1977 \mathrm{a})$ \\
$\mathrm{O}_{2}+h \nu \rightarrow \mathrm{O}_{2}^{+}\left(a^{+} \pi_{\mathrm{u}}\right)+e$ & $1.6 \times 10^{-7 *}$ & OPPENHEIMER et al. $(1977 \mathrm{a})$ \\
$\mathrm{N}+h \nu \rightarrow \mathrm{N}^{+}+e$ & $1.9 \times 10^{-7}$ & D. TORR et al. $(1974)$ \\
$\mathrm{He}+h \nu \rightarrow \mathrm{He}^{+}+e$ & $6.8 \times 10^{-8}$ & OPPENHEIMER et al. $(1978)$ \\
$\mathrm{O}^{+}+h \nu \rightarrow \mathrm{O}^{2+}+e$ & $8.7 \times 10^{-8}$ & BREIG et al. (1977) \\
\hline
\end{tabular}

* These rates for $\mathrm{O}^{+}$production include production by relaxation of excited states of $\mathrm{O}^{+}$produced in inner shell ionizations. Rates for all species include ionization by photons produced by these relaxation processes. Rates for $\mathrm{N}_{2}^{+}, \mathrm{O}_{2}{ }^{+}\left({ }^{2} \pi\right)$ and $\mathrm{O}_{2}{ }^{+}\left({ }^{4} \pi\right)$ include ionization into excited states followed by cascading.

Note: These ionization frequencies update the cross sections given in Table 1 and can be used to scale the latter. 
Table $2^{*}$. Effective photoelectron impact ionization rates

(i) OPPENHEIMER et al. (1977)

\begin{tabular}{ccc} 
& \multicolumn{2}{c}{ Percentage of the EUV production rate } \\
\cline { 2 - 3 } & $150 \mathrm{~km}$ & $250 \mathrm{~km}$ \\
$\mathrm{O}+e \rightarrow \mathrm{O}^{+}\left({ }^{4} S\right)+2 e$ & 18 & 25 \\
$\mathrm{O}+e \rightarrow \mathrm{O}^{+}\left({ }^{2} D\right)+2 e$ & 35 & 48 \\
$\mathrm{O}+e \rightarrow \mathrm{O}^{+}\left({ }^{2} \mathrm{P}\right)+2 e$ & 33 & 45 \\
$\mathrm{~N}_{2}+e \rightarrow \mathrm{N}_{2}^{+}+2 e$ & 19 & 30
\end{tabular}

(ii) D. TORR and TORR (1978)

$\begin{array}{lc}\mathrm{O}+e \rightarrow \mathrm{O}^{+}\left({ }^{4} \mathrm{~S}\right)+2 e & 15-30 \\ \mathrm{O}+e \rightarrow \mathrm{O}^{+}\left({ }^{4} \mathrm{D}\right)+2 e & 15-30 \\ \mathrm{O}+e \rightarrow \mathrm{O}^{+}\left({ }^{2} \mathrm{P}\right)+2 e & 15 \\ \mathrm{O}_{2}+e \rightarrow \mathrm{O}_{2}^{+}+2 e & 30 \\ \mathrm{~N}_{2}+e \rightarrow \mathrm{N}_{2}^{+}+2 e & 30\end{array}$

* These values are meant to be typical. Actual values depend upon atmospheric composition and fractional ionization.

production rates. They used the largest impact ionization rate that is consistent (within the experimental error limits) with $7320 \AA$ auroral and airglow measurements. The value of $45 \%$ given by OPPENHEIMER et al. (1977a) for the unattenuated

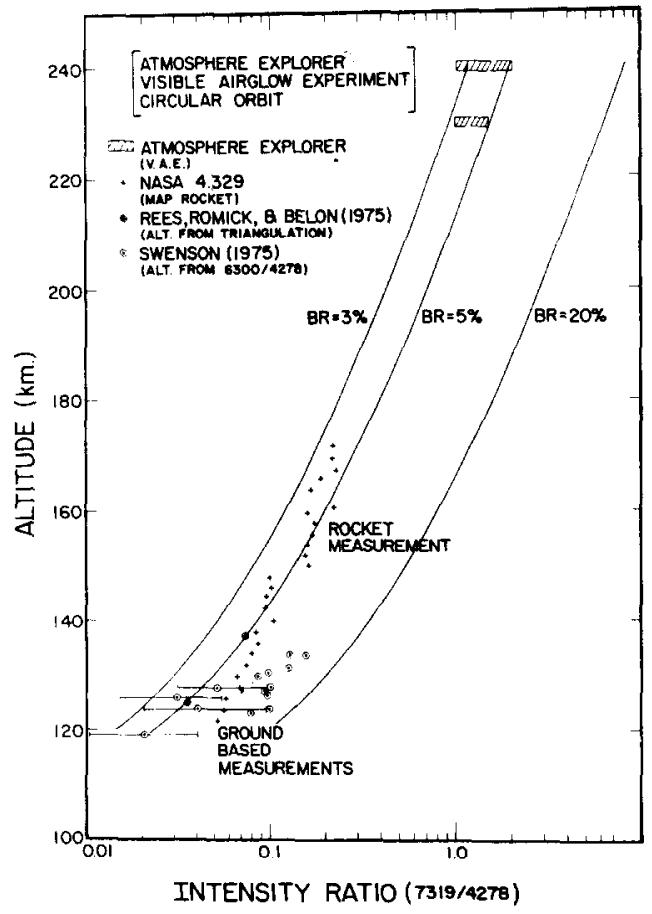

Fig. 3. The ratio of the surface brightness of $7320 \AA$ to $4278 \AA$ emissions as a function of altitude in the aurora from HAYs et al. (1975). (The reference to REES, REMICK and BELON (1975) was cited by HAYs et al., 1975.) impact fraction of the $\mathrm{O}^{+}\left({ }^{2} P\right)$ source function requires significantly different quenching process than those obtained for a $\mathbf{1 5 \%}$ fractional ionization rate. TORR and ORsINI (1978) have shown that a large source of $\mathrm{O}^{+}\left({ }^{2} D\right)$ ions presents serious problems in interpreting measurements of $\mathrm{N}_{2}^{+}$. According to photochemical results reviewed by TORR and TORR (1979a) the theoretical photoelectron ionization rates for $\mathrm{O}^{+}\left({ }^{2} P\right)$ given by OPPENHEIMER et al. (1977a) are too high by up to a factor of 3 . The theoretical photoelectron fluxes in turn are a factor of 2 to 3 lower than the measured fluxes of Petersen et al. (1977). If the latter are correct, a significant revision of our understanding of the chemistry of $\mathrm{O}^{+}\left({ }^{2} P\right)$ and several other species will be required.

To complete the discussion on sources of ionization in the thermosphere we have included a discussion of recent results on various kinds of charged particle sources at mid-latitudes.

\subsection{Nocturnal sources of ionization}

2.3.1 EUV radiation. DONAHUE (1968) pointed out that the presence of an $\left[\mathrm{NO}^{+}\right]$peak at night implies a nighttime ionization source. A number of authors have suggested potentially important photoionization sources. Proposed radiation sources include $\mathrm{HI} \operatorname{Ly} \alpha$ and $\operatorname{Ly} \beta, \mathrm{HeI} 584$ and HeII $304 \AA$. These emissions originate from solar radiation that has been resonantly scattered through the terrestrial atmosphere from the day-tonight sector. Extraterrestrial sources can also be significant. STrober et al. (1974) present plots of the scattered fluxes as a function of altitude and 
zenith angle. These were computed from multiple scattering models and are normalized to or are consistent with direct measurements of the EUV emissions. Stronel et al. (1974) find that the production rate at $150 \mathrm{~km}$ is $\sim 0.2 \mathrm{~cm}^{-3} \mathrm{~s}^{-1}$ and $0.05 \mathrm{~cm}^{-3} \mathrm{~s}^{-1}$ for $\mathrm{O}_{2}^{+}$and $\mathrm{NO}^{+}$, respectively, due to resonantly scattered hydrogen geocorona. The extraterrestrial source of $\mathrm{O}_{2}{ }^{+}$is about a factor of 2 lower. It is negligible for $\mathrm{NO}^{+}$. The latter and scattered Ly $\beta$ form the dominant EUV sources of nocturnal ionization.

\subsubsection{Charged and neutral particle fluxes.}

(a) Electrons and protons. The question of whether there is a significant source of corpuscular radiation at night at middle latitudes has been controversial for over a decade (PAULIKAS, 1975). The literature abounds with many one-of-a-kind measurements which are difficult to explain. However, recent observations by the $\mathrm{AE}$ satellites have placed upper limits on average low- and mid-latitude electron and proton fluxes as a function of latitude and local time (i.e. day or night). Daytime fluxes are negligible sources of ionization at mid-latitudes. Figure 4 from D. Torr et al. (1976a) shows the total energy flux between 250 and $350 \mathrm{~km}$ as a function of invariant latitude as measured by the low energy electron experiment on AE-C (R. HofFMAN et al., 1973). The average electron flux at mid-latitudes at night was found to be $\sim(1-5) \times 10^{-4} \mathrm{erg} \mathrm{cm}^{-2} \mathrm{~s}^{-1}$. Recent unpublished work indicates values closer to $1 \times 10^{-4} \mathrm{erg} \mathrm{cm}^{-2} \mathrm{~s}^{-1}$. The proton flux is about a factor of 2 lower. Measurements of the nocturnal $\mathrm{N}_{2}{ }^{+} 3914 \AA$ emission by MERrwetHER and WALKER $(1977,1978)$ also support the lower particle fluxes, since the emission is consistent with production of $\mathrm{N}_{2}{ }^{+}$by scattered EUV radiation. The results of $\mathrm{D}$. TORR et al. (1976a) show that the particle energy flux may increase by morc than an order of magnitude at times of high Kp. Meriwether and WALKER (1978) have reported an enhancement of $\mathrm{N}_{2}^{+}$emission during large magnetic disturbances. Simultaneous measurements of the $\mathrm{N}_{2}^{+}$rotational temperature suggest that the emission arises primarily from the $D$-region. It might, however, be difficult to deconvolve an $F$-region component from the higher energy fluxes which also increase during magnetically disturbed periods. D. TORR et al. (1976a) estimated that the low energy component should produce about $0.3-10$ ions $\mathrm{cm}^{-3} \mathrm{~s}^{-1}$ at the base of the $F$-region at mid-latitudes at night.

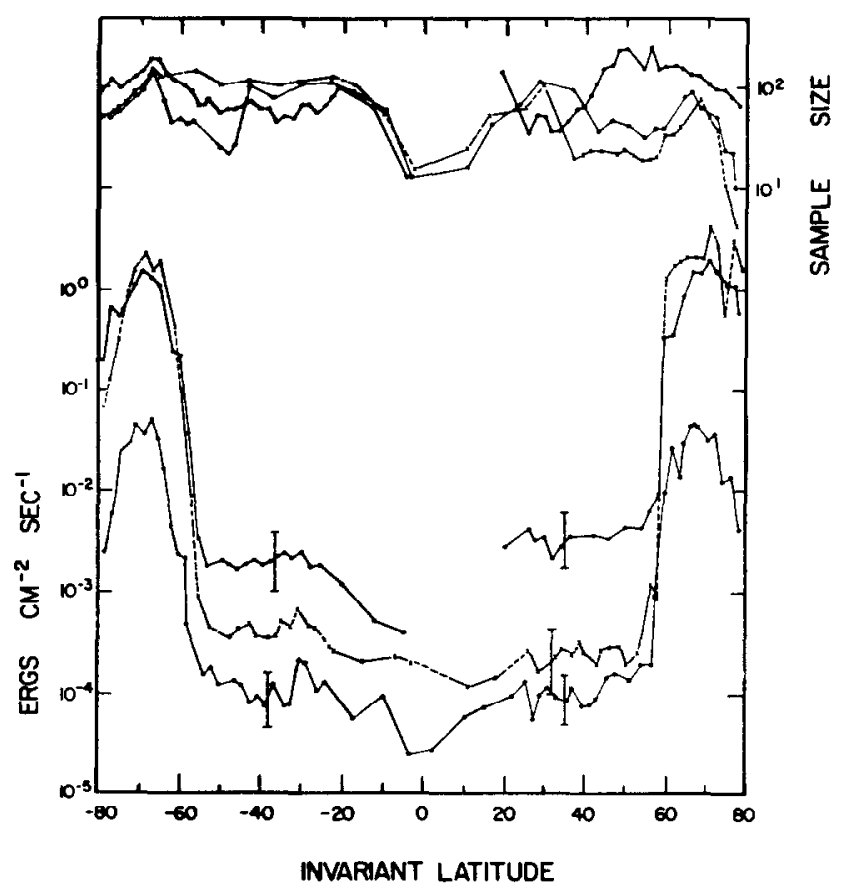

Fig. 4. The total energy flux between 250 and $300 \mathrm{~km}$ altitude as a function of invariant latitude: $(\mathrm{O}-\mathrm{O})$ electrons, daytime; $(-x-)$ electrons, nighttime; $(\mathrm{O}-\mathrm{O})$ protons, nighttime. The three uppermost curves show the sample size for each invariant latitude bin (D. TORR et al., 1976a). 
(b) Ring current particles. Tinsley (1978) has reported the detection of $\mathrm{O}^{+}, \mathrm{H}$, and $\mathrm{He}^{+}$emissions at low latitudes at night. He attributes the emissions to excitation by energetic neutrals produced at several Earth radii by charge exchange of ring current ions. Detailed calculations of this process were originally carried out by Prölss (1975). The associated ionization in the $E$-region can be an order of a magnitude larger than ambient nighttime levels. TrNSLEY (1978) estimates that since the energy input into the ring current is an order of magnitude more than the input into particle precipitation or Joule heating in auroral zones, the integrated low latitude energy input due to the precipitation of ring current particles is comparable to that of particle precipitation in the polar aurora. Although the energy flux is significantly smaller, the direct energy input into the low latitude thermosphere during larger storms is comparable with that carried by winds and waves from high latitudes.

(c) Heavy ion precipitation. SHARP et al. (1976) have reported large energy fluxes of heavy ions at middle latitudes. The peak energy deposition due to the precipitating ions is comparable with that due to precipitating ring current particles.

M. TORR et al. (1974) calculated the energy deposition rate due to precipitating $\mathrm{O}^{+}$ions together with estimates of heat input, excitation and ionization rates. Their results indicated significant heating due to momentum transfer from the fast oxygen neutrals which are produced by charge exchange of the incident $\mathrm{O}^{+}$ions.

The results also indicated that precipitation of fast $\mathrm{O}^{+}$ions results in a large $\left(>10^{7} \mathrm{~cm}^{-2} \mathrm{~s}^{-1}\right)$ neutral oxygen escape flux. An interesting aspect of the phenomenon is that it appears to be potentially self sustaining. The outward flowing ncutrals enter ballistic orbits and may be re-ionized and accelerated back into the atmosphere to produce a fresh flux of escaping neutrals.

\section{MAJOR ION CHEMISTRY}

\subsection{Introduction}

Figure 2 depicts the main chemical processes that govern the balance of ionization in the thermosphere. Ionization of $\mathrm{O}$ and $\mathrm{N}_{2}$ by photons and photoelectrons constitute the major sources of ionization. Photoionization of $\mathrm{O}_{2}$ is a minor source of $\mathrm{O}_{2}^{+}$. Fifty-two percent of the $\mathrm{O}^{+}$ions are produced in metastable states (OPPENHEIMER et al., 1977a), of which a significant fraction (which varies with altitude and season) is transformed into $\mathrm{N}_{2}^{+}$through charge exchange with $\mathrm{N}_{2}$. In the F2-layer most of the $\mathrm{O}^{+}\left({ }^{4} S\right)$ is converted into $\mathrm{NO}^{+}$. At $E$-region heights most of the $\mathrm{O}^{+}\left({ }^{4} S\right)$ is converted into $\mathrm{O}_{2}{ }^{+}$. The conversion of $\mathrm{O}_{2}^{+}$into $\mathrm{NO}^{+}$through ion atom interchange with $\mathrm{N}$ can be a significant low altitude loss process for $\mathrm{O}_{2}{ }^{+}$, especially at night. Ion atom interchange of $\mathrm{N}_{2}{ }^{+}$with $\mathrm{O}$ accounts for the bulk of the loss of $\mathrm{N}_{2}^{+}$ions produced in the ionosphere. Recombination is an important high altitude loss process for $\mathrm{N}_{2}^{+}$ions. Recombination of $\mathrm{NO}^{+}$is the main sink for thermospheric ionization.

The processes shown in Fig. 2 have been studied quantitatively using $\mathrm{AE}$ data and the reaction rates and branching ratios indicated have all been determined. In carrying out these studies, the large dynamic range that occurs in nature for most aeronomic parameters has been used to select data for conditions that emphasize processes to be studied, and minimize others. Data can be sorted or analyzed as a function of any measured parameter such as temperature $\left(T_{e}, T_{i}\right.$ or $\left.T_{n}\right)$, density, etc. In many cases it has been possible to reduce the chemistry of a constituent to one source and one sink by appropriate data selection. Generally the circumstances chosen for study include one known and one unknown process. This allows the unknown rate coefficient to be unambiguously determined. In some cases it is useful to study two processes where the rate coefficients are both unknown in order to determine the ratio of rate coefficients.

We describe in subsequent sections the quantitative determination of the rate coefficients of the processes shown in Fig. 2.

\subsection{Determination of the $\mathrm{NO}^{+}$recombination rate coefficient}

The nitric oxide ion $\mathrm{NO}^{+}$is the main ionic species in the lower thermosphere. Since it has the lowest heat of formation of the five major thermospheric ions, it is removed chemically by recombination only and it is produced by reactions involving all other ions. An accurate knowledge of nitrogen atom production depends strongly on the rate of recombination of $\mathrm{NO}^{+}$. However, a controversy currently exists concerning the electron temperature dependence of this rate coefficient. We use the aeronomic determination of this parameter to illustrate the general approach that has been used to determine many other rate coefficients.

The $\mathrm{NO}^{+}$recombination rate coefficient has been measured in the laboratory by two differept techniques. The most recent measurement was made by HuANG et al. (1975) who used a microwaveafterglow spectrometer apparatus. They found that 
the recombination rate, $\alpha_{1}$, varied as $T_{e}{ }^{0.37}$. The second group, Walls and DunN (1974), used an ion trap to store the ions prior to recombination. They found that $\alpha_{1}$ varied as $T_{e}^{-0.83}$. WALIs and DunN (1974) effectively normalized their results to those of MEHR and Biondi (1969) by using the well established measurements on $\mathrm{O}_{2}{ }^{+}$recombination at $2000 \mathrm{~K}$ to calibrate their instrument. This calibration does not depend significantly on ion species.

The difference in temperature dependence derived by the two groups results in a difference of a factor of 2 in $\alpha_{1}$ at $2000 \mathrm{~K}$, i.e. for typical daytime $F$-region electron temperatures. Such an uncertainty seriously affects the calculation of the production of $\mathrm{N}\left({ }^{2} D\right)$ atoms and hence our knowledge of the concentration of odd nitrogen species in the thermosphere.

It has been difficult to find an explanation for the discrepancy in the laboratory measurements. The only obvious difference lies in the vibrational state of the $\mathrm{NO}^{\prime}$ ions in each experiment. In the microwave-afterglow apparatus the ions are believed to be produced mainly in the $v=1$ and $v=2$ states of the ground electronic state of $\mathrm{NO}^{+}$. WALLS and DunN (1974), on the other hand, store their ions for long enough to ensure that they recombine principally in the $v=0$ state. Since vibrational lifetimes of $\mathrm{NO}^{+}$are of the order of tens of milliseconds (TAKANAYAGI, 1964), it seems reasonable to expect that the results of WALLS and DUNN 11974) will correspond more closely to actual conditions in the upper atmosphere where the chemical lifetime of $\mathrm{NO}^{+}$is of the order of tens to hundreds of seconds. However, theoretical studies of the physics of the recombination process suggest that the rate coefficient should decrease for $v>0$ (Michels, 1974).

The question as to which rate should be used in the atmosphere was resolved by $\mathrm{D}$. Torr et al. $\left(1976 \mathrm{~b}\right.$ ). They used the photochemistry of $\mathrm{NO}^{+}$at night to determine $\alpha_{1}$ from a sample of $\sim 3000$ measurements. They constrained their data to that taken above $240 \mathrm{~km}$ at mid-latitudes, thus reducing the chemistry to one source and one sink, namely the reactions

$$
\mathrm{O}^{+}+\mathrm{N}_{2} \stackrel{k_{1}}{\longrightarrow} \mathrm{NO}^{+}+\mathrm{O}
$$

and

$$
\mathrm{NO}^{+}+e \stackrel{\alpha_{1}}{\rightarrow} \mathrm{N}+\mathrm{O},
$$

so that $\alpha_{1}$ is given by

$$
\alpha_{1}=\frac{k_{1}\left[\mathrm{O}^{+}\right]\left[\mathrm{N}_{2}\right]}{\left[\mathrm{NO}^{+}\right]\left[\mathrm{N}_{e}\right]} \text {. }
$$

For the bulk of their data the ion temperature lay close to $750 \mathrm{~K}$, thus eliminating the effect of a temperature dependence in $k_{1}$ on the results. This analysis was later refined by M. TORR et al. (1977b) and M. TORR and TORR (1979a) using the rate coefficient for the $\mathrm{O}^{+}+\mathrm{N}_{2}$ reaction discussed in Section 3.3.

Figure 5 shows the results obtained by $M$. TorR and TORR (1979a), where an analytical fit to the data is given by the exponential limits of the equation

$$
\alpha_{1}=(4.3 \pm 1) \times 10^{-7}\left(T_{e} / 300\right)^{-0.83_{-0.08}^{+0.16}} \mathrm{~cm}^{3} \mathrm{~s}^{-1} .
$$

The results of MEHR and Biondi (1969) are also shown.

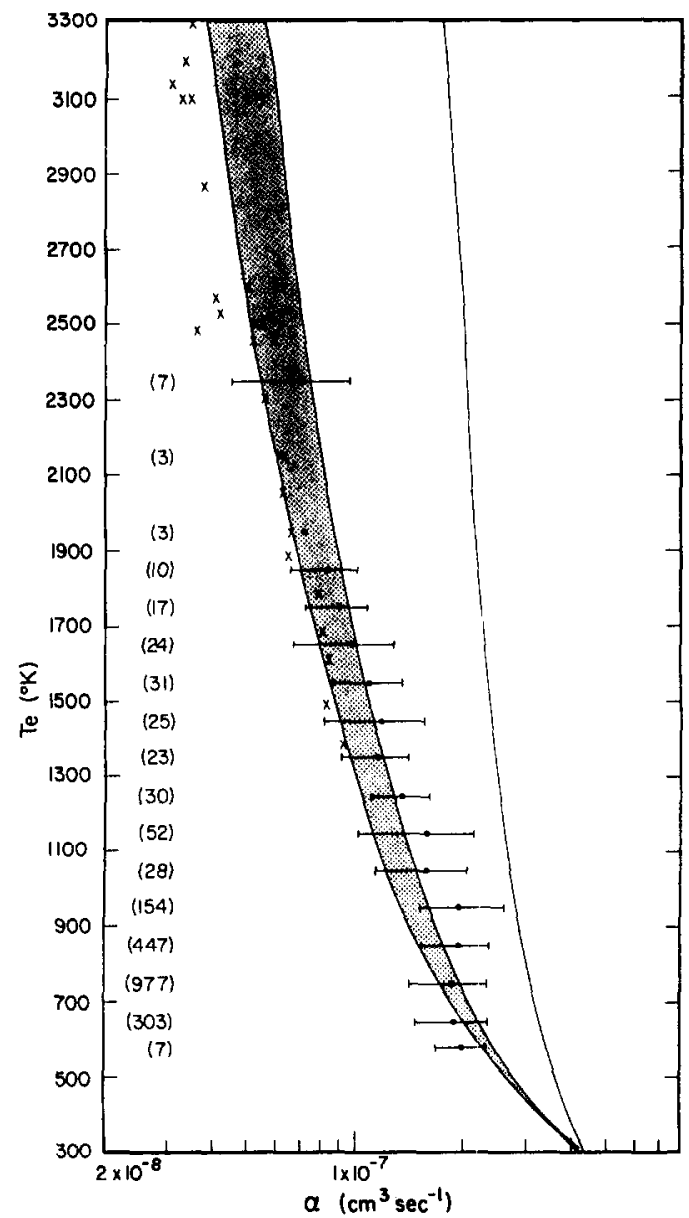

Fig. 5. Comparison of the results of $\alpha_{1}$ of WALLS and DUNN (1974) (shaded curve) and MEHR and BIONDI (1969) with the earlier AE results of M. TORR et al. (1977b) (1- ) and the most recent AE results of $M$. TORR and TORR (1979a) $(x)$. 
The crosses represent the most recent results which increase the range in electron temperature further (TORR and TORR, 1979a). This is in excellent agreement with the temperature dependence of WALLs and DunN (1974). The absolute values which are based on the $\mathrm{O}_{2}^{+}$recombination rate measurements of MEHR and BIONDI (1969) yield values for $k_{1}$ which are in excellent agreement with the laboratory results of Albritton et al. (1977) (see Section 3.3).

We address below the question of possible sources of error in analyses of the type described above. Problems that might arise in atmospheric determinations of rate coefficients stem largely from the fact that some basic knowledge of the photochemistry being studied is assumed. The possibility always exists that a reaction might have been overlooked. In particular, this would be true in the case of a 'hidden reaction', i.e. one whose effects might not be readily detectable because of cancelling processes. An example would be a reversible process providing both a source and sink for the same constituent.

M. BIONDI (private communication, 1978) has brought to our attention the fact that the temperature dependence of $\alpha_{1}$ determined by WalLs and DunN (1974) depends rather critically on a single point at the low temperature end, where the measurement is difficult to make using the ion storage technique. Because of this uncertainty, and the unresolved controversy in the laboratory results we have searched for possible sources of error in the above analysis.

M. BIONDI (private communication, 1978) suggested that the mechanism

$$
\mathrm{N}\left({ }^{2} \mathrm{D}\right)+\mathrm{O} \stackrel{k_{2 a}}{\longrightarrow} \mathrm{NO}^{+}+e-0.37 \mathrm{eV},
$$

might be an additional source of $\mathrm{NO}^{+}$. This process has been studied experimentally by ZIPF (1978). For cases where $\mathrm{N}\left({ }^{2} D\right)$ atoms are produced with sufficient kinetic energy, such as in the aurora, (3.5a) will constitute an important source of $\mathrm{NO}^{+}$ ions. However, in the nocturnal mid-latitude ionosphere the only significant source of $\mathrm{N}\left({ }^{2} D\right)$ atoms is recombination of $\mathrm{NO}^{+}$. If we include reaction (3.5a) in the $\mathrm{NO}^{+}$chemistry then (3.4) for $\alpha_{1}$ is modified to:

$$
\alpha_{\mathrm{NEW}}=\alpha_{1}\left(k_{2 a}+k_{2 b}\right) / k_{2 b},
$$

where $k_{2 b}$ is rate coefficient for $\mathrm{O}$ quenching of $\mathrm{N}\left({ }^{2} D\right)$. Clearly inclusion of (3.5a) does not alter the temperature dependence of $\alpha_{1}$. The results of $M$. TORR and TORR (1979a) demonstrate a dependence of the form $T_{c}^{-1}$ rather than $T_{c}^{-0.4}$. Thus (3.5a) is not an acceptable explanation for the discrepancy between the $\mathrm{AE}$ results for $\alpha_{1}$ and the measurements of HuANG et al. (1975).

Another difficulty experienced in analyses conducted with a multi-instrument system involves the estimation of absolute errors. Three main approaches have been adopted in assessing these in the $\mathrm{AE}$ results.

3.2.1 Duplication of measurements and inter calibration with ground based facilities. In designing the AE payloads provision was made to duplicate the measurements of most of the important aeronomic parameters by using two instruments employing different measuring techniques. In each case where two instruments have measured the same parameters, detailed comparisons have been made between the results obtained. During the period August 1974-February 1975 comparisons were made between measurements made by the magnetic ion mass spectrometer (MIMS) (J. HoFFMAN et al., 1973) and the Bennett ion mass spectrometer (BIMS) (Brinton et al., 1973). These measurements showed that BIMS and MIMS agreed to within $\pm 25 \%$ for the major ion densities. The electron density and total ion concentration were measured by the cylindrical electrostatic prohe (CF.P) (Brace. et al., 1973) and the retarding potential analyzer (RPA) (HANSON et al., 1973). These measurements agreed to within $\pm 10 \%$. The RPA ion temperatures and the CEP electron temperatures have been compared with incoherent scatter measurements and are believed to be accurate to within $\pm 5 \%$ (BENSON et al., 1977). Airglow measurements made by the Visible Airglow Experiment (VAE) (HAYs et al., 1973) were compared with a network of ground based stations, and despite the difficulties involved with such intercomparisons, agreement with well calibrated ground stations amounted to $\pm 30 \%$ (M. TORR et al, 1977a).

The $\mathrm{N}_{2}$ density was measured by the open source mass spectrometer (OSS) (NIER et al., 1973) and by the neutral atmosphere composition experiment (NACE) (Pelz et al., 1973). The NACE measurements were compared with simultaneous measurements of neutral densities made by OSS. The $O$ and $\mathrm{N}_{2}$ densities measured by the two instruments were found to agree to within $\pm 10 \%$ (G. R. CARIGNAN, private communication, 1976). Neutral temperatures measured by the neutral atmosphere temperature instrument (NATE) (SPENCER et al., 1973) were compared with those obtained from neutral density scale heights and other techniques (cf. Hedin et al., 1976). The agreement was good. 


\subsubsection{Different photochemical studies of the same} rate coefficient. A second means of checking the reliability of measurements is provided by the constraints imposed by studying the same reaction under a different set of photochemical conditions, i.e. with different related source or sink terms. OPPENHEIMER et al. (1977b) have repeated the determination of the $\mathrm{NO}^{+}$recombination rate using measurements taken during the daytime. In the sunlit ionosphere the reaction

$$
\mathrm{N}_{2}^{+}+\mathrm{O} \rightarrow \mathrm{NO}^{+}+\mathrm{N},
$$

must be included in the chemistry.

The analysis of the $\mathrm{NO}^{+}$recombination process was the first in a series of quantitative rate coefficient determinations made using the AE data. It has been our experience with the AE data that an inconsistency in a single major parameter can be readily detected when large samples (thousands) of data are analyzed. The values derived for several ionospheric reactions have subsequently been incorporated into a comprehensive general diurnally varying photochemical model of the ionosphere, where self-consistent results have been obtained for all major ionic species (D. ToRR et al., 1979). This is discussed further in Section 3.5 .

3.2.3 Comparison with laboratory results. Finally, comparisons have been made whenever possible with laboratory results, and in the large majority of cases excellent agreement has been achieved. The two notable exceptions are the $\mathrm{NO}^{+}$recombination, and the recombination of $\mathrm{N}_{2}^{+}$where a missing process was identified in the ion chemistry used for the AE analysis. This is discussed further in Section 3.5 .

Because no quantitative assessment can be readily made of the absolute accuracy of the rate cocfficients determined from the AE data, the "center of gravity' approach has been adopted in the application of the results derived in one situation to another situation, i.e. the mean value is used without further error analysis. The effect of errors in the input rate coefficients will have the effect of increasing the standard deviation on the resultant rate coefficient thus determined. Error bars, unless otherwise stated, indicate the standard deviation arising from the statistical analysis, and should not be taken to mean absolute error.

However, because of the excellent self consistency obtained from one ion species to another, and because of the good agreement with laboratory results in general, the standard deviations can, for most cases, be regarded as 'error bars'.

\subsection{Sources of $\mathrm{NO}^{+}$ions}

As indicated in Fig. 1 the major sources of $\mathrm{NO}^{+}$ at altitudes above $155 \mathrm{~km}$ are the reactions

$$
\begin{aligned}
& \mathrm{O}^{+}+\mathrm{N}_{2} \stackrel{k_{3}}{\longrightarrow} \mathrm{NO}^{+}+\mathrm{N}, \\
& \mathrm{N}_{2}^{+}+\mathrm{O}_{\stackrel{k_{4}}{\longrightarrow}}^{\longrightarrow} \mathrm{NO}^{+}+\mathrm{N} .
\end{aligned}
$$

Above about $300 \mathrm{~km}$ the reaction

$$
\mathrm{N}^{+}+\mathrm{O}_{2} \stackrel{k_{5}}{\longrightarrow} \mathrm{NO}^{+}+\mathrm{O}
$$

becomes non-negligible, and at altitudes below $200 \mathrm{~km}$ reactions

$$
\begin{gathered}
\mathrm{O}_{2}^{+}+\mathrm{N} \stackrel{k_{6}}{\longrightarrow} \mathrm{NO}^{+}+\mathrm{O}, \\
\mathrm{O}_{2}^{+}+\mathrm{NO} \stackrel{k_{7}}{\longrightarrow} \mathrm{NO}^{+}+\mathrm{O}_{2},
\end{gathered}
$$

are potentially important sources of $\mathrm{NO}^{+}$. The latter two processes are discussed in Section 3.4.

3.3.1 $\mathrm{N}_{2}+\mathrm{O} \rightarrow \mathrm{NO}^{+}+\mathrm{N}$. D. TorR et al. (1977) studied the $\mathrm{N}_{2}^{+}+\mathrm{O}$ reaction using data taken at altitudes below $200 \mathrm{~km}$. Under these conditions the chemistry of $\mathrm{N}_{2}^{+}$which is discussed in Section 3.5 is simple, and the $\mathrm{N}_{2}{ }^{+}$concentration is given by

$$
Q_{\mathrm{N}_{2}} / k_{4}[\mathrm{O}] \text {, }
$$

where $Q_{\mathrm{N}_{2}}$ represents all the photoelectron and photoionization and charge exchange sources of $\mathrm{N}_{2}{ }^{+}$referred to in Section 3.5. D. TORR et al. (1977) searched through all the AE-C data taken at altitudes below $200 \mathrm{~km}$ for mid- and low-latitude daytime conditions and calculated values of $k_{4}$ from (3.11) as a function of ion temperature. The agreement with the laboratory results of MCFARLAND et al. (1974) is excellent at $600 \mathrm{~K}$. At higher temperatures there is a small but systematic divergence between the $\mathrm{AE}$ and laboratory results. $\mathrm{D}$. TORR et al. (1977) attributed this to their neglect of recombination which is a small term below $200 \mathrm{~km}$. D. TORR et al. (1978) have subsequently shown that not all the $\mathrm{O}^{+}\left({ }^{2} D\right)$ ions charge exchange to form $\mathrm{N}_{2}{ }^{+}$at low altitudes. Some are quenched and some charge exchange with $\mathrm{O}_{2}$. The latter process, however, only becomes a significant sink for $\mathrm{O}^{+}\left({ }^{2} D\right)$ at altitudes below $160 \mathrm{~km}$. The bulk of the data analyzed by D. Torr et al. (1977) was taken between $160 \mathrm{~km}$ and $200 \mathrm{~km}$ where (3.11) is valid.

3.3.2 $\mathrm{O}^{+}+\mathrm{N}_{2} \stackrel{k_{3}}{\longrightarrow} \mathrm{NO}^{+}+\mathrm{N}$. Using nocturnal measurements when (3.7) is a negligible source of $\mathrm{NO}^{+}$, and daytime measurements when it is a 
major source, M Torr et al. (1977b) determined the temperature dependence of $k_{3}$ for altitudes between 240 and $340 \mathrm{~km}$ [in order to eliminate reactions (3.8) to (3.10)]. The $\mathrm{NO}^{+}$recombination rate discussed in the previous section was used in the analysis. We remind the reader that in the recombination rate determination, data were chosen to keep the ion temperature constant at $\sim 750 \mathrm{~K}$. The derivations of the temperature dependences of $\alpha$, and $k_{3}$ are therefore independent.

Figure 6 shows $k_{3}$ as a function of ion temperature as determined from the AE data. Also shown in Fig. 6 are the calculations of $k_{3}$ of M. TORR et al. (1977b) as a function of ion temperature using the cross sections of Albritton et al. (1977) as described by St-MAurice and TORR (1978). Curve 1 represents a non-drifting Maxwellian ion velocity distribution; curve 2 a drifting Maxwellian in an $\mathrm{N}_{2}$ atmosphere and curve 3 a drifting Maxwellian in an $\mathrm{O}$ atmosphere. The bars on the curves represent variations that would arise as a result of the diurnal variation of $T_{n}$, since $T_{i}$ is related to $T_{n}$ and $u$ by the expression

$$
3 k T_{i}=3 k T_{n}+m_{b} u^{2},
$$

where $m_{\mathrm{b}}$ is the mass of the buffer gas and $u$ is the relative drift velocity.

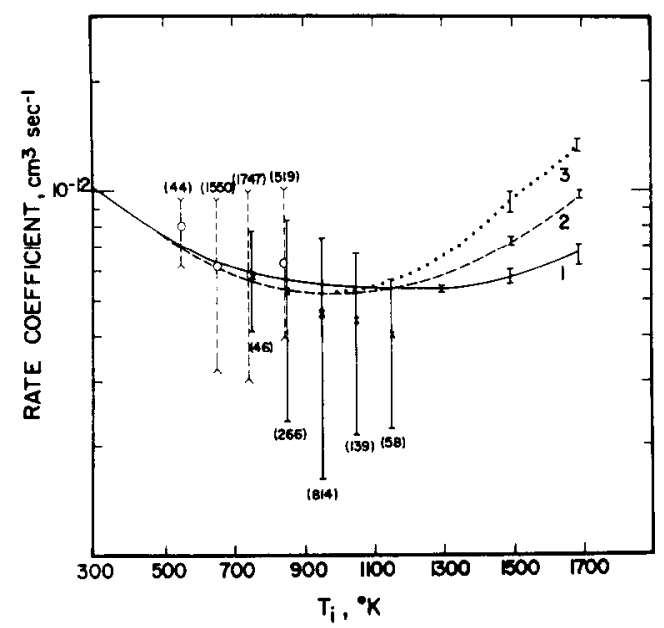

Fig. 6. The rate coefficient $k_{1}$ as a function of ion temperature. The points with full standard deviation bars are the AE determination from data measured during the day, and the dashed bars are the nighttime determination. The curves represent the calculation of $k_{3}$ for various ionospheric conditions using the cross sections of ALBRITTON et al. (1977); curve 1 is the non-drifting Maxwellian ion velocity distribution, curve 2 is the drifting Maxwellian distribution in an $N_{2}$ atmosphere, and curve 3 is the drifting Maxwellian distribution in an $\mathrm{O}$ atmosphere $(\mathrm{M}$ TORR et al., 1977).
The results presented in Fig. 6 indicate how the rate coefficient will vary in the atmosphere as a function of $T_{i}$ as a result of variations in the relative velocity distributions of the reactants. In Fig. 7 we show the same theoretical results plotted as a function of effective temperature defined by

$$
T_{\text {eff }}=\frac{2}{3 k} K E_{r m} \text {, }
$$

where

$$
K E_{\mathrm{cm}}=\left(\frac{m_{n}}{m_{\mathrm{i}}+m_{n}}+\frac{m_{1} u^{2}}{2}+\frac{3 k T_{\mathrm{i}}}{2}-\frac{3 k T_{n}}{2}\right)+\frac{3 k T_{n}}{2},
$$

and $m_{i}$ and $m_{n}$ are the ion and neutral masses, respectively. Also shown in Fig. 7 are values calculated from an expression given by MCFARLAND et al. (1973) for comparison, since these have been used extensively in the literature. The MCFARLAND curves represent an empirical fit to the earlier laboratory results of several groups (see M. TORR et al., 1977b). The AE results agree with curve A derived from the most recent laboratory measurements of AlbritTon et al. (1977). Curve B illustrates how the rate coefficient is sensitive to the 'buffer' gas for a drifting Maxwellian velocity distribution.

ST-MAURICE and TORR (1978) have carried out a polynomial fit to the results shown in Fig. 7. They find that $k_{3}$ can be approximated to within $\pm 15 \%$ by the expression

$$
\begin{aligned}
k_{3}= & 1.533 \times 10^{-12}-5.92 \times 10^{-13}\left(T_{\text {eff }} / 300\right)+8.6 \\
& \times 10^{-14}\left(T_{\text {eff }} / 300\right)^{2} \text { for } 300 \leq T_{\text {eff }} \leq 1700 \mathrm{~K},
\end{aligned}
$$

and

$$
\begin{aligned}
k_{3}= & 2.73 \times 10^{-12}-1.155 \times 10^{-12}\left(T_{\text {eff }} / 300\right)+1.483 \\
& \times 10^{-13}\left(T_{\text {eff }} / 300\right)^{2} \text { for } 1700<T_{\text {eff }}<6000 \mathrm{~K} .
\end{aligned}
$$

From their studies of variations in the velocity distribution for a variety of atmospheric situations St-MAurice and Torr (1978) drew the following conclusions.

(1) The $\mathrm{O}^{+}+\mathrm{N}$ rate coefficient is controlled largely by the population in the tail of the relative speed distribution owing to a strong increase in the cross section, $\sigma(v)$ at high relative speeds.

(2) Rate coefficients in the laboratory and in the thermosphere are approximately the same for the same value of $K E_{c m}$, if a thermal-equilibrium apparatus such as a static or flowing afterglow system is used in the laboratory. 


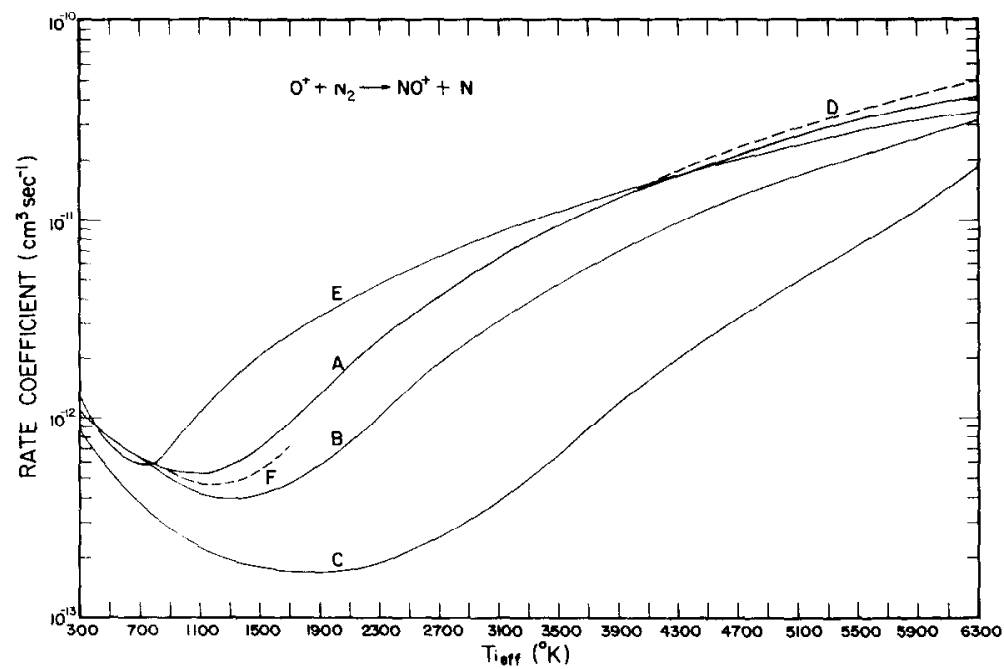

Fig. 7. Rate coefficient as a function of $\mathrm{T}_{\text {eff }}$ for the $\mathrm{O}^{+}+\mathrm{N}_{2}$ reaction, under various assumptions. Curve $\mathrm{A}$ is the rate coefficient at mid-latitude and for displaced bi-Maxwellian ion velocity distributions in convecting high-latitude regions; curve B, displaced Maxwellian in a helium buffer; curve C, (see ST-MAURICE and TORR, 1978); curve D, same as curve $A$ but with highly non-Maxwellian ion velocity distributions; curve E, rate given by MCFARLAND et al. (1973); and curve F, displaced Maxwellian in the topside ionosphere under periods of fast convection. Details on the various assumptions are given by ST-MAURICE and TORR (1978).

(3) The rate coefficients are in general not the same in the atmosphere as in drift-tube experiments, although for $\mathrm{O}^{+}$in a helium buffer the difference is about $25 \%$ or less.

\section{$3.4 \mathrm{O}_{2}{ }^{+}$chemistry}

There are three processes which result in the destruction of $\mathrm{O}_{?}{ }^{+}$ions in the ionosphere at $E$ - and $F$-region heights, namely recombination:

$$
\mathrm{O}_{2}^{+}+e \stackrel{\alpha_{2}}{\longrightarrow} \mathrm{O}+\mathrm{O},
$$

and charge exchange with $\mathrm{N}$ and NO (reactions 3.9 and 3.10 , respectively). Recombination is the only significant loss process for $\mathrm{O}_{2}{ }^{+}$during the day at altitudes above $-190 \mathrm{~km}$. The rate coefficient is well established. There is excellent agreement between different laboratory measurements (e.g. Mehr and Biondi, 1969; Walls and DunN, 1974), and D. TorR et al. (1976c) have confirmed that $\mathrm{O}_{2}{ }^{+}$recombines at the same rate in the ionosphere as in the laboratory, namely

$$
\alpha_{2}=1.6 \times 10^{-7}\left(T_{e} / 300\right)^{-0.55} \text {. }
$$

In the aeronomic determination of $\alpha_{2} \mathrm{D}$. TORR et al. (1976c) analyzed $\mathrm{AE}$ data taken between 190 and $240 \mathrm{~km}$ for solar zenith angles less than $80^{\circ}$. Under these conditions the only significant source of $\mathrm{O}_{2}{ }^{+}$is

$$
\mathrm{O}^{+}+\mathrm{O}_{2} \stackrel{k_{8}}{\longrightarrow} \mathrm{O}_{2}^{+}+\mathrm{O}
$$

The reactions

$$
\begin{gathered}
\mathrm{O}_{2}+h \nu \longrightarrow \mathrm{O}_{2}^{+}+e, \\
\mathrm{O}^{+}\left({ }^{2} \mathrm{D}\right)+\mathrm{O}_{2} \stackrel{k_{9}}{\rightarrow} \mathrm{O}_{2}^{+}+\mathrm{O}, \\
\mathrm{N}^{+}+\mathrm{O}_{2} \longrightarrow \mathrm{O}_{2}{ }^{+}+\mathrm{N},
\end{gathered}
$$

comprise less than $20 \%$ of the total $\mathrm{O}_{2}{ }^{+}$source function over the above given altitude regime. Neglect of these minor sources is approximately compensated for by omitting loss reactions with odd nitrogen over the same altitude range.

Under these conditions the recombination rate coefficient $\alpha_{2}$ is given hy

$$
\alpha_{2}=\frac{k_{8}\left[\mathrm{O}^{+}\right]\left[\mathrm{O}_{2}\right]}{\left[\mathrm{O}_{2}^{+}\right]\left[\mathrm{N}_{\mathrm{e}}\right]} \text {. }
$$

In their determination of $\alpha_{2}$ D. TORR et al. used the values of MCFARLAND et al. (1973) for $k_{8}$. Ionospheric values for $k_{8}$ have subsequently been calculated by ST-MAURICE and TORR (1978) from cross sections of Albritton et al. (1977). The latter used laboratory measurements of $k_{8}$ to derive the cross sections as a function of energy. The results of St-MAURICE and TORR (1978) are shown in Fig. 8. Also shown are the values of McFARLAND et al. (1973) which were used for $k_{8}$ by TORR et al. (1976c) (curve E). At temperatures below $1900 \mathrm{~K}$ the ionosphere values for midlatitude conditions for $k_{8}$ (curve A) lie close to the results of 


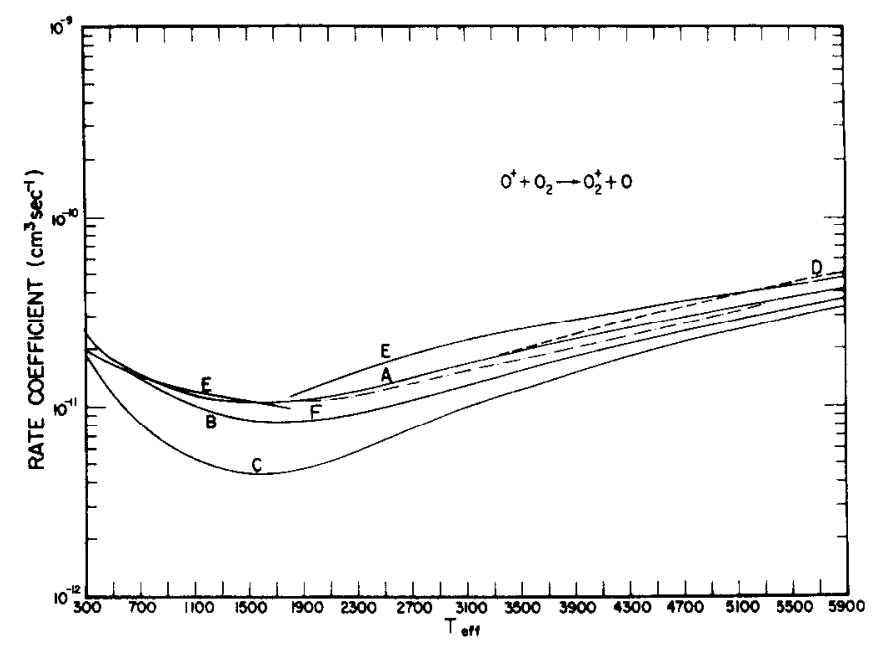

Fig. 8. Same as Fig. 7, but for the reaction $\mathrm{O}^{+}+\mathrm{O}_{2} \rightarrow \mathrm{O}_{2}^{+}+\mathrm{O}$.

MCFarland et al. (1973). Therefore the new values for $k_{8}$ do not change the values for $\alpha_{2}$ derived by TORR et al. (1976c) for the $\mathrm{O}_{2}{ }^{+}$recombination rate coefficient.

A polynomial fit to the ionospheric rate coefficient $k_{8}$ as a function of $T_{\text {eff }}$ is given by STMAURICE and TORR (1978).

$$
\begin{aligned}
k_{8} & =2.82 \times 10^{-11}-7.74 \times 10^{-12}\left(T_{\text {eff }} / 300\right)+1.073 \\
& \times 10^{-12}\left(T_{\text {eff }} / 300\right)^{2}-5.17 \times 10^{-14}\left(T_{\text {eff }} / 300\right)^{3} \\
& +9.65 \times 10^{-16}\left(T_{\text {eff }} / 300\right)^{4} \text { for } 300 \leq T_{\text {eff }} \leq 6000 \mathrm{~K} .
\end{aligned}
$$

3.4.1 The effect of reactions with $\mathrm{N}$ and $\mathrm{NO}$ on $\mathrm{O}_{2}{ }^{+}$. Measurements of the $5200 \AA \mathrm{N}\left({ }^{4} S-{ }^{2} D\right)$ emission made by the visible airglow experiment on $\mathrm{AE}$ (HAys et al., 1973) led Rusch et al. (1975a) to infer surprisingly high values for the concentration of atomic nitrogen in the thermosphere $([\mathrm{N}]>$ $10^{7} \mathrm{~cm}^{-3}$ at $\left.200 \mathrm{~km}\right)$. These findings were confirmed soon thereafter by direct measurements of the $\mathrm{N}$ density at $400 \mathrm{~km}$ by the AE open source mass spectrometer (MAUERSBERGER et al., 1975) $\left([\mathrm{N}] \approx 10^{6} \mathrm{~cm}^{-3}\right.$ at $\left.400 \mathrm{~km}\right)$. The chemistry of odd nitrogen in the thermosphere is treated in Section 4.2. In this section we discuss the effect of $\mathrm{N}$ densities of this magnitude on the chemistry of $\mathrm{O}_{2}{ }^{+}$.

Figure 9 (M. TorR et al., 1975) shows a comparison of results obtained using the theory given above compared with nighttime AE measurements of $\mathrm{O}_{2}{ }^{\dagger}$. The discrepancy shown was identified as being due to neglect of $\mathrm{O}_{2}{ }^{+}$destruction by odd nitrogen (reactions 3.9 and 3.10). From the data shown in Fig. 9, M. TORR et al. (1975) deduced values of $\sim 10^{7} \mathrm{~cm}^{-3}$ at $200 \mathrm{~km}$ for [N] at night. The $\mathrm{N}$ density on orbit 3671 was probably enhanced by about a factor of 2 with respect to normal behavior, as the data were selected because of the clearly observable discrepancy. Analyzing daytime AE-C ion and neutral composition measurements $D$. TORR et al. (1976d) found that the $\mathrm{N}$ densities of Rusch et al. (1975a) between 160 and $200 \mathrm{~km}$ were consistent with the measured $\mathrm{O}_{2}^{+}$concentrations. The high altitude measurements of MAUERSBerger et al. (1975) which were made at low-latitudes could only be reconciled with the $\mathrm{O}_{2}^{+}$ measurements near perigee $(\sim 160 \mathrm{~km})$ if a strong latitude gradient in $\mathrm{N}$ exists between the equator and mid-latitudes, resulting in a decrease in concentration at $\sim 160 \mathrm{~km}$ of a factor of 3 . The measured $\mathrm{O}_{2}{ }^{+}$concentrations place a limit of $\sim 2-3 \times$ $10^{7} \mathrm{~cm}^{-3}$ on the $\mathrm{N}$ density at $160 \mathrm{~km}$ during daytime conditions. If the $\mathrm{N}$ density were to exceed

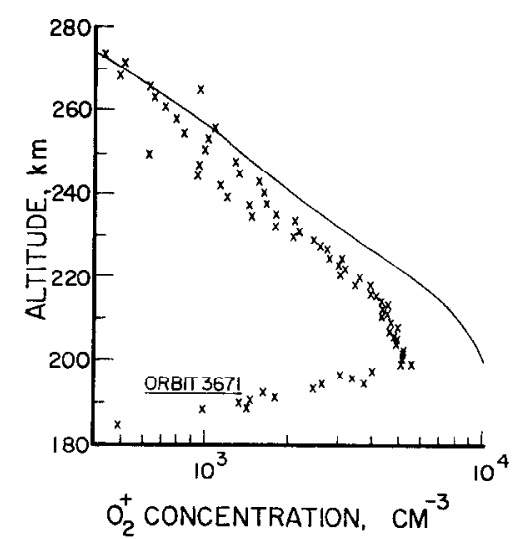

Fig. 9. Concentrations of $\mathrm{O}_{2}^{+}$as a function of altitude at night on AE-C orbit 3613 (15 October 1974, 0300 LT). The full line joins theoretical values ignoring $\mathrm{N}\left({ }^{4} S\right)(\mathrm{M}$. TORR et al., 1975); the crosses are MIMS measurements (J. HOFFMAN et al., 1973). 
(a)

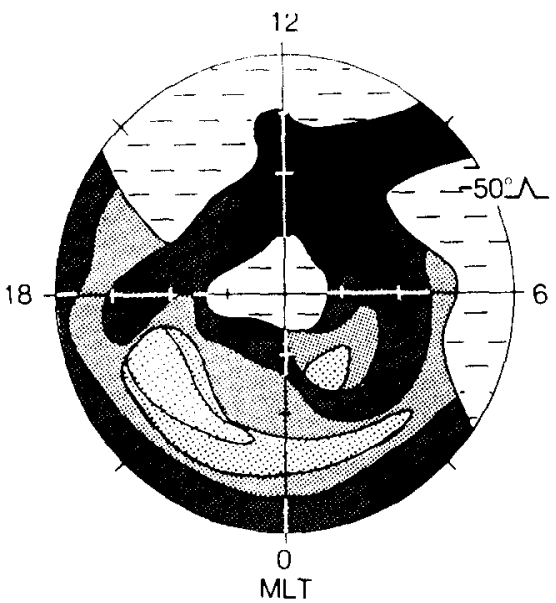

(b)

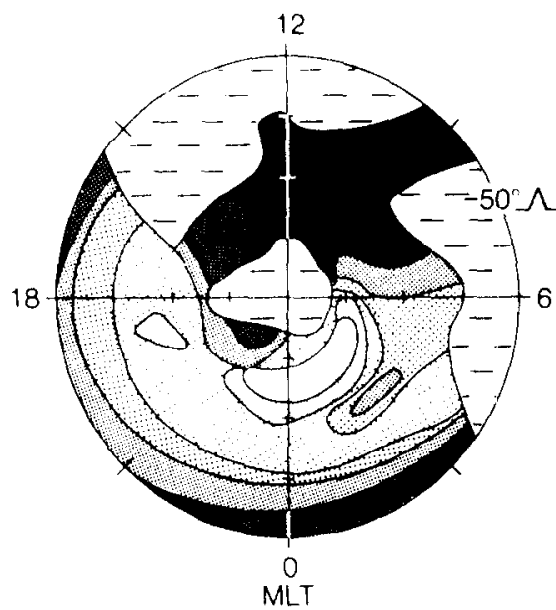

$1.2 \times 10^{2}-2.7 \times 10^{2}$

$=$ NO DATA COVERAGE

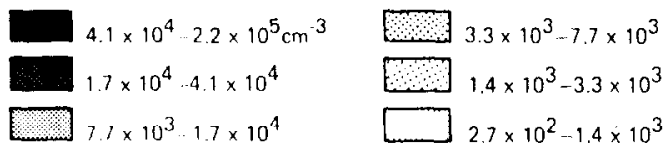

Fig. 10. Topographic maps of $\mathrm{O}^{+}$concentrations indicating for any MLT-A location, the maximum (a) and minimum (b) $\mathrm{O}^{+}$density measured at that point during the 100 -day period comprising the database (BRINTON et al., 1978).

this concentration a measurable decrease in $\left[\mathrm{O}_{2}{ }^{+}\right]$ would be observed at $160 \mathrm{~km}$. Loss of $\mathrm{O}_{2}{ }^{+}$due to NO amounts to about $30 \%$ at $160 \mathrm{~km}$ of that due to $\mathrm{N}$, and is therefore of marginal importance over the altitude range covered by $\mathrm{AE}$. At lower altitudes, and at high-latitudes reactions with NO have a major effect on ionospheric composition (cf. Donahue et al., 1970; Sharp, 1978).

3.4.2 Effects of atomic nitrogen at high latitudes. Effects of odd nitrogen on the chemistry of the ionosphere at high-latitudes is complex and poorly understood. However, mapping of ion concentrations at high-latitudes at altitudes of $\sim 300 \mathrm{~km}$ in winter by BRINTON et al. (1978) has revealed several interesting topographical ionic features which can be understood in terms of the $\mathrm{O}_{2}{ }^{+}$ and $\mathrm{NO}^{+}$chemistry discussed in the preceeding sections. Figure 10 shows a typical topographical map for $\mathrm{O}^{+}$derived by Brinton et al. (1978) from AE data. The map shows a depletion of ionization on the eastward night side of the polar cap. Figure 11 identifies the dominant molecular ion in the vicinity of the ionization hole as $\mathrm{NO}^{+}$. Figure 12 shows measurements made by AE-C on orbit 14,182 . The trajectory passed through the ionization hole. The plots of ion concentrations show that in the hole $\mathrm{O}_{2}{ }^{+}$decreases to below the threshold of detection. Brinton et al. (1978) observed that the variations in $\mathrm{O}_{2}{ }^{+}$correlated closely with those in $\mathrm{O}^{+} . \mathrm{NO}^{+}$, on the other hand, does not correlate well with variations in $\mathrm{O}^{+}$, but with changes in $T_{e}$.
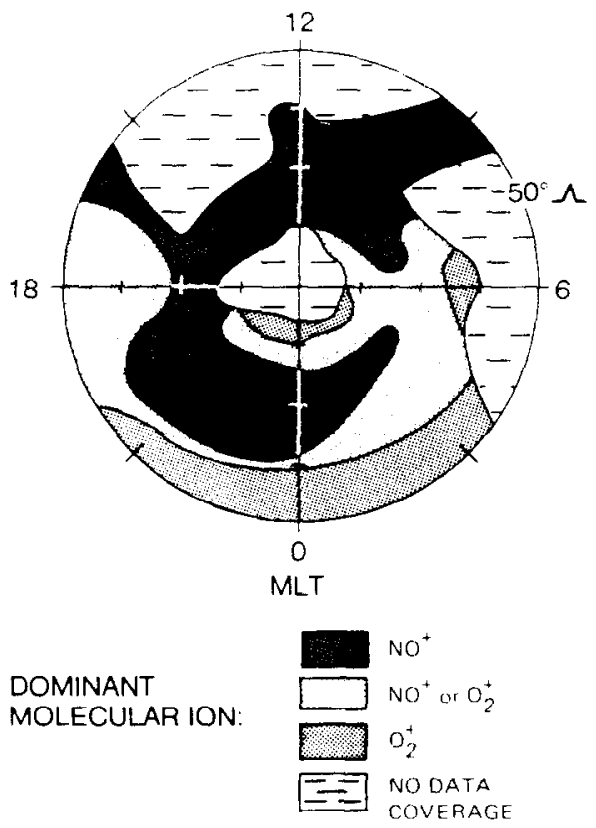

Fig. 11. Topographical map indicating regions at highlatitudes where $\mathrm{NO}^{+}$or $\mathrm{O}_{2}^{+}$was the dominant molecular ion (BRINTON et al., 1978). 


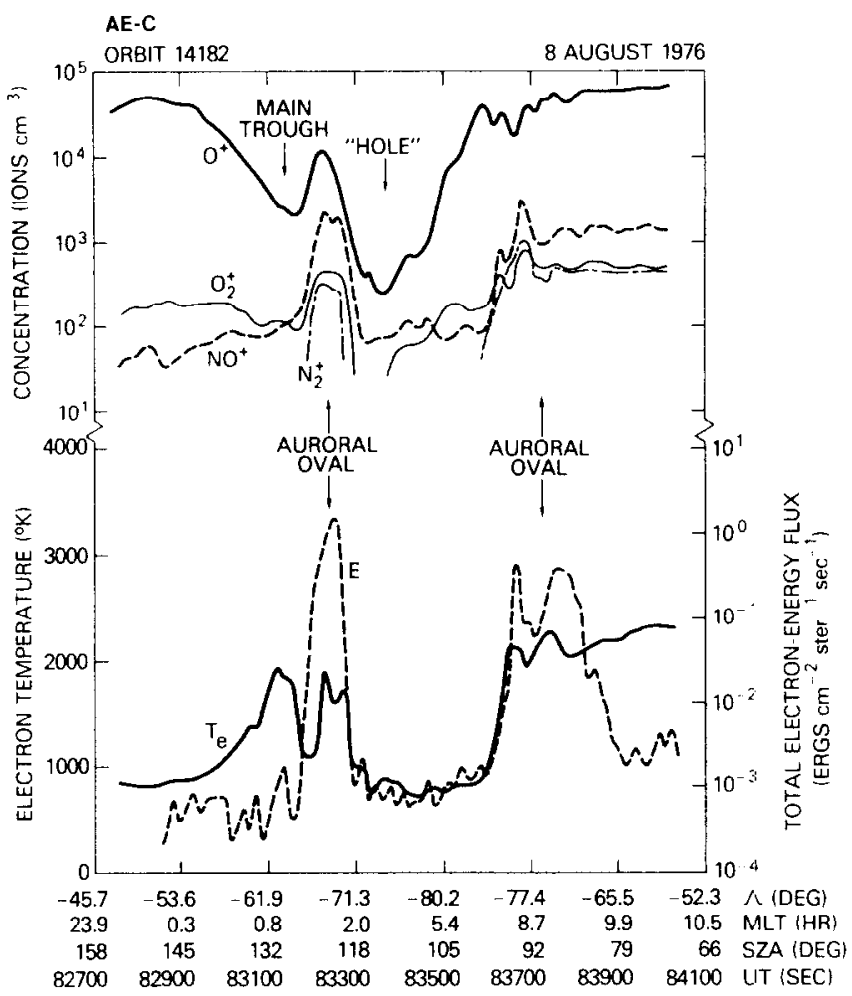

Fig. 12. Simultaneous measurements of ion composition, $T_{e}$, and energetic electron flux on AE-C orbit 14,182 through the winter $F$-region at southern high-latitudes. Prominent ionospheric features are indicated with arrows. (BRINTON et al., 1978).

Brinton et al. (1978) interpreted their observations in terms of the occurrence of long residence times over the polar cap caused by small drift velocities $\left(0.1 \mathrm{~km} \mathrm{~s}^{-1}\right)$ in the anti-sunward direction. As a result of the absence of sources of ionization the electron density decays to a very low level. Under these conditions quasi-photochemical equilibrium is eventually reached (M. TORR and TORR, 1979a) and the concentrations of $\mathrm{O}_{2}{ }^{+}$and $\mathrm{NO}^{+}$are given, respectively, by

$$
\left[\mathrm{O}_{2}^{+}\right]=\frac{k_{8}\left[\mathrm{O}_{2}\right]\left[\mathrm{O}^{+}\right]}{k_{6}[\mathrm{~N}]},
$$

since $\alpha_{2}\left[N_{e}\right] \ll k_{6}[N]$ in the ionization hole, (BRNTON et al., 1978): and

$$
\begin{aligned}
{\left[\mathrm{NO}^{+}\right] } & =\frac{k_{3}\left[\mathrm{~N}_{2}\right]\left[\mathrm{O}^{+}\right]}{\alpha_{1}\left[\mathrm{~N}_{e}\right]} \\
& \approx 1.5 \times 10^{-4}\left[\mathrm{~N}_{2}\right] T_{e}^{0.85},
\end{aligned}
$$

since $\left[\mathrm{O}^{+}\right] \approx\left[\mathrm{N}_{e}\right]$ at $300 \mathrm{~km}$ altitude.

Equations (3.22) and (3.24) explain why $\mathrm{O}_{2}{ }^{+}$ covaries with $\mathrm{O}^{+}$, and $\mathrm{NO}^{+}$with $T_{e}$.

The concentration of molecular ions in main ionospheric trough (which is shown in Figs. 11 and
12) exhibit similar dependences on $N$ and $T_{e}$. The trough is observed to be deepest near dusk. The mechanism responsible for this behavior has been identified as the cancellation of plasma co-rotation by solar wind induced plasma convection velocities (SPIRo et al., 1978). This results in long residence times in the dusk sector, which does not occur in the dawn sector. In contrast to $\mathrm{NO}^{+}$, a minimum in $\mathrm{O}_{2}{ }^{+}$density occurs between $-60^{\circ}$ and $-70^{\circ}$ invariant latitude after dusk, coincident with the deepest part of the main $\mathrm{O}^{+}$trough. Associated with these effects is a peak in $T_{e}$ caused by energy transported downward from the protonosphere by heat conduction. The lower in density in the trough causes reduced electron-ion cooling, thus permitting the downward-flowing protonospheric heat to be conducted deep into the $F$-region where it produces the observed $T_{e}$ enhancement. The elevated $\mathrm{NO}^{+}$densities are caused by the elevated electron temperatures which decrease the recombination rate. The depleted $\mathrm{O}_{2}{ }^{+}$is caused by loss with N.

The above simplified discussion of how purely chemical effects impact the behavior of the highlatitude ionosphere demonstrates how important it 
is to have quantitative information on rate coefficients before we can understand the details of the processes discussed above.

Ionospheric chemistry also plays an important role in regimes which are dominated by dynamical effects. Several key rate coefficients are highly energy dependent (cf. Figs. 7 and 8 for the reactions $\mathrm{O}^{+}+\mathrm{N}_{2}$ and $\mathrm{O}^{+}+\mathrm{O}_{2}$ ) and increase significantly in the presence of drifts caused by high-latitude convection electric fields (Schunk et al., 1976; BANKS et al., 1974).

BRINTON et al. (1978) report observations of regions of localized $\mathrm{O}^{+}$depletions in the cusp region associated with corresponding molecular ion increases. These are attributed to enhanced reaction rates due to high speed plasma drifts. The rate coefficients $k_{3}$ and $k_{8}$ have been computed by STMAURICE and Torr (1978) for cases of high speed plasma drift where the relative velocity distributions of reactants may be highly non-Maxwellian (see curves D and F in Figs. 7 and 8). These results can be used to quantitatively model ion concentrations in regions of convective electric fields provided that the effective temperature (cf. $3.13,3.14$ ) is used in (3.15) and (3.21).

3.4.3 The effects of reactions of metastable $\mathrm{O}^{+}$ ions on $\left[\mathrm{O}_{2}^{+}\right]$. D. Torr et al. (1978) demonstrated that under conditions of enhanced molecular constituent densities at F2-layer altitudes the reaction

$$
\mathrm{O}^{+}\left({ }^{2} \mathrm{D}\right)+\mathrm{O}_{2} \stackrel{k_{10}}{\longrightarrow} \mathrm{O}_{2}^{+}+\mathrm{O},
$$

becomes an important, if not a major, source of $\mathrm{O}_{2}{ }^{+}$ions. This happens because of a reduction in the $\mathrm{O}^{+}$concentration (and hence $\left[\mathrm{N}_{e}\right]$ ) as a result of ion molecule interactions between $\mathrm{O}^{+}\left({ }^{4} S\right)$ and $\mathrm{N}_{2}$. The reducrion in $\left[\mathrm{N}_{e}\right]$ also leads to enhanced $\mathrm{O}^{+}\left({ }^{2} \mathrm{D}\right)$ densities as a result of a corresponding decrease in electron quenching (see Section 3.5 and Fig. 2). The enhanced $\mathrm{N}_{2}$ densities and reduced electron densities result in reaction (3.25) exceeding the conventional major source of $\mathrm{O}_{2}{ }^{+}$, namely (3.18). D. TORr et al. (1978) show that under these conditions the ratio $\mathrm{R}$ of the sources of $\mathrm{O}_{2}{ }^{+}$ due to (3.25) to that due to (3.18) is given by

$$
R \approx \frac{1}{4 J} \frac{k_{10} k_{3}^{2}}{k_{8} k_{11}} \frac{\left[\mathrm{N}_{2}\right]^{2}}{[\mathrm{O}]},
$$

where $J$ is the photoionization frequency for $\mathrm{O}^{+}\left({ }^{4} S\right), k_{11}$ is the $\mathrm{O}^{+}\left({ }^{2} D\right)$ electron quenching rate coefficient (see Section 3.5). Equation 3.26 yields values between 0.1 and 1 for the range typical observed for the ratio $\left[\mathrm{N}_{2}\right]^{2} /[\mathrm{O}]$ at $300 \mathrm{~km}$. The rate coefficient $k_{10}$ was found to be $1 \pm 0.6 \times$ $10^{-9} \mathrm{~cm}^{3} \mathrm{~s}^{-1}$.

D. TORR et al. (1979) also examined the low altitude case where $\mathrm{O}^{+}\left({ }^{2} D\right)$ ions were believed to be lost primarily in reactions with $\mathrm{N}_{2}$. In this case, including reaction (3.25), $R$ is given by

$$
R \approx \frac{\left[\mathrm{O}_{2}\right]}{0.25\left[\mathrm{~N}_{2}\right]+\left[\mathrm{O}_{2}\right]}
$$

This result shows that reaction (3.25) is a significant sink for $\mathrm{O}^{+}\left({ }^{2} D\right)$ ions in the lower $F$ - and $E$-regions, as well as constituting a detectable source of $\mathrm{O}_{2}^{+}$. In the altitude range $190-240 \mathrm{~km}$ there is a transition from the high altitude to low altitude chemistry where charge exchange of $\mathrm{O}^{+}\left({ }^{2} \mathrm{D}\right)$ with $\mathrm{O}_{2}$ constitutes less than $20 \%$ of the total source of $\mathrm{O}_{2}{ }^{+}$. Below $200 \mathrm{~km}$, reaction (3.25) begins to compete as a sink for $\mathrm{O}^{+}\left({ }^{2} D\right)$ ions. For example at $200 \mathrm{~km}$ the $\left[\mathrm{O}_{2}\right] /\left[\mathrm{N}_{2}\right]$ ratio $\approx 0.1$ and $R \approx 0.3$, and reaction $(3.25)$ is $40 \%$ of reaction (3.18). At $120 \mathrm{~km}\left[\mathrm{O}_{2}\right] /\left[\mathrm{N}_{2}\right] \approx 0.2$ and $R \approx 0.5$ and reaction (1) is $80 \%$ of reaction (3.18).

Fifty-two per cent of the $\mathrm{O}^{+}$ions are produced in metastable states. Of this $37 \%$ are $\mathrm{O}^{+}\left({ }^{2} P\right)$ ions. If we assume that $\mathrm{O}^{+}\left({ }^{2} P\right)$ behaves like $\mathrm{O}^{+}\left({ }^{2} D\right)$, then $85 \%$ of all the $\mathrm{O}^{+}$ions produced will be converted into $\mathrm{O}_{2}{ }^{+}$ions in the $E$-region. The remainder will charge exchange with $\mathrm{N}_{2}$ to form $\mathrm{N}_{2}{ }^{+}$. This value $(85 \%)$ takes into account that $\sim 30 \%$ of the reactions of $\mathrm{O}^{+}\left({ }^{2} D\right)$ with $\mathrm{N}_{2}$ proceed via quenching as was shown by TORR and OrsinI (1978).

\subsection{Chemistry of $\mathrm{N}_{2}^{+}$}

In the quiet daytime ionosphere $\mathrm{N}_{2}$ is ionized primarily by absorption of ultraviolet photons:

$$
\mathrm{N}_{2}+h \nu \rightarrow \mathrm{N}_{2}{ }^{+}+e
$$

by impact of energetic photoelectrons:

$$
\mathrm{N}_{2}+e \rightarrow \mathrm{N}_{2}^{+}+e+e,
$$

and by charge transfer reactions with metastable $\mathrm{O}^{+}$ions:

$$
\begin{aligned}
& \mathrm{O}^{+}\left({ }^{2} \mathrm{D}\right)+\mathrm{N}_{2} \stackrel{k_{12}}{\longrightarrow} \mathrm{N}_{2}{ }^{\prime}+\mathrm{O}, \\
& \mathrm{O}^{+}\left({ }^{2} \mathrm{P}\right)+\mathrm{N}_{2} \stackrel{k_{13}}{\longrightarrow} \mathrm{N}_{2}^{+}+\mathrm{O} .
\end{aligned}
$$

The $\mathrm{N}_{2}{ }^{+}$ions are removed primarily by reactions with atomic and molecular oxygen:

$$
\begin{array}{r}
\mathrm{N}_{2}^{+}+\mathrm{O} \stackrel{k_{4}}{\longrightarrow} \mathrm{NO}^{+}+\mathrm{N}, \\
\stackrel{k_{14}}{\longrightarrow} \mathrm{O}^{+}+\mathrm{N}_{2}, \\
\mathrm{~N}_{2}^{+}+\mathrm{O}_{2} \stackrel{k_{13}}{\longrightarrow} \mathrm{N}_{2}+\mathrm{O}_{2}^{+} .
\end{array}
$$


[3.34 is insignificant at altitudes above $\sim 150 \mathrm{~km}$. The branching ratio for 3.33 is $7 \%$ (LINDINGER et al., 1974)], and by dissociative recombination with electrons:

$$
\mathrm{N}_{2}^{+}+e \stackrel{\alpha_{3}}{\rightarrow} \mathrm{N}+\mathrm{N}
$$

The chemistry of $\mathrm{N}_{2}^{+}$has proved to be considerably more complex than depicted by the above photochemistry. A quantitative study requires reliable values for the metastable $\mathrm{O}^{+}$densities. In the case of $\mathrm{O}^{+}\left({ }^{2} P\right)$, measured values were obtained on $\mathrm{AE}$ from the VAE $7320 \AA$ surface brightness observations. The sources and sinks of $\mathrm{O}^{+}\left({ }^{2} P\right)$ have been quantitatively determined by WAt.Ker et al. (1975), and Rusch et al. (1977a). The situation regarding the concentration of $\mathrm{O}^{+}\left({ }^{2} D\right)$ ions is not as simple. No measurements were made of this species on AE. It is therefore treated as an integral part of the photochemistry of $\mathrm{N}_{2}^{+}$and studied simultaneously with other processes which control the behavior of $\mathrm{N}_{2}{ }^{+}$in the thermosphere. The chemistry of $\mathrm{O}^{+}\left({ }^{2} P\right)$, on the other hand, is treated independently.

Prior to $\mathrm{AE}$ it was known that $\mathrm{O}^{+}\left({ }^{2} \mathrm{D}\right)$ is produced by photoionization and by photoelectron impact ionization of atomic oxygen. HENRY et al. (1969) determined the loss rate by electron quenching. GARSTANG (1956) calculated the radiative lifetime, and found it to be long $(3.6 \mathrm{~h})$. Laboratory measurements of RUTHERFORD and Vroom (1971) and Stemaings et al. (1966) indicated the $\mathrm{O}^{+}\left({ }^{2} D\right)$ charge exchanges rapidly with $\mathrm{N}_{2}$, i.e. at a gas kinetic rate. Prior to $\mathrm{AE}$ no information was available on rates at which $\mathrm{O}^{+}\left({ }^{2} D\right)$ is quenched by $\mathrm{O}, \mathrm{O}_{2}$ and $\mathrm{N}_{2}$. In addition to production by ionization of $\mathrm{O}, \mathrm{O}^{+}\left({ }^{2} \mathrm{D}\right)$ ions are created by processes which deactivate $\mathrm{O}^{+}\left({ }^{2} P\right)$. The photochemistry of $\mathrm{O}^{+}\left({ }^{2} D\right)$ therefore comprises the following reactions:

Production:

$$
\begin{aligned}
& \mathrm{O}+h \nu \longrightarrow \mathrm{O}^{+}\left({ }^{2} D\right)+e \\
& \mathrm{O}+e \longrightarrow \mathrm{O}^{+}\left({ }^{2} \mathrm{D}\right)+2 e \\
& \mathrm{O}^{+}\left({ }^{2} P\right) \longrightarrow \mathrm{O}^{+}\left({ }^{2} D\right)+h \nu \\
& \mathrm{O}^{+}\left({ }^{2} P\right)+e \stackrel{k_{17}}{\longrightarrow} \mathrm{O}^{+}\left({ }^{2} \mathrm{D}\right)+e \\
& \mathrm{O}^{+}\left({ }^{2} P\right)+\mathrm{O} \stackrel{k_{18}}{\longrightarrow} \mathrm{O}^{+}\left({ }^{2} D\right)+\mathrm{O} \\
& \mathrm{O}^{+}\left({ }^{2} P\right)+\mathrm{N}_{2} \stackrel{k_{19}}{\longrightarrow} \mathrm{O}^{+}\left({ }^{2} D\right)+\mathrm{N}_{2}
\end{aligned}
$$

Loss:

$$
\begin{aligned}
& \mathrm{O}^{+}\left({ }^{2} \mathrm{D}\right)+\mathrm{N}_{2} \stackrel{k_{12}}{\longrightarrow} \mathrm{N}_{2}^{+}+\mathrm{O}, \\
& \mathrm{O}^{+}\left({ }^{2} \mathrm{D}\right)+\mathrm{N}_{2} \stackrel{k_{30}}{\longrightarrow} \mathrm{O}^{+}\left({ }^{4} S\right)+\mathrm{N}_{2}, \\
& \mathrm{O}^{+}\left({ }^{2} \mathrm{D}\right)+\mathrm{O} \stackrel{k_{21}}{\longrightarrow} \mathrm{O}^{+}\left({ }^{4} S\right)+\mathrm{O},
\end{aligned}
$$

$$
\begin{gathered}
\mathrm{O}^{+}\left({ }^{2} \mathrm{D}\right)+e \stackrel{\mathrm{k}_{22}}{\longrightarrow} \mathrm{O}^{+}\left({ }^{4} \mathrm{~S}\right)+e, \\
\mathrm{O}^{+}\left({ }^{2} \mathrm{D}\right)+\mathrm{O}_{2} \stackrel{k_{23}}{\longrightarrow} \mathrm{O}_{2}{ }^{+}+\mathrm{O} .
\end{gathered}
$$

[In previous studies (ORSINI et al., 1977a, b; TORR and Orsin, 1977) (3.43) was neglected, because laboratory measurements (RUTHERFord and Vroom, 1971) indicated that $k_{12}$ lay close to the Langevin limit. The present work which shows that (3.43) is not negligible updates all earlier work.]

The concentration of $\mathrm{O}^{+}\left({ }^{2} P\right)$ is given by

$$
\frac{1.15 J_{1}[\mathrm{O}]}{0.218+k_{0}[\mathrm{O}]+k_{\mathrm{N}_{2}}\left[\mathrm{~N}_{2}\right]+k_{\mathrm{N}_{2}}\left[\mathrm{~N}_{e}\right]}
$$

where $I_{1}$ is the attenuated photoinnization frequency. The factor of 1.15 includes the component due to photoelectrons discussed in Section 2.2; $k_{0}=5.2 \pm 2.5 \times 10^{-11} \mathrm{~cm}^{3} \mathrm{~s}^{-1}$ (Rusch et al., 1977a), $k_{\mathrm{N}_{2}}=4.8 \pm 1.4 \times 10^{-10} \mathrm{~cm}^{3} \mathrm{~s}^{-1}$ (Rusch et al., 1977a) and $k_{\mathrm{N}_{e}}=1.9 \times 10^{-7}\left(T_{e} / 300\right)^{-0.5} \mathrm{~cm}^{3} \mathrm{~s}^{-1}$ (HENRY et al., 1969). A similar expression can be written for $\left[\mathrm{O}^{+}\left({ }^{2} \mathrm{D}\right)\right]$, i.e.

$$
\begin{aligned}
& {\left[\mathrm{O}^{\prime}\left({ }^{2} \mathcal{D}\right)\right]} \\
& \quad=\frac{Q_{2}}{k_{12}\left[\mathrm{~N}_{2}\right]+k_{20}\left[\mathrm{~N}_{2}\right]+k_{21}[\mathrm{O}]+k_{22}\left[\mathrm{~N}_{e}\right]+k_{23}\left[\mathrm{O}_{2}\right]},
\end{aligned}
$$

where $Q_{2}$ is the source of $\mathrm{O}^{+}\left({ }^{2} \mathrm{D}\right)$ due to photoionization, photoelectron impact excitation and deactivation of $\mathrm{O}^{+}\left({ }^{2} P\right)$. We arrive at the following expression for $\left[\mathrm{N}_{2}{ }^{+}\right]$:

$$
\left[\mathrm{N}_{2}{ }^{+}\right]=\frac{\mathrm{Q}_{1}+k_{12}\left[\mathrm{~N}_{2}\right]\left[\mathrm{O}^{+}\left({ }^{2} \mathrm{D}\right)\right]}{k_{4}[\mathrm{O}]+\alpha\left[\mathrm{N}_{\mathrm{e}}\right]}
$$

where $Q_{1}$ is the source of $\mathrm{N}_{2}^{+}$due to photoionization, photoelectron impact and charge exchange of $\mathrm{O}^{+}{ }^{2}$ P) with $\mathrm{N}_{2}$. Equations (3.48) and (3.49) may be combined to yield an expression which illustrates how the above chemistry can be used to readily determine all the rate coefficients shown in (3.48) and (3.49) from the AE data.

At low altitudes $(200 \mathrm{~km})(3.49)$ very nearly becomes $\left[\mathrm{N}_{2}{ }^{+}\right]=\mathrm{Q}_{1} / k_{4}[\mathrm{O}] . \mathrm{Q}_{1}$ can be reliably calculated from AE data and $k_{4}$ is determined. This was done by D. Torr et al. (1977) and D. Tork (1979). D. TORR (1979) took into account recombination, and $\mathrm{N}_{2}$ quenching of $\mathrm{O}^{+}\left({ }^{2} D\right)$. Figure 13 shows a comparison of his results with those of McFARLAND et al. (1974). The small discrepancy which occurred in the case of the earlier determination is removed.

Substituting for $\mathrm{O}^{+}\left({ }^{2} \mathrm{D}\right)$ in (3.49) we derive the equation

$$
\begin{aligned}
k_{12}\left[\mathrm{~N}_{2}\right]+ & k_{20}\left[\mathrm{~N}_{2}\right]+k_{21}[\mathrm{O}] \\
& +k_{22}\left[\mathrm{~N}_{e}\right]+k_{23}\left[\mathrm{O}_{2}\right]=k_{12}\left[\mathrm{~N}_{2}\right] R
\end{aligned}
$$




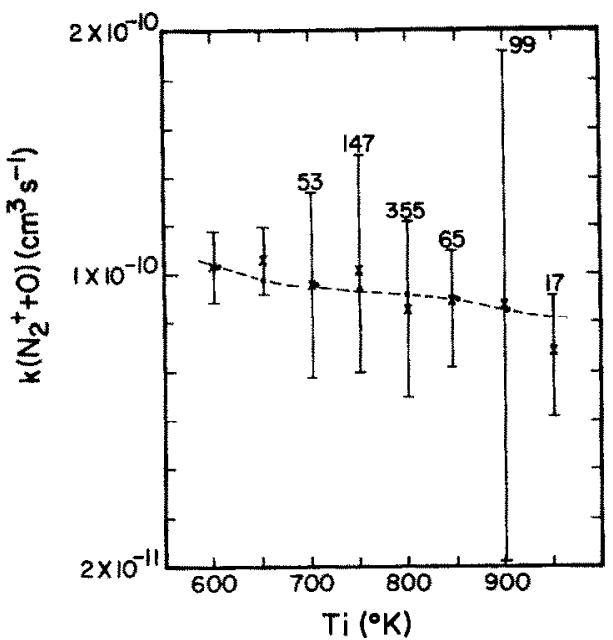

Fig. 13. The rate coefficient for the reaction $\mathrm{N}_{2}{ }^{+}+\mathrm{O}$ as a function of ion temperature. The broken curve is the laboratory results of McFARLAND et al. (1974). The crosses are the AE results of D. TORR (1978).

where

$$
R=\frac{Q_{2}}{\left(k_{4}[\mathrm{O}]+\alpha_{3} \mathrm{~N}_{e}\right)-Q_{1}},
$$

i.e, $R$ is the ratio of the total $\mathrm{O}^{+}\left({ }^{2} D\right)$ production to loss by charge exchange, and is calculated from the AE measurements. Equation (3.50) simply states that the $\mathrm{O}^{+}\left({ }^{2} \mathrm{D}\right)$ loss frequency is equal to the $\mathrm{O}^{+}\left({ }^{2} \mathrm{D}\right)$ production frequency. It is formulated to illustrate the ease with which all the rate coefficients can be unambiguously determined. For example if we select data where $\alpha_{3} \mathrm{~N}_{e} \ll k_{4}[\mathrm{O}]$ we remove the effects of uncertainties in $\alpha_{3}$ from $R$. If the altitude range is limited to heights greater than $220 \mathrm{~km}, k_{23}\left[\mathrm{O}_{2}\right]$ is negligible. Rearranging (3.50) under these conditions we find

$$
k_{21}-k_{20} \frac{\left[\mathrm{N}_{2}\right]}{[\mathrm{O}]}=k_{12} \frac{\left[\mathrm{N}_{2}\right]}{[\mathrm{O}]}(R-1)-k_{22} \frac{\left[\mathrm{N}_{e}\right]}{[\mathrm{O}]} \text {. }
$$

All the terms on the right-hand side are known, with the exception of $k_{12}$ which has only been measured at energies greater than $0.5 \mathrm{eV}$ (RUTHERFord and VROOM, 1971). Figure 14 shows the results of plotting $\left[\mathrm{N}_{2}\right] /[\mathrm{O}]$ against the right-hand side of (3.52) for several values of $k_{12}$. The results show that $k_{21} \approx 0\left(\ll 3 \times 10^{-11} \mathrm{~cm}^{3} \mathrm{~s}^{-1}\right)$. Therefore the term $k_{21}[\mathrm{O}]$ can be dropped from (3.50). Rearranging (3.52) to solve for $k_{12}$ and $k_{z 0}$ we obtain

$$
k_{20}+k_{12}(1-R)=k_{22} \frac{\left[\mathrm{N}_{e}\right]}{\left[\mathrm{N}_{2}\right]} .
$$

The results of plotting $1-R$ against $k_{22}\left[\mathrm{~N}_{e}\right] /\left[\mathrm{N}_{2}\right]$ are shown in Fig. 15a. These results show

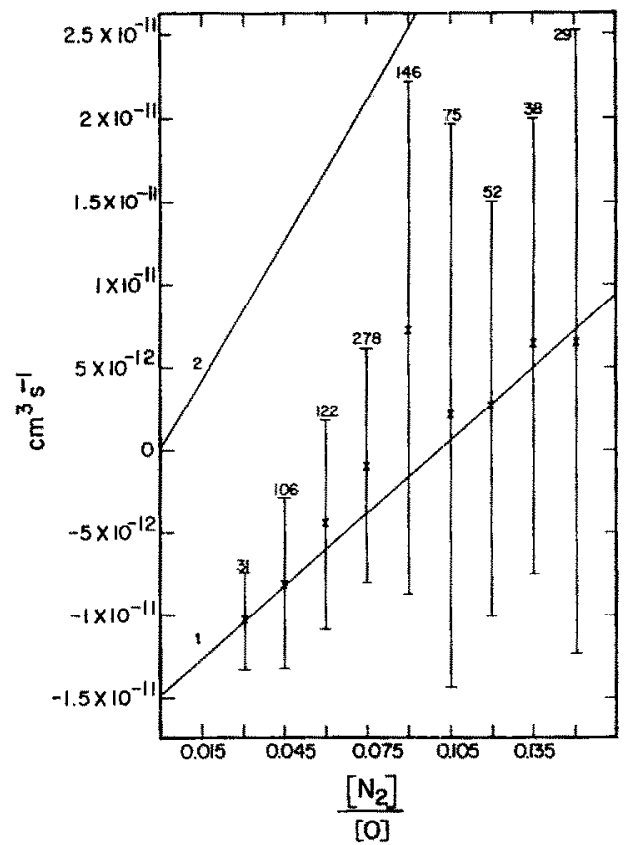

Fig. 14. The ratio $\left[\mathrm{N}_{2}\right][\mathrm{O}]$ plotted against the right-hand side of (3.52). The slope gives $k_{20}\left(N_{2}\right.$ quenching of $\left.\mathrm{O}^{+}\left({ }^{2} D\right)\right)$ and the intercept $k_{21}(\mathrm{O}$ quenching). A value of $1 \times 10^{-10} \mathrm{~cm}^{3} \mathrm{~s}^{-1}$ was used for $k_{12}$ (charge exchange) for curve (1) and $2.5 \times 10^{-10} \mathrm{~cm}^{3} \mathrm{~s}^{-1}$ for curve 2 . The results imply that $k_{21} \approx 0$.

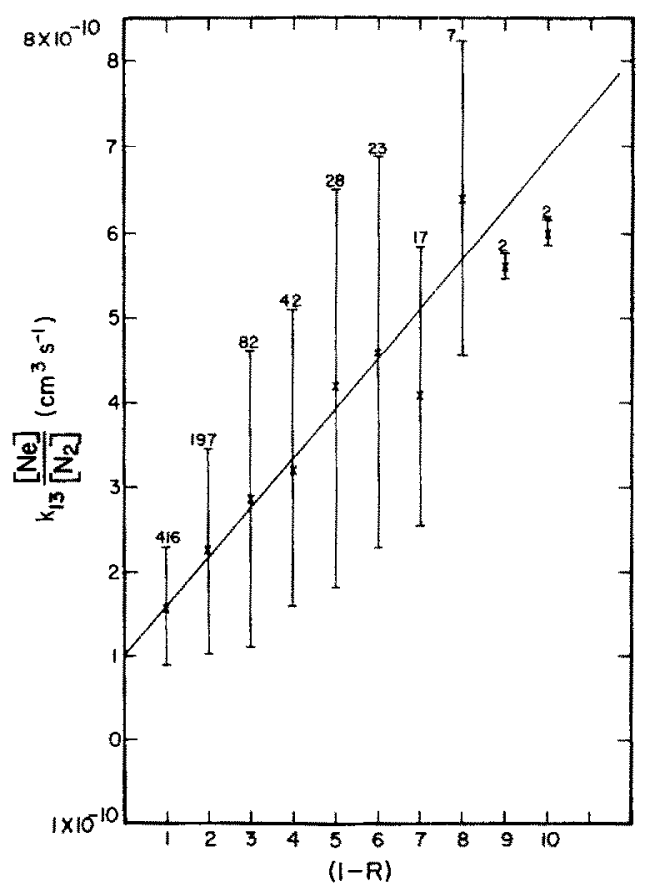

Fig. 15a. The ratio $\left.\left[\mathrm{N}_{e}\right] / \mathrm{N}_{2}\right]$ as a function of the quantity $(1-R)$ in $(3.53)$. The slope gives $k_{12}$ (charge exchange) and the intercept $k_{20}\left(\mathbb{N}_{2}\right.$ quenching); here $k_{21}=0$. 


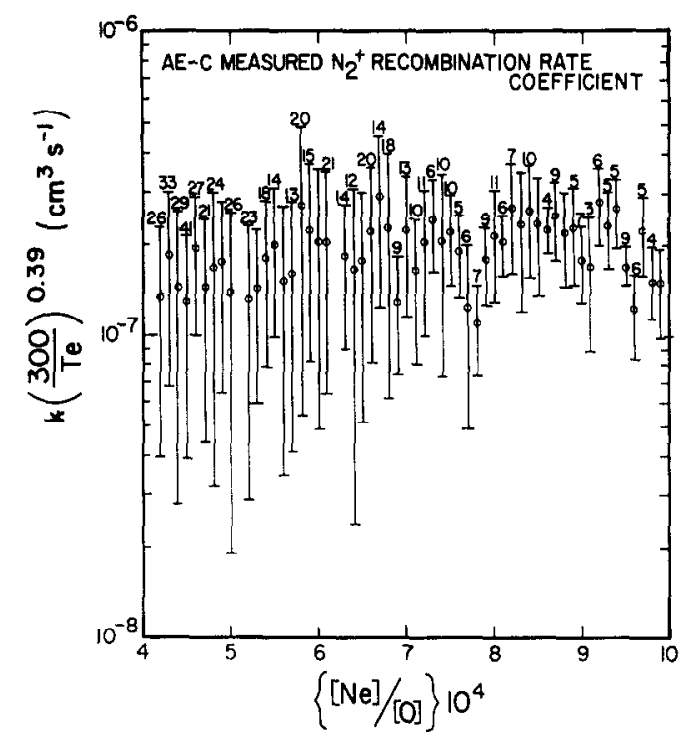

Fig. 15b. The recombination rate coefficient of $\mathrm{N}_{2}^{+}$determined from AE data as a function of $\left[\mathrm{N}_{e}\right] /[\mathrm{O}]$. that $k_{20}<2 \times 10^{-10} \mathrm{~cm}^{3} \mathrm{~s}^{-1}$ and that $k_{12}=$ $1\left\{\begin{array}{l}+1 \\ -0.5\end{array}\right\} \times 10^{-10} \mathrm{~cm}^{3} \mathrm{~s}^{-1}$. Thus we conclude that charge exchange of $\mathrm{O}^{+}\left({ }^{2} D\right)$ with $\mathrm{N}_{2}$ is about an order of magnitude smaller at thermal energies than at $E>0.5 \mathrm{eV}$ (cf. RuTHERFORD and VROOM, 1971). $\mathrm{N}_{2}$ quenching accounts for about $30 \%$ of all the reactions of $\mathrm{O}^{+}\left({ }^{2} \mathrm{D}\right)$ with $\mathrm{N}_{2}$.

Using the above chemistry $N$. OrsinI has independently determined the $\mathrm{N}_{2}{ }^{+}$recombination rate coefficient, $\alpha_{3}$ including reaction (3.43). His unpublished results are shown in Fig. 15b. The agreement with the laboratory results of MEHR and BIONDI (1969) is good. This updates the earlier result published by Orsini et al. (1977b).

\subsection{Diurnal variations of ion concentrations}

In the preceeding sections we have described how the AE data were used in special studies designed to isolate specific processes to determine

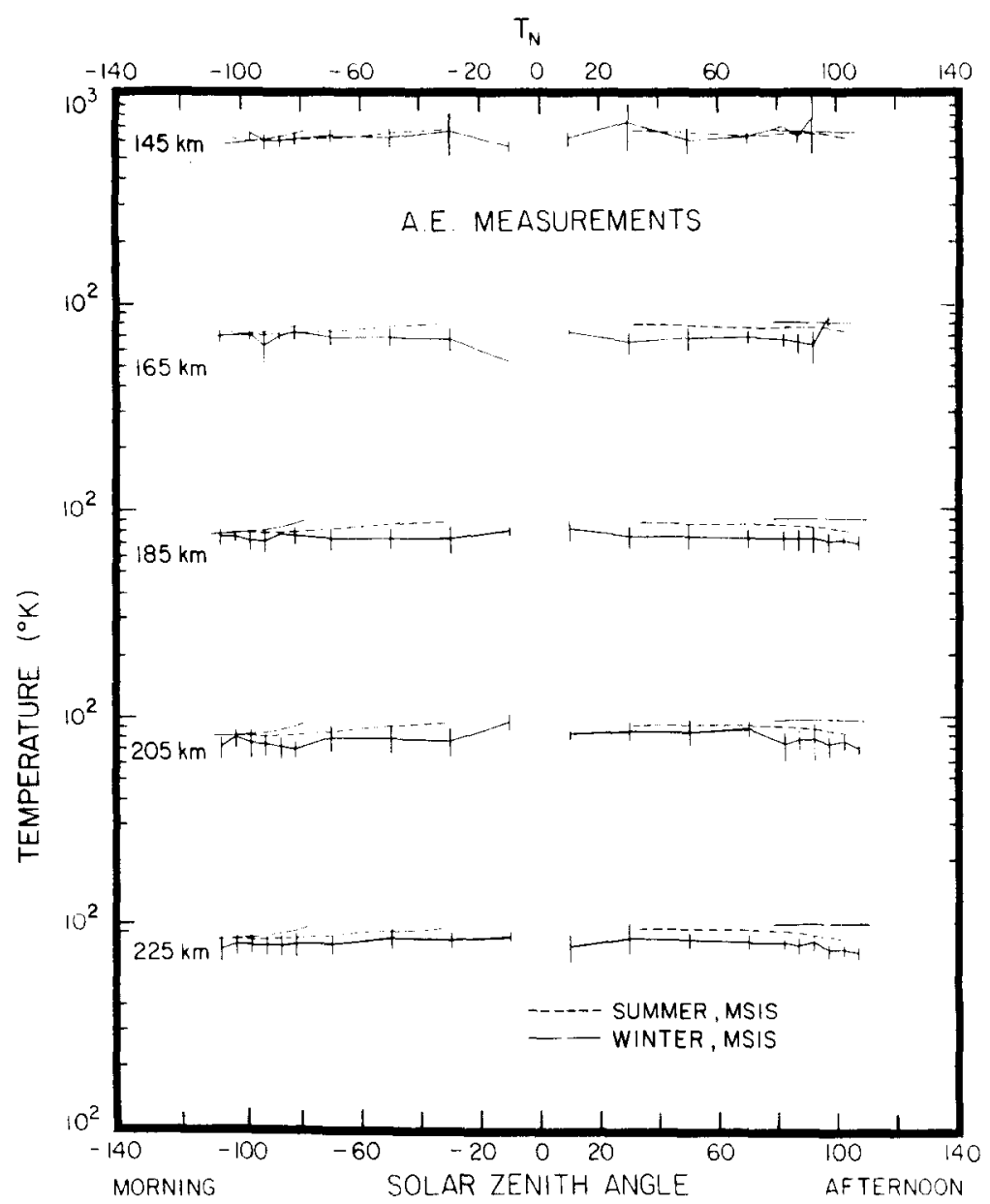

Fig. 16. The measured neutral temperature (SPENCER et al., 1973) as a function of solar zenith angle and altitude averaged for the period 1974-76 from D. TORR et al. (1979). 
or confirm the relevant rate coefficients. The combined information emerging from these studies has brought us to a point where it is possible to develop a model of the photochemical regime of the $F 1$ layer, sufficiently free of ambiguity to provide a valid check on the overall photochemical picture of the major constituents in this region. Such a study was carried out by D. Torr et al. (1979). The purpose of the study was to check the overall consistency of the photochemistry. They excluded those regimes from the study where transport effects or ionization by sources such as precipitating particles are significant, i.e. they used altitudes below $220 \mathrm{~km}$, solar zenith angles less than $\sim 100^{\circ}$ and invariant latitudes less than $55^{\circ}$. This corresponds to the sunlit F1-layer of the mid-latitude ionosphere.

Several theoretical models have been described in the literature which attempt to describe the diurnal variation of the F1-layer (see for example, Keneshea et al., 1970; TORR et al., 1972; SCHUNK and Walker, 1973). Until now we have not had direct measurements of ion concentrations made over a full diurnal cycle with which to compare such models. This situation has been remedied with the AE database. D. TORR et al. (1979) used almost all the data taken by AE-C to determine as a function of altitude the diurnal, seasonal and latitudinal variation of ion concentrations, and the input parameters required to model the former. They found that data taken below $225 \mathrm{~km}$ could be averaged as a function of altitude and solar zenith angle. Use of the latter parameter eliminates nearly all of the seasonal and latitudinal variations. Averages of directly measured quantities such as $\left[\mathrm{O}^{+}\right]$, $\left[\mathrm{NO}^{+}\right],\left[\mathrm{O}_{2}^{+}\right],\left[\mathrm{N}_{2}^{+}\right],[\mathrm{O}],\left[\mathrm{N}_{2}\right], T_{n}, T_{i}$, and $T_{e}$ were calculated together with standard deviations at intervals of $10 \mathrm{~km}$ in altitude and $10^{\circ}$ in solar zenith angle.

Average maps for $T_{n}, T_{i}$ and $T_{e}$ are shown in Figs. 16-18, respectively. The approximate number of samples per bin is several hundred. Figures 19

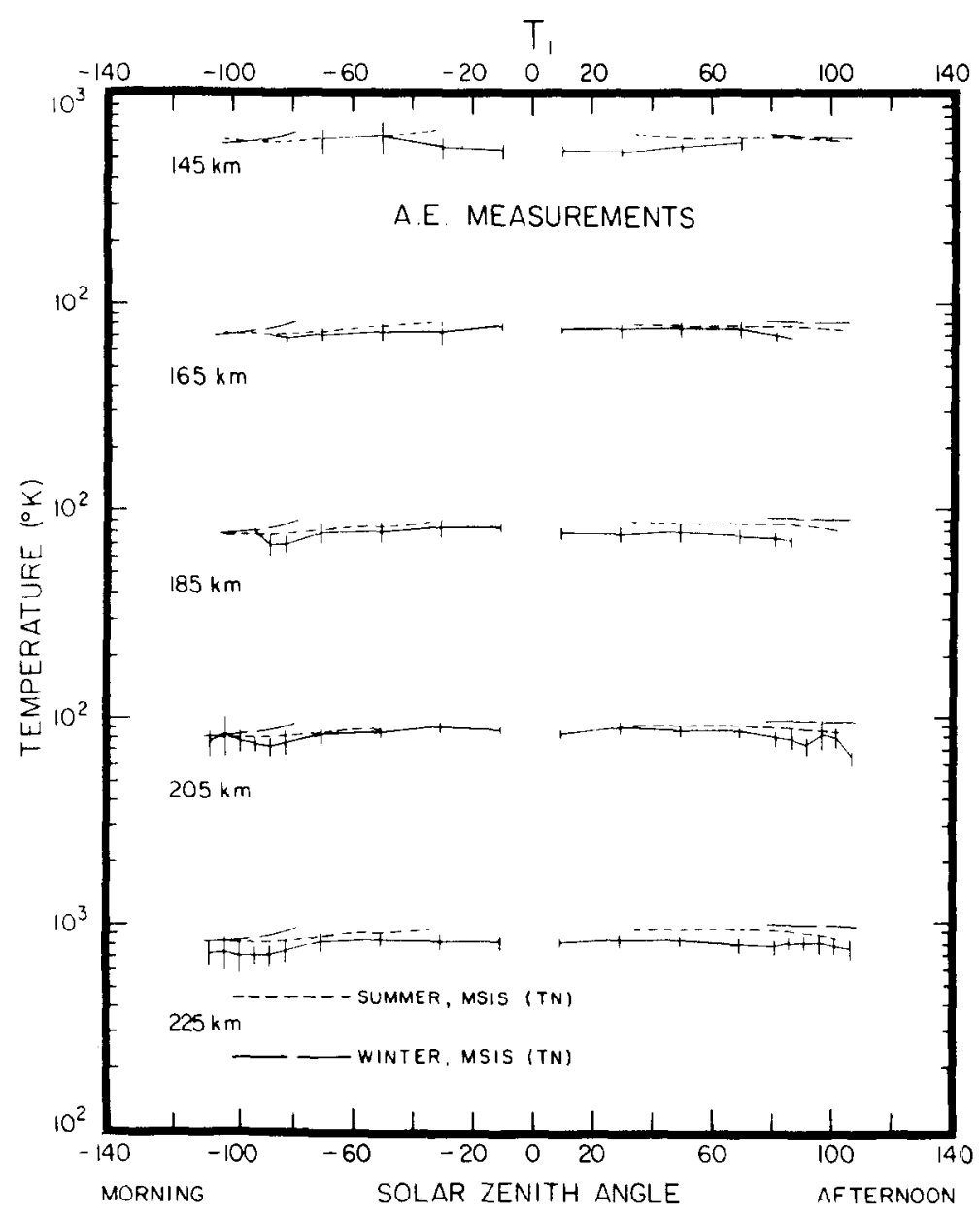

Fig. 17. Same as Fig. 16 for $T_{i}$ (HANSON et al., 1973) (cf. D. TORR et al., 1979). 


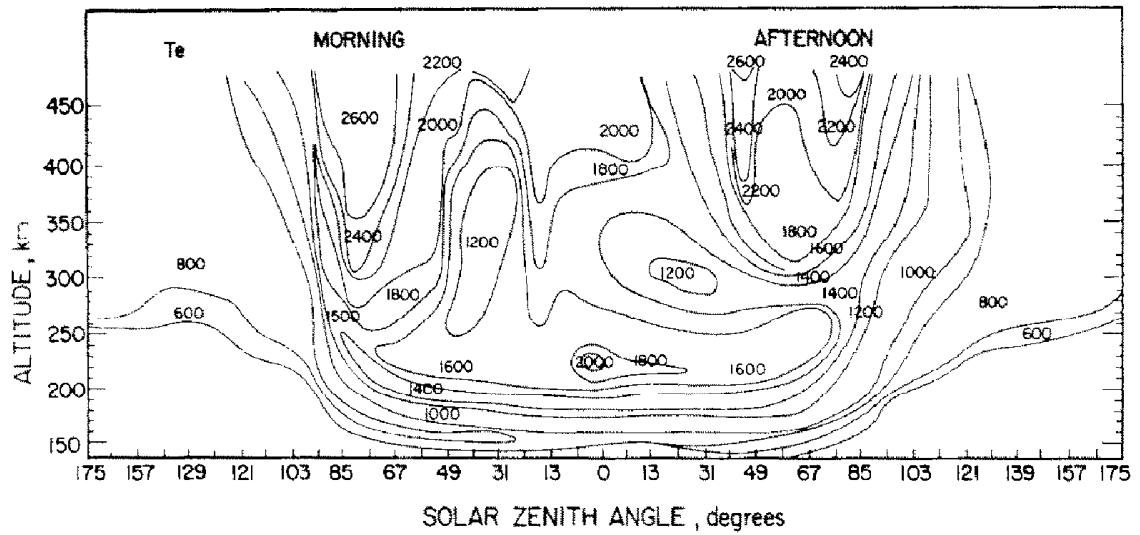

Fig. 18. Contours of constant $T_{e}$ as a function of altitude and solar zenith angle derived from AE-C measurements (BRACE et al., 1973) (D. TORR et al., 1979).

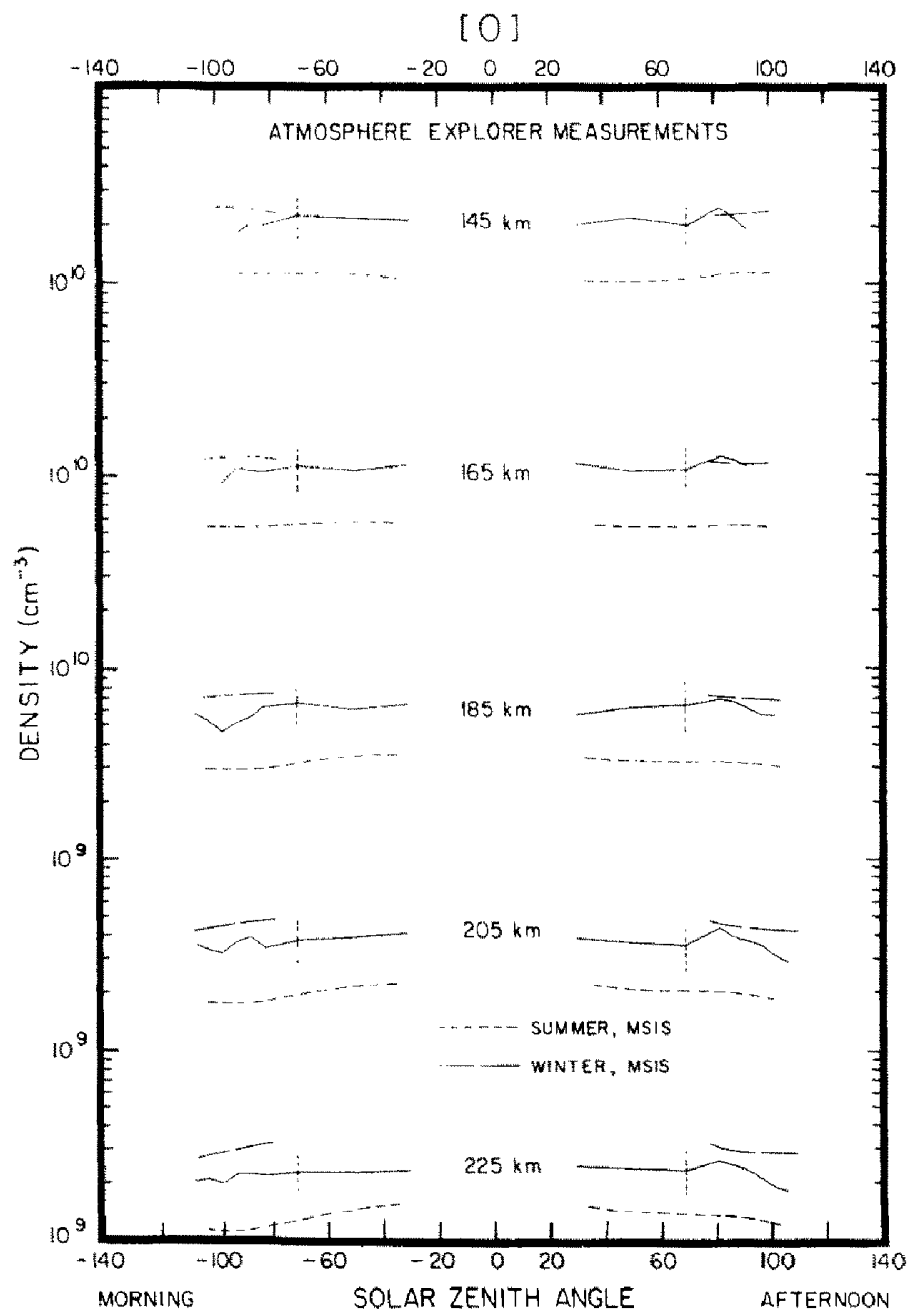

Fig. 19. Same as Fig. 16 for [O] (PELz et al., 1973; NiER et al., 1973) (cf. D. Torr et al, 1979). 
and 20 show the diurnal variations of $[\mathrm{O}]$ and $\left[\mathrm{N}_{2}\right]$. Values for the $\mathrm{O}_{2}$ density were determined from both the $\mathrm{O}_{2}{ }^{+}$ion chemistry discussed in Section 3.4 (cf. OPPENHEIMER et al., 1976) and from direct measurements of $\left[\mathrm{O}_{2}\right]$. Only a limited sample of directly measured values of $\left[\mathrm{O}_{2}\right\rfloor$ were available because the quantity measured by conventional neutral mass spectrometers is the total oxygen abundance $2\left[\mathrm{O}_{2}\right]+[\mathrm{O}]$ which is not easily resolved into atomic and molecular components. NiER et al. (1974) developed a new technique to measure the $\left[\mathrm{O}_{2}\right]$ in which use is made of the satellite velocity to distinguish atmospheric $\left[\mathrm{O}_{2}\right]$ from $\left[\mathrm{O}_{2}\right]$ which is formed by the recombination of atomic oxygen on the walls of the instrument. D. Torr et al. (1979) also attempted to use the method described by Kirby-Docken and Oppenheimer (1977). The method involves subtracting extrapolated $[\mathrm{O}]$ from the total oxygen concentration. D. TorR et al. found, however, then even at altitudes as low as $150 \mathrm{~km}$ the $\left[\mathrm{O}_{2}\right]$ comprised such a small fraction of the total oxygen abundance that the subtraction of the atomic oxygen component extrapolated from higher altitudes (assuming diffusive equilibrium) resulted in large errors. This method was therefore not used in deriving the $\mathrm{O}_{2}$ densities which are given in Fig. 21.

Ion concentrations were calculated by $\mathrm{D}$. TORR et al. (1979) using the chemistry and rate coefficients described in the preceeding sections. Figures 22-26 show the measured and theoretical ion concentrations as a function of zenith angle. In general the agreement between experiment and theory is very good. In the case of $\left[\mathrm{O}^{+}\right]$and $\left[\mathrm{N}_{2}^{+}\right]$there is

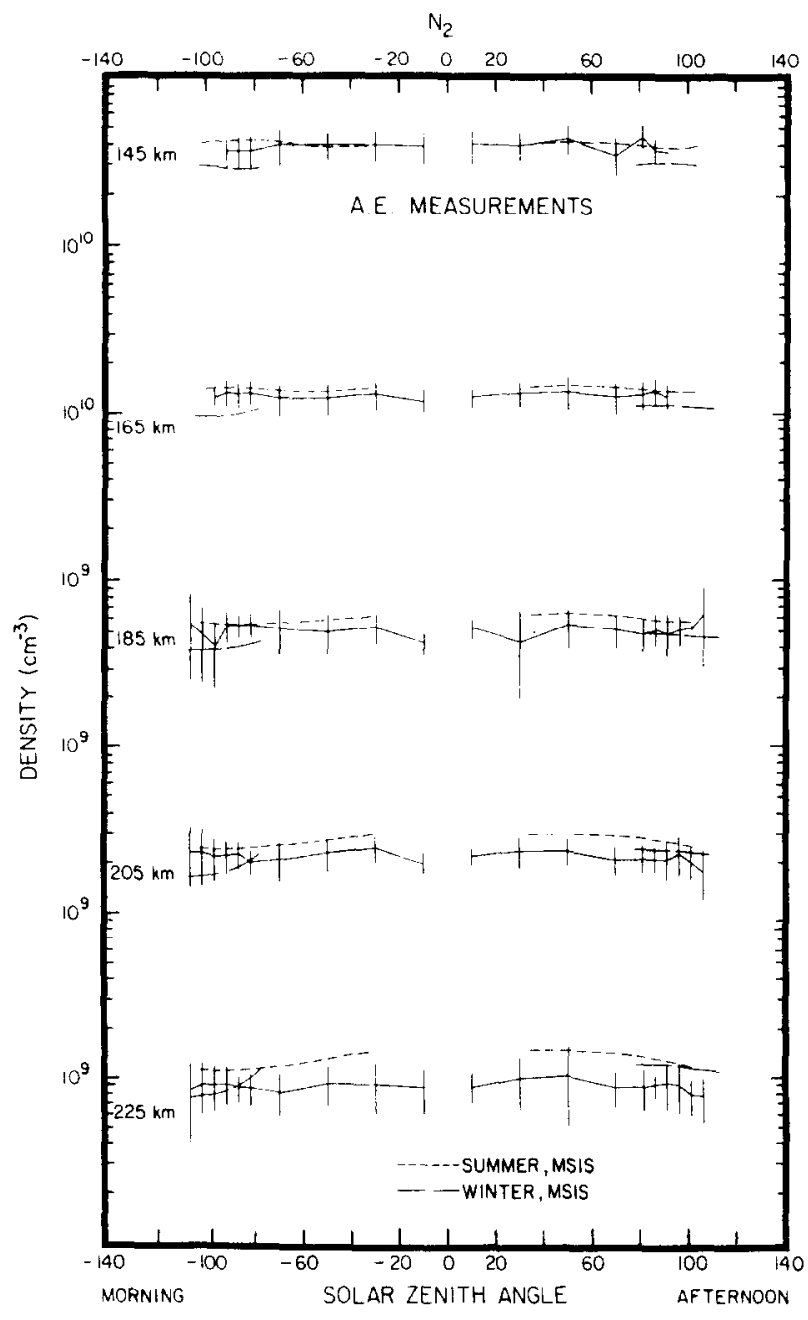

Fig. 20. Same as Fig. 19 for $\mathrm{N}_{2}$. 


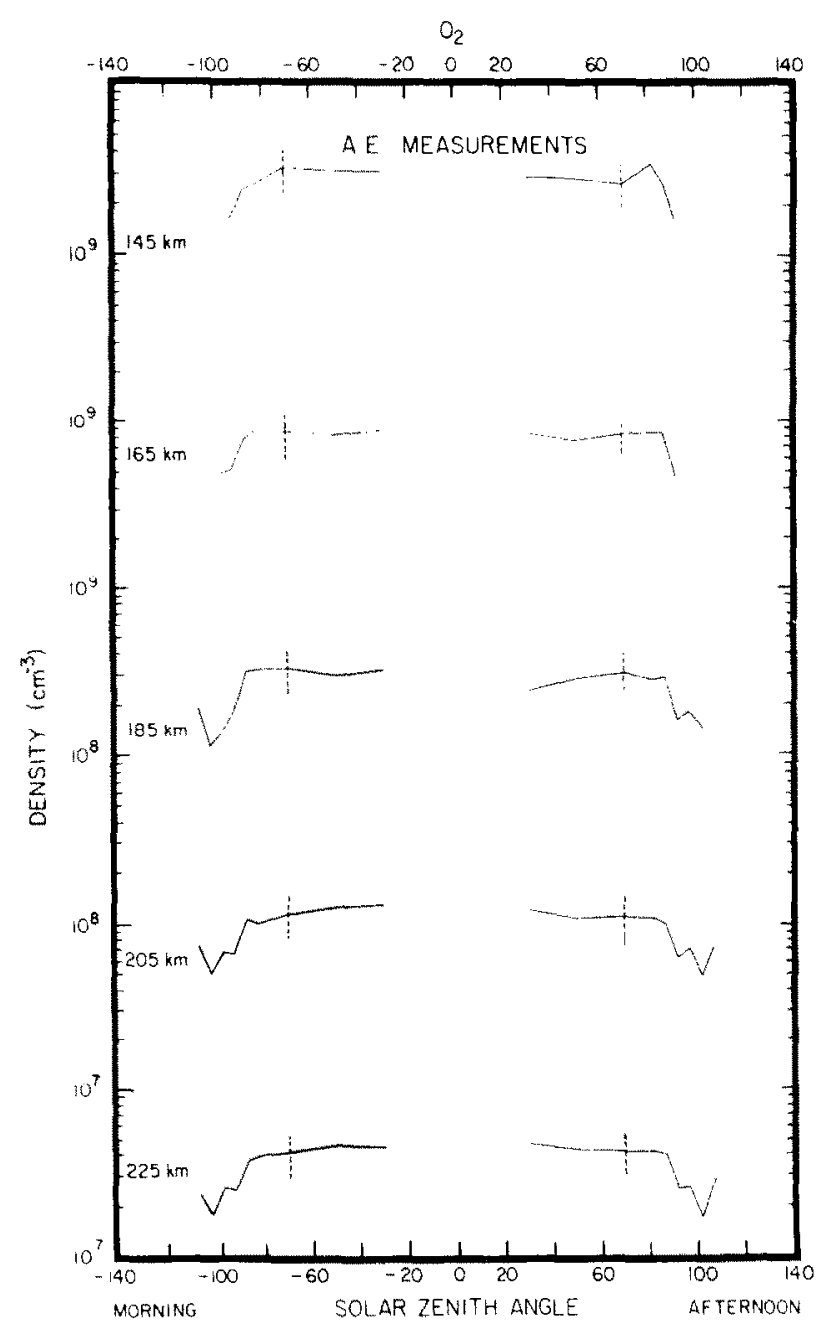

Fig. 21. The average concentration of $\mathrm{O}_{2}$ derived as a function of zenith and altitude from both direct measurements of $\left[\mathrm{O}_{2}\right]$ at $\sim 200 \mathrm{~km}$ by OSS (Nren et al., 1973, 1974) and from the $\mathrm{O}^{+}$ion chemistry using measured parameters (D. TorR et al., 1979).

some disagreement at $145 \mathrm{~km}$. This is due to the 'ram effect'. The latter is not well understood, but is seen as an increase in low ion concentrations $\left(<10^{3} \mathrm{~cm}^{3}\right)$ when the ion mass spectrometer is looking into the satellite velocity vector at low perigree altitudes $(<150 \mathrm{~km})$. The fact that the $\mathrm{O}_{2}{ }^{+}$ and $\mathrm{NO}^{+}$concentrations agree well with the measured values establishes the validity of the theoretical values for the low altitude $\left[\mathrm{O}^{+}\right]$and $\left[\mathrm{N}_{2}{ }^{+}\right]$since $\mathrm{O}_{2}{ }^{+}$is produced mainly by the reaction $\mathrm{O}^{+}+\mathrm{O}_{2} \rightarrow$ $\mathrm{O}_{2}^{+}+\mathrm{O}$ and $\mathrm{N}_{2}^{+}$by $\mathrm{N}_{2}^{+}+\mathrm{O} \rightarrow \mathrm{NO}^{+}+\mathrm{N}$.

\subsection{Ion chemistry conclusion}

These results show that with the parameters measured by the AE satellite it has been possible to reduce ambiguities and uncertainties in the photochemistry of the major species of the daytime, mid-latitude $F$-layer to the point where we now believe that this photochemistry is well determined. There is no longer any leeway to scale rate coefficients and branching ratios by factors of 2 or more, as has been done in the past in order to bring theory into agreement with measurement.

Table 3 summarizes all rate coefficients used in Section 3 .

\section{THERMOSPHERIC CHEMISTRY}

\subsection{Introduction}

This section of the review deals primarily with results of neutral metastable species measured by 
Table 3. Ionospheric rate coefficients

\begin{tabular}{|c|c|c|}
\hline Reaction & Rate coefficients $\left(\mathrm{cm}^{3} \mathrm{~s}^{-1}\right)$ & \\
\hline $\mathrm{O}^{+}+\mathrm{N}_{2} \stackrel{k_{1}}{\longrightarrow} \mathrm{NO}^{+}+\mathrm{N}$ & $k_{1}=k_{3}$ see equation $(3.15)$ & $\begin{array}{l}\text { ST-MAURICE and TORR (1978); } \\
\text { Al.BuTton et al. (1977) }\end{array}$ \\
\hline $\mathrm{NO}^{+}+e \stackrel{x_{1}}{\longrightarrow} \mathrm{N}+\mathrm{O}$ & $4.2 \times 10^{-7}\left(T_{e} / 300\right)^{-0.85}$ & $\begin{array}{l}\text { M. TORR and TORR (1979a); } \\
\text { WALLS and DUNN }(1974)\end{array}$ \\
\hline $\mathrm{N}\left({ }^{2} \mathrm{D}\right)+\mathrm{O} \stackrel{k_{3 a}}{\longrightarrow} \mathrm{NO}^{+}+e-0.37 \mathrm{eV}$ & $k_{2 a} \leqslant 2 \times 10^{-13}$ for $T_{\text {eff }}<1000 \mathrm{~K}$ & M. TORR and TORR (1979b) \\
\hline $\mathrm{N}_{2}^{+}+\mathrm{O} \stackrel{k_{4}}{\longrightarrow} \mathrm{NO}^{+} \mid \mathrm{N}$ & $1.4 \times 10^{-10}\left(T_{i} / 300\right)^{-0.44} T<1500 \mathrm{~K}$ & $\begin{array}{l}\text { D. TORR et al. (1977); D. TORR } \\
\text { (1979); McFARLAND et al. (1974) }\end{array}$ \\
\hline $\mathrm{N}_{2}^{+}+\mathrm{O} \longrightarrow \mathrm{O}^{+}+\mathrm{N}_{2}$ & $0.07 k_{4}(T / 300)^{0.21}$ & MCFARLAND et al. (1974) \\
\hline $\mathrm{N}^{+}+\mathrm{O}_{2} \stackrel{k_{5}}{\longrightarrow} \mathrm{NO}^{+}+\mathrm{O}$ & $2 \times 10^{-10}$ & HUNTRESS and ANICICH (1976) \\
\hline $\mathrm{N}^{+}+\mathrm{O}_{2} \longrightarrow \mathrm{O}_{2}^{+}+\mathrm{N}$ & $4 \times 10^{-10}$ & HuNTRESS and ANICICH (1976) \\
\hline $\mathrm{N}^{+}+\mathrm{O}_{2} \longrightarrow \mathrm{O}^{+}+\mathrm{NO}$ & $2 \times 10^{-11}$ & HUNTRESS and ANICICH (1976) \\
\hline \multirow[t]{2}{*}{$\mathrm{O}_{2}^{\cdots}+\mathrm{N} \stackrel{k_{6}}{\longrightarrow} \mathrm{NO}^{+}+\mathrm{O}$} & $1.8 \times 10^{-10}$ & GoLDAN et al. (1966) \\
\hline & $1.0 \times 10^{-10}$ & D. TORR et al. (1976d) \\
\hline $\mathrm{O}_{2}^{+}-\mathrm{NO} \stackrel{k_{7}}{\longrightarrow} \mathrm{NO}^{+}+\mathrm{O}_{2}$ & $4.4 \times 10^{-10}$ & LINDINGER et al. (1975) \\
\hline $\mathrm{O}_{2}^{+}+e \stackrel{\alpha_{2}}{\longrightarrow} \mathrm{O}+\mathrm{O}$ & $1.6 \times 10^{-7}\left(T_{e} / 300\right)^{-0.55}$ & $\begin{array}{l}\text { D. TORR et al. (1076c); MEHR and } \\
\text { BTONDI }(1969)\end{array}$ \\
\hline $\mathrm{O}^{+}+\mathrm{O}_{2} \stackrel{k_{8}}{\rightarrow} \mathrm{O}_{2}^{+}+\mathrm{O}$ & see equation (3.21) & $\begin{array}{l}\text { ST-MAURICE and TORR (1978); } \\
\text { ALBRTtTon et al. (1977) }\end{array}$ \\
\hline $\mathrm{O}^{+}\left({ }^{2} \mathrm{D}\right)+\mathrm{O}_{2} \stackrel{k_{9}}{\longrightarrow} \mathrm{O}_{2}^{+}+\mathrm{O}$ & $k_{9}=k_{23}=1 \pm 0.6 \times 10^{-10}$ & D. ToRR et al. (1978) \\
\hline $\mathrm{N}^{+}+e \stackrel{\alpha_{3}}{\longrightarrow} \mathrm{N}+\mathrm{N}$ & $1.8 \times 10^{-7}\left(T_{e} / 300\right)^{-0.39}$ & $\begin{array}{l}\text { MFHR and Bronni (1969): confirmed } \\
\text { by N. OrsinI (unpublished) } \\
\text { (see Fig. 15b) }\end{array}$ \\
\hline $\mathrm{O}^{+}\left({ }^{2} \mathrm{D}_{1}+\mathrm{N}_{2} \stackrel{k_{12}}{\longrightarrow} \mathrm{N}_{2}^{+}+\mathrm{O}\right.$ & $1\left\{\begin{array}{c}+1 \\
-0.5\end{array}\right\} \times 10^{-10}$ & $\begin{array}{l}\text { D. TORR and ORsini (1978); } \\
\text { this paper Fig. 15a. }\end{array}$ \\
\hline $\mathrm{O}^{+}\left({ }^{2} \mathrm{P}\right)+\mathrm{N}_{2} \stackrel{k_{13}}{\longrightarrow} \mathrm{N}_{2}^{+}+\mathrm{O}$ & $4.8 \pm 1.4 \times 10^{-10}$ & Rusch et al. (1977a) \\
\hline $\mathrm{N}_{2}+\mathrm{O}_{2} \stackrel{k_{15}}{\longrightarrow} \mathrm{O}_{2}^{+}+\mathrm{N}_{2}$ & $\begin{array}{l}\sim 1.5 \times 10^{-11} \text { at } 800 \mathrm{~K} \text { see } \\
\text { reference for } T \text { dependence }\end{array}$ & LINDINGER et al. (1974) \\
\hline $\mathrm{O}^{+}\left({ }^{2} P\right)+e \stackrel{k_{17}}{\longrightarrow} \mathrm{O}^{+}\left({ }^{2} \mathrm{D}\right)+e$ & $1.5 \times 10^{-7}\left(300 / T_{e}\right)^{1 / 2}$ & HENRY et al. (1969) \\
\hline $\mathrm{O}^{+}\left({ }^{2} P\right)+\mathrm{O} \stackrel{k_{18}}{\longrightarrow} \mathrm{O}^{+}+\mathrm{O}$ & $5.2 \pm 2.5 \times 10^{10}$ & Rusch et al. (1977a) \\
\hline $\mathrm{O}^{+}\left({ }^{2} P\right)+\mathrm{N}_{2} \stackrel{k_{10}}{\longrightarrow} \mathrm{O}^{+}\left({ }^{2} \mathrm{D}\right)+\mathrm{N}_{2}$ & assumed $k_{19}=0$ & \\
\hline $\mathrm{O}^{+}\left({ }^{2} \mathrm{D}\right)+\mathrm{N}_{2} \stackrel{k_{20}}{\longrightarrow} \mathrm{O}^{+}\left({ }^{4} S\right)+\mathrm{N}_{2}$ & $2 \times 10^{-11}<k_{20}<2 \times 10^{-10}$ & (This paper) \\
\hline $\mathrm{O}^{+}\left({ }^{2} \mathrm{D}\right)+\mathrm{O} \stackrel{\mathrm{k}_{24}}{\longrightarrow} \mathrm{O}^{+}\left({ }^{4} S\right)+\mathrm{O}$ & $<1 \times 10^{-11}$ & $\begin{array}{l}\text { Orsin et al. (1977); (this } \\
\text { paper Fig. 14) }\end{array}$ \\
\hline $\mathrm{O}^{+}\left({ }^{2} D\right)+e \stackrel{k_{22}}{\longrightarrow} \mathrm{O}^{+}\left({ }^{4} S\right)+e$ & $7.8 \times 10^{-8}\left(T_{e} / 300\right)^{1 / 2}$ & HENRY et al. (1969) \\
\hline
\end{tabular}




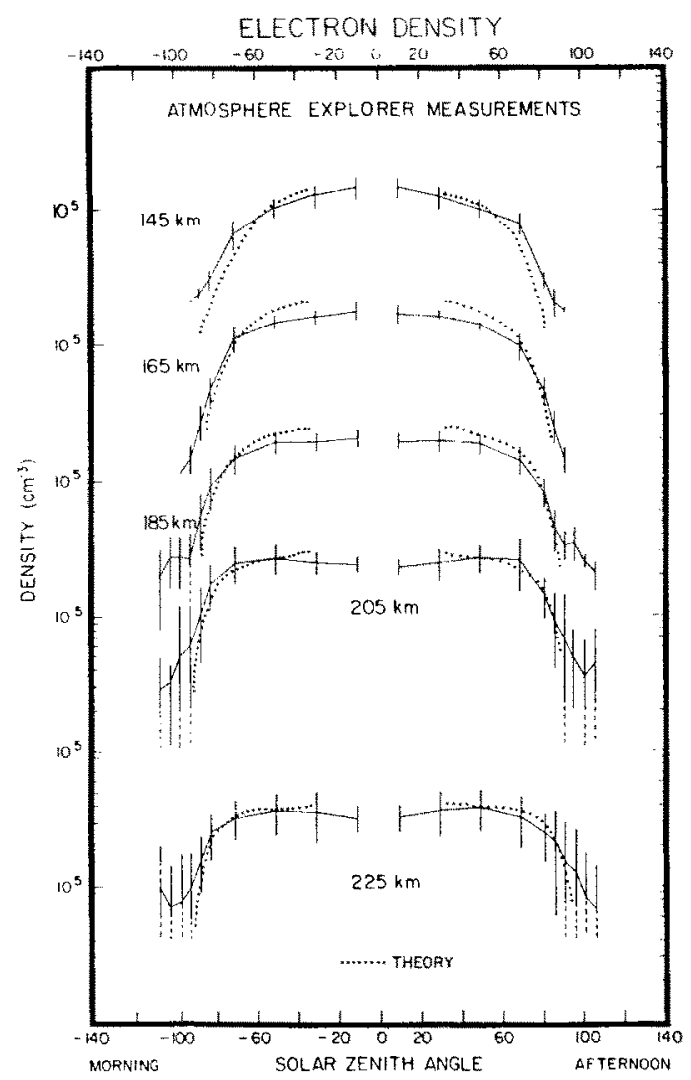

Fig. 22. Average measured and calculated electron densities as a function of solar zenith angle and altitude. Data used were taken over the period 1974-76 (D. ToRR et al., 1979).

the visible airglow experiment (VAE) (HAYs et al., 1973), and odd nitrogen concentrations measured by the UV nitric-oxide experiment (BARTH et al., 1973), and the open source neutral mass spectrometer (Nrer et al., 1973). Although the substance of the AE work done in this area is comparable in extent to that in ion chemistry we have kept this section brief, because it is not possible within the scope of this treatment to cover all aspects of the AE work on ionospheric and thermospheric chemistry. Highlights that we discuss include odd nitrogen measurements and theory, including diurnal, seasonal and latitudinal variations; sources and sinks of $O\left({ }^{1} S\right)$ and $O\left({ }^{3} D\right)$ atoms including the diurnal variation of the latter; the section is concluded with a study of the source of $\mathrm{N}_{2}[2 P](0-0)$ emission in the thermosphere.

\subsection{Atomic nitrogen}

One of the first results to emerge from the analyses of the AE data were deductions by Rusch et al. (1975a) that the peak concentrations of $N\left({ }^{4} S\right)$ must exceed $\sim 10^{7} \mathrm{~cm}^{-3}$. This conclusion was based on an analysis of $5200 \AA$ airglow measurements by VAE. The $5200 \AA$ emission arises from the transition $\mathrm{N}\left({ }^{4} S-{ }^{2} D\right)$ and is a direct measure of the ${ }^{2} D$ density. Surface brightness measurements were inverted to yield volume emissions rate profiles as a function of altitude. Thus, sources and sinks of $\mathrm{N}\left({ }^{2} D\right)$ could be studied as a function of altitude. Prior to AE, details of the chemistry of $\mathrm{N}\left({ }^{4} S\right)$ and $\mathrm{N}\left({ }^{2} D\right)$ were uncertain. The satellite studies resulted in a large reduction in these uncertainties.

Figure 27 summarizes the processes which result in the production and destruction of nitrogen atoms in the thermosphere. Atomic nitrogen is produced primarily by ion-atom interchange of $\mathrm{N}_{2}{ }^{+}$with $\mathrm{O}$

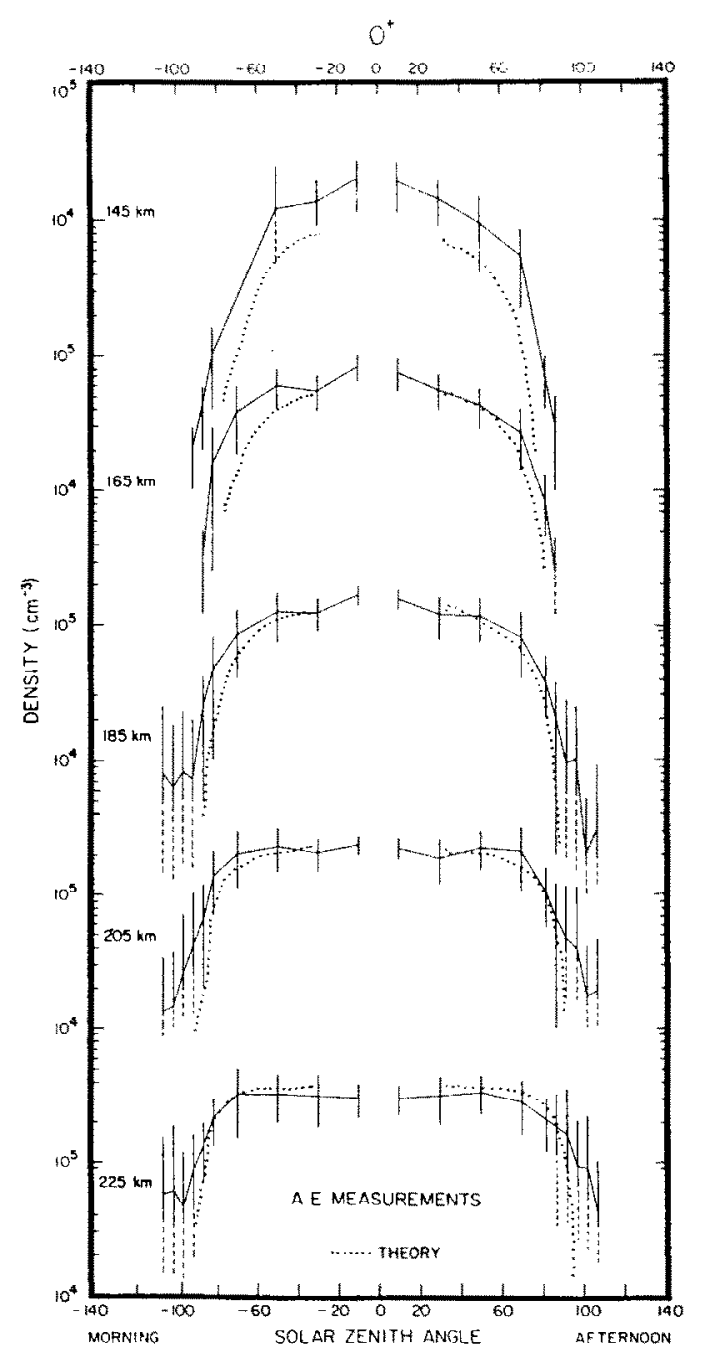

Fig. 23. Same as Fig. 22 for $\left[\mathrm{O}^{+}\right]$. 


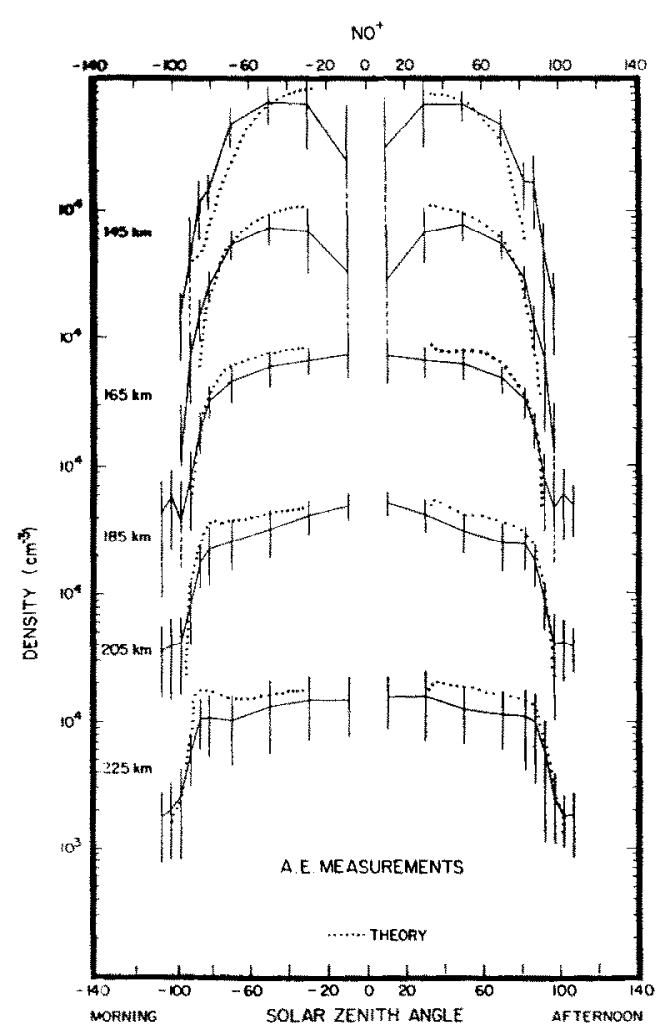

Fig. 24. Same as Fig. 22 for $\left[\mathrm{NO}^{+}\right]$.

and by dissociative recombination of $\mathrm{NO}^{+}$at altitudes above $200 \mathrm{~km}$. Above $300 \mathrm{~km}$ recombination of $\mathrm{N}_{2}^{+}$becomes a significant source. Below $200 \mathrm{~km}$ photoelectron impact dissociation of $\mathrm{N}_{2}$ dominates. The branching ratios for the production of $\mathrm{N}\left({ }^{2} D\right)$ and $\mathrm{N}\left({ }^{4} S\right)$ are critical in determining the $\mathrm{NO}$ and $\mathrm{N}\left({ }^{4} S\right)$ densities in the thermosphere, because $N\left({ }^{2} D\right)$ produces NO and the odd nitrogen is cannibalistically destroyed. Predominant production of $\mathrm{N}\left({ }^{2} \mathrm{D}\right)$ at low altitudes results in an NO rich atmosphere, since $\mathrm{N}\left({ }^{2} D\right)$ reacts with $\mathrm{O}_{2}$ to form NO. The latter in turn destroys $N\left({ }^{4} S\right)$. The ratio of $[\mathrm{O}] /\left[\mathrm{O}_{2}\right]$ increases with altitude and $\mathrm{O}$ quenching of $\mathrm{N}\left({ }^{2} D\right)$ becomes the main source of $\mathrm{N}\left({ }^{4} S\right)$. The latter in turn becomes a major source of $\mathrm{NO}$ by reacting with $\mathrm{O}_{2}$, a reaction which is highly temperature dependent. The buildup of $N\left({ }^{4} S\right)$ tends to be self sustaining.

Studies by Norton and Barth (1970), Strobel. et al. (1970), and Rusch (1973) identificd the following production and loss mechanisms.

4.2.1 $\mathrm{N}\left({ }^{2} \mathrm{D}\right) . \mathrm{N}\left({ }^{2} \mathrm{D}\right)$ is produced mainly by the processes:

$$
\mathrm{NO}^{+}+e \stackrel{\mathrm{B}_{1} \boldsymbol{\alpha}_{1}}{\longrightarrow} \mathrm{N}\left({ }^{2} \mathrm{D}\right)+\mathrm{O}
$$

$$
\begin{gathered}
\mathrm{N}_{2}^{+}+e \stackrel{2 \beta_{2} \alpha_{3}}{\longrightarrow} \mathrm{N}\left({ }^{2} D\right)+\mathrm{N}, \\
\mathrm{N}_{2}^{+}+\mathrm{O} \stackrel{\beta_{3} k_{4}}{\longrightarrow} \mathrm{N}\left({ }^{2} D\right)+\mathrm{NO}^{+}, \\
e+\mathrm{N}_{2} \stackrel{\beta_{4} I_{4}}{\longrightarrow} \mathrm{N}\left({ }^{2} D\right)+\mathrm{N}, \\
\mathrm{N}^{+}+\mathrm{O}_{2} \stackrel{k_{24}}{\longrightarrow} \mathrm{N}\left({ }^{2} D\right)+\mathrm{O}_{2}{ }^{+} .
\end{gathered}
$$

The loss processes are:

$$
\begin{gathered}
\mathrm{N}\left({ }^{2} D\right)+\mathrm{O} \stackrel{k_{2 b}}{\longrightarrow} \mathrm{N}\left({ }^{4} S\right)+\mathrm{O}, \\
\mathrm{N}\left({ }^{2} D\right)+\mathrm{O}_{2} \stackrel{k_{25}}{\longrightarrow} \mathrm{NO}+\mathrm{O} . \\
\mathrm{N}\left({ }^{2} D\right)+e \stackrel{k_{2 b}}{\longrightarrow} \mathrm{N}\left({ }^{4} S\right)+e .
\end{gathered}
$$

In addition to (4.6) ZIPF (1978) has observed that energetic $\mathrm{N}\left({ }^{2} D\right)$ atoms associatively ionize in the laboratory to form $\mathrm{NO}^{+}$, i.e.

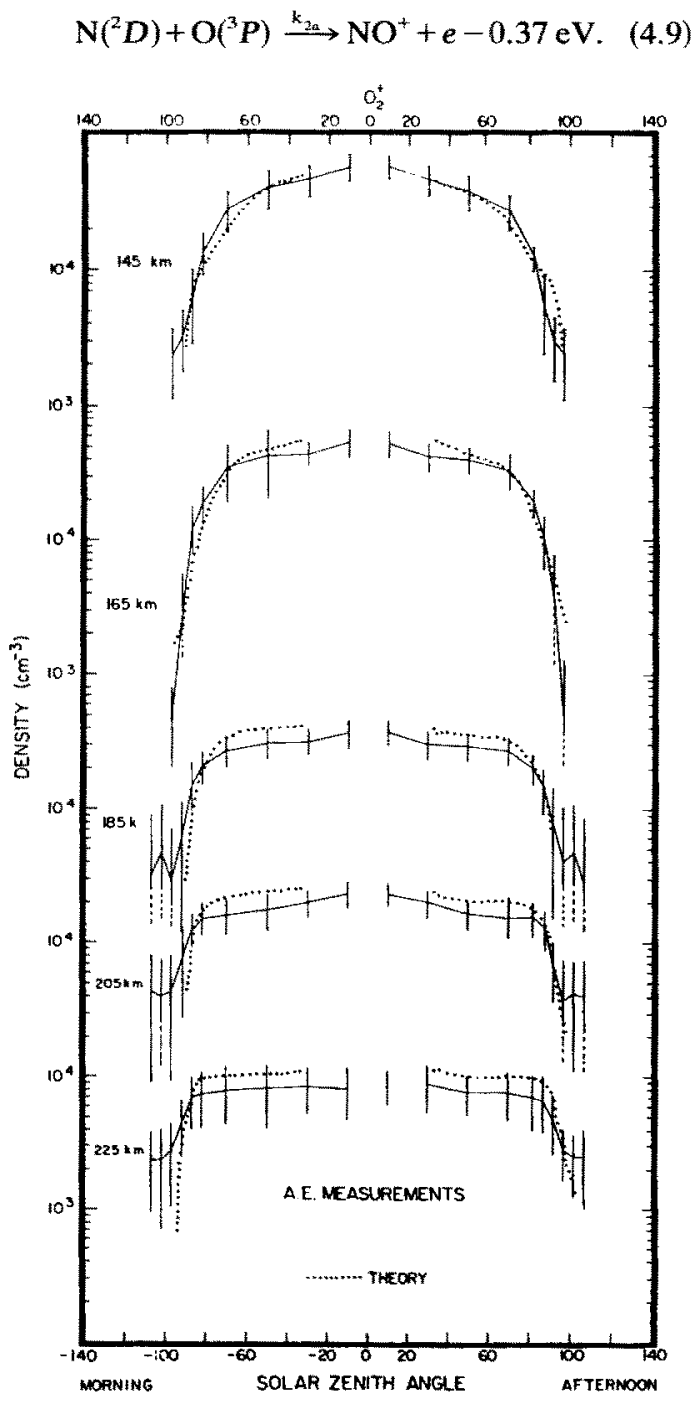

Fig. 25. Same as Fig. 22 for $\left[\mathrm{O}_{2}^{+}\right]$. 


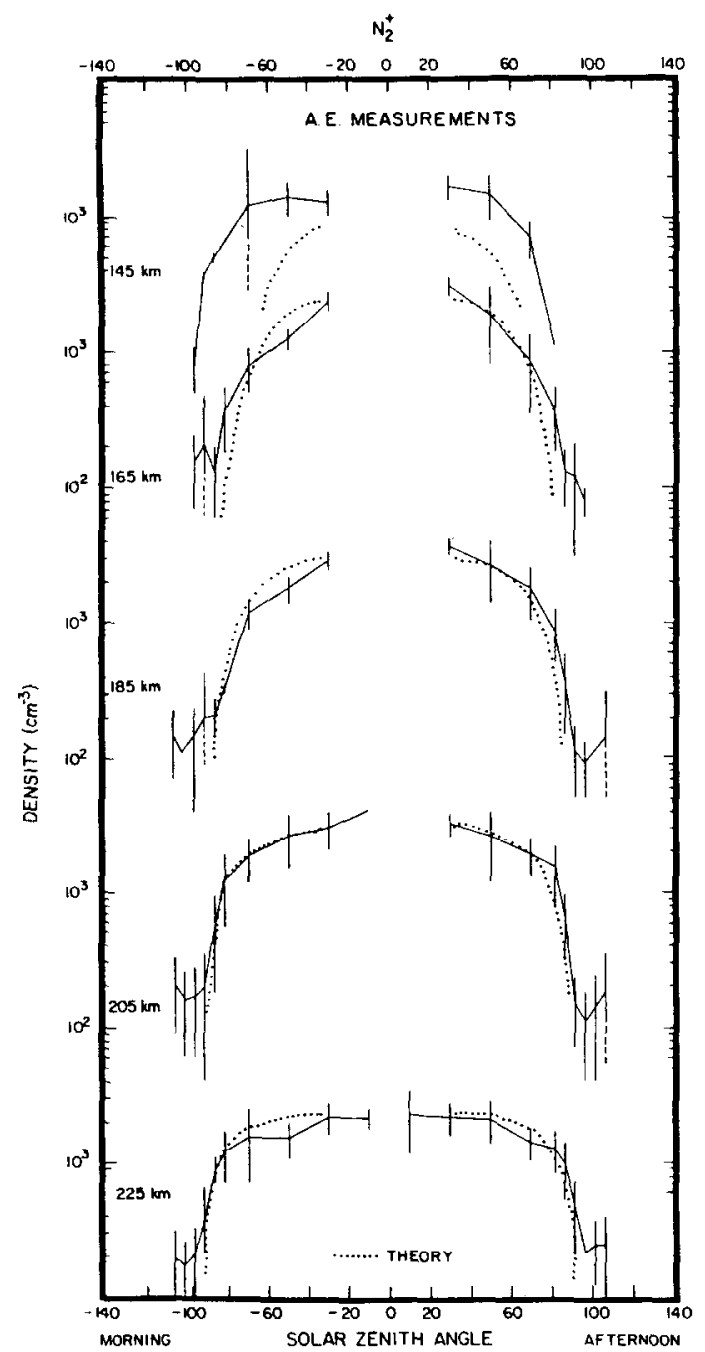

Fig. 26. Same as Fig. 22 for $\left[\mathrm{N}_{2}{ }^{+}\right]$.

Reaction (4.9) has also been investigated using $\mathrm{AE}$ data to establish whether it is a significant sink for $\mathrm{N}\left({ }^{2} D\right)$ atoms at thermal temperatures (M TORR and TORR, 1979b)

Prior to AE the branching ratios $\beta_{1}$ to $\beta_{4}$, the ratc coefficients $k_{2 b}, k_{25}$ and $k_{26}$ were unknown or uncertain. Values deduced for $\beta_{1}$ from early photochemical studies (Hernandez and Turtie, 1969; Strobel et al., 1970; Norton and Barth, 1970; Oran et al., 1975) ranged from 0.1 to 0.85 . From theoretical studies BARDSLEY (1968) estimated $0.5 \leq \beta_{1} \leq 1$. In the case of $k_{25}$, three laboratory measurements had been made, with two in close agreement giving $k_{25} \approx 6 \times 10^{-12} \mathrm{~cm}^{3} \mathrm{~s}^{-1}$ (BL.ACK et al., 1969; Lin and Kaufman, 1971). The third measurement gave $k_{25}=4.4 \times 10^{-12}$ (SLANGER et al., 1971). In the case of $k_{26}$, HENRY and WIL-
LIAMS (1968) and SEATON (1956) calculated values of $3 \times 10^{-9} \mathrm{~cm}^{3} \mathrm{~s}^{-1}$ and $8.0 \times 10^{-10} \mathrm{~cm}^{3} \mathrm{~s}^{-1}$, respectively.

Using the VAE $5200 \AA$ data and the measured neutral ion densities and temperatures and photoelectron fluxes, Rusch et al. (1975a) drew the following conclusions.

(1) The yield of $\mathrm{N}\left({ }^{2} D\right)$ must be near the maximum allowable value, i.e. $\beta_{1} \approx \beta_{2} \approx \beta_{3} \approx 1.0$.

(2) Quenching by atomic oxygen is a major loss process for $\mathrm{N}\left({ }^{2} D\right)$ in the thermosphere; $k_{2 b} \leqslant$ $6 \times 10^{-13} \mathrm{~cm}^{3} \mathrm{~s}^{-1}$ which tends to agree with early ground based work of WerLl (1969).

(3) Electron quenching is important above $250 \mathrm{~km}$.

(4) $\mathrm{O}_{2}$ quenching is important below $200 \mathrm{~km}$.

These conclusions were confirmed by subsequent aeronomic investigations by STROBEL et al. (1976) and Frederick and Rusch (1977). The latter work narrowed down the uncertainties on these rate coefficients further.

The atomic oxygen quenching rate coefficient was subsequently measured in the laboratory by DAVENPORT et al. (1976). They derived a value of $2 \times 10^{-12} \mathrm{~cm}^{3} \mathrm{~s}^{-1}$ at $300 \mathrm{~K}$ which increases to $\sim 1 \times$ $10^{-11} \mathrm{~cm}^{3} \mathrm{~s}^{-1}$ at $700 \mathrm{~K}$ if a conservative value of $0.5 \mathrm{kcal} \mathrm{molc}^{-1}$ is adopted for the activation energy for the reaction implied by the measurements. This directly contradicts the aeronomic determination of $k_{2 b}$. It is conceivable that reaction (4.9) might explain part of the discrepancy between the aeronomic and laboratory results. However, this would require that the laboratory reactants possess sufficient translational energy to partially counteract the energy deficit.

A subsequent quantitative study using both nighttime and daytime AE data by FrEDERICK and Rusch (1977) reconfirmed the low value for $k_{2 b}$ $\left(4 \times 10^{-13} \mathrm{~cm}^{3} \mathrm{~s}^{-1}\right)$. TORR and TORR $\left.1979 \mathrm{~b}\right)$ have deduced an upper limit of $\sim 2 \times 10^{-13} \mathrm{~cm}^{3} \mathrm{~s}^{-1}$ for $k_{2 a}$ in the nighttime mid-latitude ionosphere. FreDERICK and Rusch determined that the electron quenching rate of $\mathrm{N}\left({ }^{2} D\right)$ lies between 3.6-6.5 $10^{-10}\left(T_{e} / 300\right)^{1 / 2} \mathrm{~cm}^{3} \mathrm{~s}^{-1}$. They found $k_{25}$ (the $\mathrm{O}_{2}$ quenching rate coefficient) to be in good agreement with the laboratory results, i.e. $6 \pm 1 \times 10^{-12} \mathrm{~cm}^{3} \mathrm{~s}^{-1}$ (LiN and KaUfman, 1971). From combined laboratory and aeronomic studies ZIPF (1978) has estimated that the fractional yield of $\mathbf{N}^{+}, \mathbf{N}\left({ }^{2} \mathbf{P}\right)$, $\mathrm{N}\left({ }^{2} D\right)$ and $\mathrm{N}\left({ }^{4} S\right)$ atoms from electron impact dissociation of $\mathrm{N}_{2}$ is approximately $0.135: 0.155: 0.31$ : 0.40 , respectively at $100 \mathrm{eV}$. Figures 28 and 29 show the production and loss rates of $N\left({ }^{2} D\right)$ calculated by Frederick and Rusch (1977) for AE-C orbit 


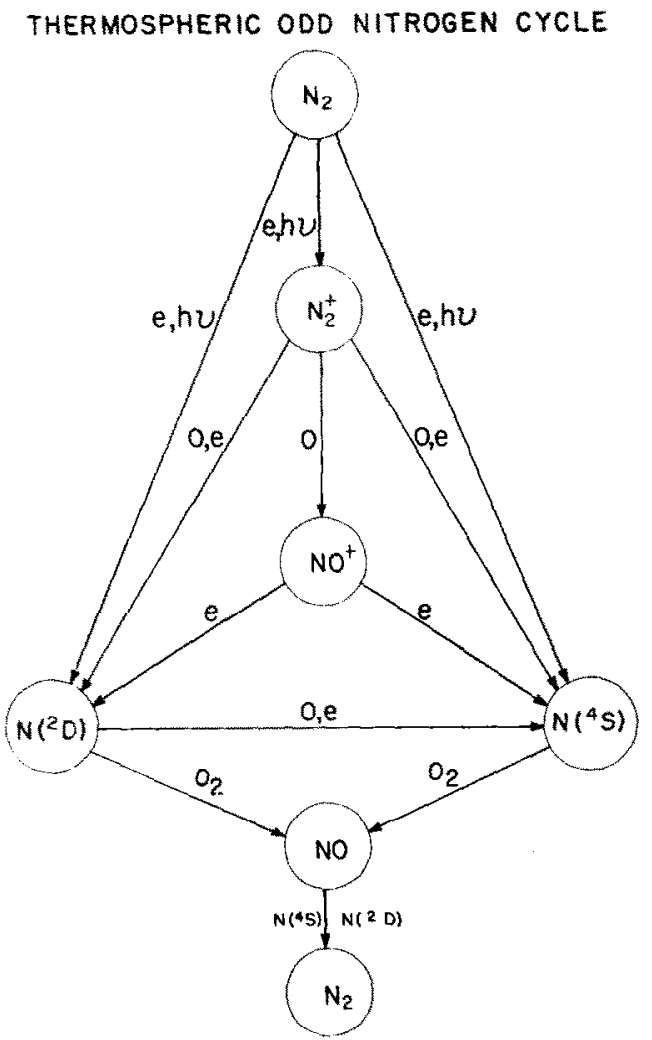

Fig. 27. Schematic illustration of the chemistry of $N\left({ }^{2} D\right)$, $\mathrm{N}\left({ }^{4} \mathrm{~S}\right)$ and $\mathrm{NO}$ in the thermosphere.

1663 using the above rate coefficients. Figures 30 and 31 show a comparison of the theoretical $5200 \AA$ results with VAE measurements for a nighttime and daytime orbit. These results illustrate the quality of the agreement between experiment and theory using the $A E$ rate coefficients. The solid curve in Fig. 31 demonstrates that the high laboratory values for $k_{2 b}\left[N\left({ }^{2} D\right)+O\right]$ are inconsistent with the satellite measurements.

4.2.2 $\mathrm{N}\left({ }^{4} \mathrm{~S}\right)$. Because the chemistry of $\mathrm{N}\left({ }^{2} D\right)$ demands that branching ratios for the production of $\mathrm{N}\left({ }^{2} \mathrm{D}\right)$ must be high, the only important sources of $N\left({ }^{4} S\right)$ are $(4.6)\left(\mathrm{O}\right.$ quenching of $\left.N\left({ }^{2} D\right)\right)$ and $(4.4)$ (photoelectron impact dissociation of $\mathrm{N}_{2}$ ). There are several other minor sources of $\mathrm{N}\left({ }^{4} \mathrm{~S}\right)$ which are shown in Fig. 32 from Ruscr et al. (1977b). This figure illustrates the crucial role played by atomic oxygen quenching of $\mathrm{N}\left({ }^{2} D\right)$ in the chemistry of $N\left({ }^{4} S\right)$. At auroral altitudes the branching ratio for the production of $N\left({ }^{4} S\right)$ and $N\left({ }^{2} D\right)$ by electron impact is the most critical parameter determining the ratio $\left[\mathrm{N}\left({ }^{4} \mathrm{~S}\right)\right] /[\mathrm{NO}]$.

4.2.3 $\mathrm{N}\left({ }^{4} \mathrm{~S}\right)$ loss rates. $\mathrm{N}\left({ }^{4} \mathrm{~S}\right)$ is lost mainly by the reactions

$$
\begin{aligned}
& \mathrm{N}\left({ }^{4} S\right)+\mathrm{O}_{2} \stackrel{k_{27}}{\longrightarrow} \mathrm{NO}+\mathrm{O}, \\
& \mathrm{N}\left({ }^{4} \mathrm{~S}\right)+\mathrm{NO} \stackrel{k_{28}}{\longrightarrow} \mathrm{N}_{2}+\mathrm{O} .
\end{aligned}
$$

The ratio of the $\mathrm{O}$ to $\mathrm{O}_{2}$ densities is also a major factor determining the ratio of $\mathrm{N}\left({ }^{4} \mathrm{~S}\right)$ to $\mathrm{NO}$ densities. Uncertainties in the $\mathrm{O}_{2}$ density on $\mathrm{AE}$ is the primary source of uncertainty in odd nitrogen calculations.

4.2.4 Nitric oxide. Reactions (4.7) and (4.10) define the thermospheric sources of nitric oxide. Reaction (4.11) is the main sink for NO, although under certain conditions minor loss processes with

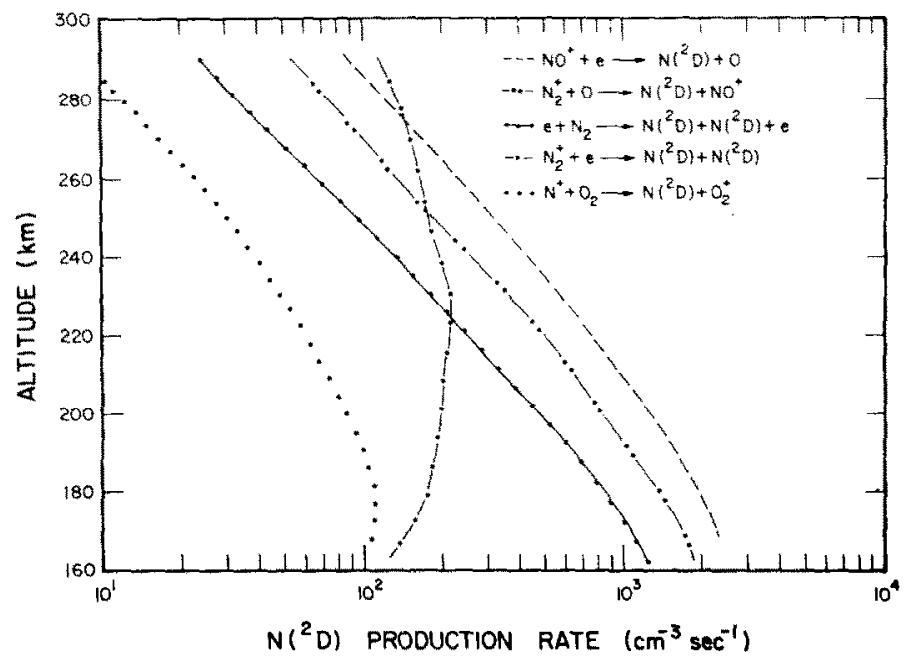

Fig. 28. The production rate of $N\left({ }^{2} \mathrm{D}\right)$ for AE-C orbit 1663 downleg on 14 May 1974 (FREDERICK and RusCH, 1977). 


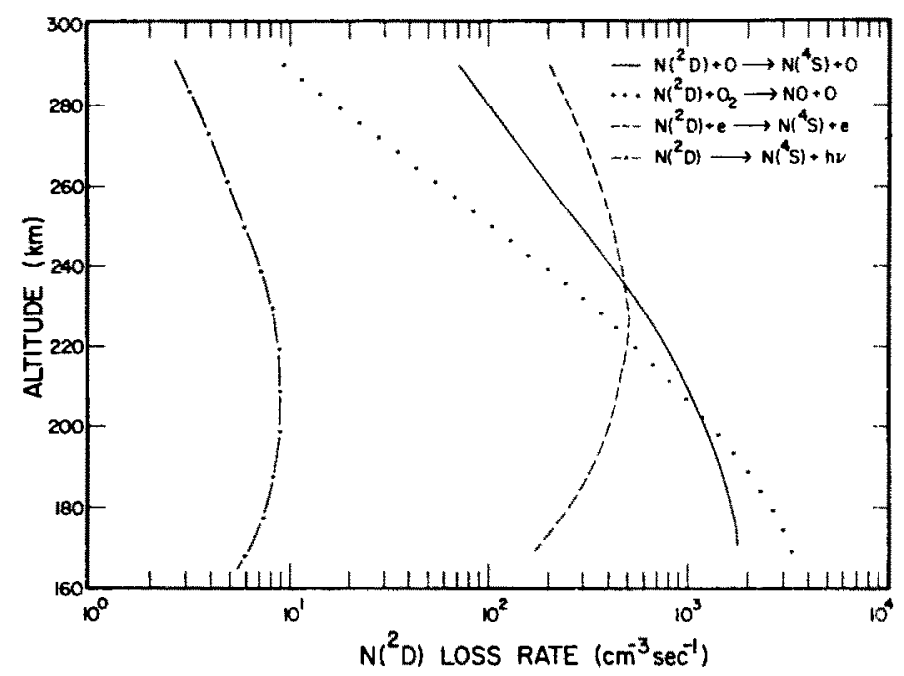

Fig. 29. $N\left({ }^{2} D\right)$ loss rates for AE-C orbit 1663 downleg on 14 May 1974.

ions become important enough to influence the odd nitrogen chemistry.

At altitudes above $160 \mathrm{~km}$ the $\mathrm{N}\left({ }^{4} S\right)$ sinks become small due to the rapid decrease in $\mathrm{O}_{2}$ and $N O$, and $\left[N\left({ }^{4} S\right)\right]$ is controlled by diffusion. Diffusion becomes important in the case of NO at altitudes above $250 \mathrm{~km}$. At low altitudes, $N\left({ }^{2} D\right)$ is converted primarily into NO which cannibalistically destroys $\mathbf{N}\left({ }^{4} \mathbf{S}\right)$ and causes it to peak at about $140 \mathrm{~km}$. Therefore at low altitudes the NO diffusion lifetime is shorter than the chemical lifetime,

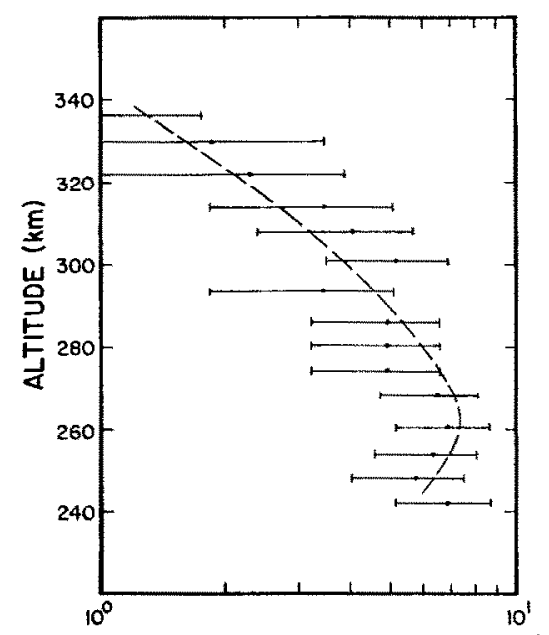

HORIZONTAL SURFACE BRIGHTNESS (R)

Fig. 30. Horizontally viewed surface brightness of the $5200 \AA$ emission for AE-C nighttime orbit 3682 downleg (points). The broken curve is the theoretical results of Frenerick and RuSCH (1977). and transport of NO into the mesosphere becomes a major thermospheric removal process.

Taking these factors into account Rusch et al. (1975a, 1977b) modeled the odd nitrogen concentrations in the thermosphere and arrived at the results shown in Fig. 33 for AE-C orbit 594.

4.2.5 AE measurements of $\mathrm{N}\left({ }^{4} \mathrm{~S}\right)$ and NO. The high $\mathrm{N}$ densities deduced from the airglow measurements were confirmed soon thereafter by direct measurements by MAUERSBERGER et al. (1975) using the open source neutral mass spectrometer (OSS). Atomic nitrogen had been detected by FEldman and Takacs (1974) by using optical spectroscopy. They used the $\gamma$ - and $\delta$-emission bands of NO to derive $\mathrm{N}$ densities of $\sim 1.9 \times 10^{7} \mathrm{~cm}$ at $140 \mathrm{~km}$. The atomic nitrogen appeared to be in diffusive equilibrium above this altitude. GHosh et al. (1968) using a rocket-borne mass spectrometer had previously reported an abundance of $\mathrm{N}$ which could be as much as $6 \%$ of $\left[\mathrm{N}_{2}\right]$. The $\mathrm{AE}$ results were further borne out by satellite measurements by Gerard (1975) who measured the NO $\delta$ hands.

The neutral mass spectrometer measurements of MAUERSBERger et al. (1975) were of special significance in that they identified the presence of a peak at mass 30 as being due primarily to $\mathrm{N}\left({ }^{4} S\right)$ which had recombined with oxygen present on the surface of the instrument to form NO. This technique has subsequently become a standard way of measuring the $\mathrm{N}\left({ }^{4} S\right)$ density. It can also be used at lower altitudes if the NO density is independently measured and subtracted from the total mass 30 measurement (ENGEBRETSON et al., 1977a). 


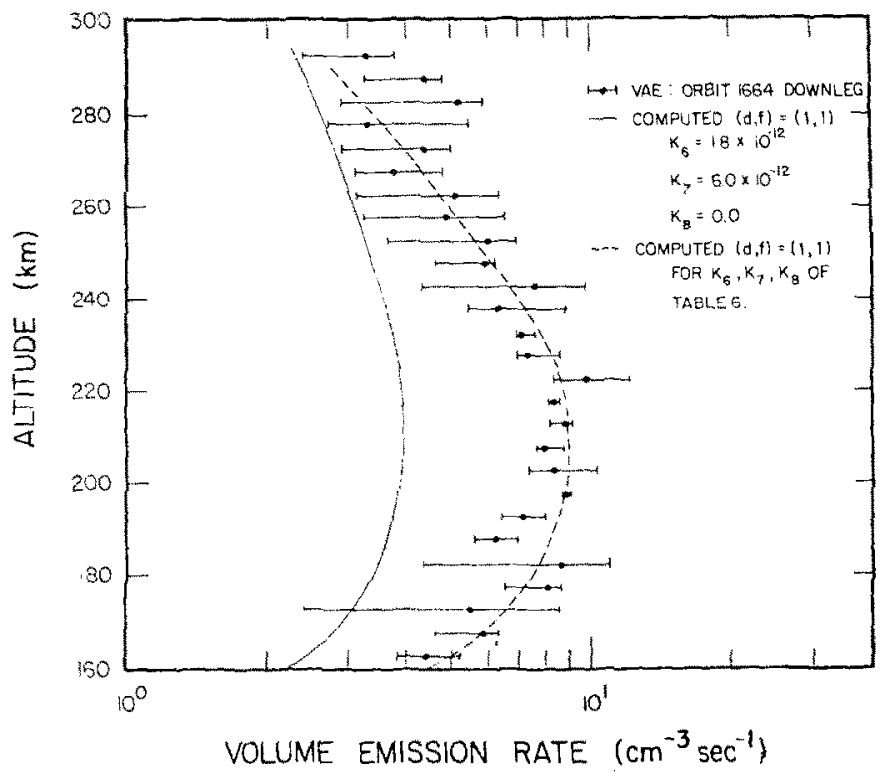

Fig. 31. Measured and calculated volume emission rate profiles for AE-C daytime orbit 1664 downleg. The broken curve was obtained by FREDERICK and RUSCH (1977) using the AE rate coefficients. The solid curve shows the effect of using $1.8 \times 10^{-12} \mathrm{~cm}^{3} \mathrm{~s}^{-1}$ for the rate coefficient for $\mathrm{O}$ quenching $\mathrm{N}\left({ }^{2} \mathrm{D}\right)$.

Mauersberger et al. (1975) observed a clear diurnal variation in both the mass 14 used and mass 30 peaks. They deduced a peak density of $\sim 10^{6} \mathrm{~cm}^{-3}$ at $400 \mathrm{~km}$.

Figure 34 shows the diurnal variation of $N\left({ }^{4} S\right)$ densities measured by the neutral atmosphere composition experiment (CARIGNAN and RUSCH, 1978) on AE-E. Also shown are their theoretical calculations which incorporated the chemistry described above. Uncertainties in the theoretical results arise

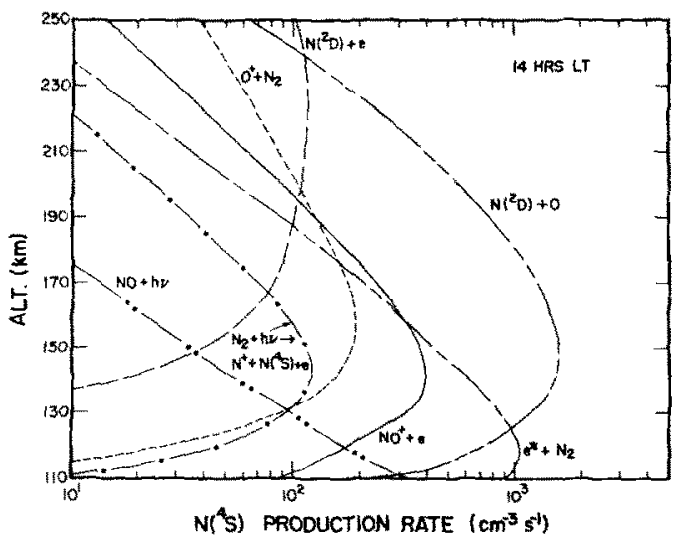

Fig. 32. Daytime sources of $N\left({ }^{4} S\right)$ derived from $\mathrm{AE}$ measurements (Ruscr et al., 1977b). primarily from uncertainties in the $\mathrm{O}_{2}$ concentration.

The agreement or disagreement between experimental and theoretical results at this stage cannot be taken to be meaningful. The experimental technique of measuring $\mathrm{N}\left({ }^{4} S\right)$, while highly successful, has not been proved as a precision measurement. Further work is needed to establish the absolute reliability of the measurements. Until the precision is established and confirmed by a tradition of experience, such as that behind the measurement of major neutral and ion densities, uncertainties in the theory cannot be reduced further. ENGEBRETSON et al. (1977b) have derived an empirical model for the $\mathrm{N}$ density at $375 \mathrm{~km}$ which reproduces the seasonal diurnal and latitudinal variations observed by the OSS instrument. These variations are large.

The importance of atomic nitrogen in the chemistry of the ionosphere was described briefly in Section 3.4.1. In the following two sections we discuss the photochemistry of the metastable constituents $O\left({ }^{1} S\right)$ and $O\left({ }^{1} D\right)$ where the presence of atomic nitrogen was found to account for the several aspects of the behavior of these species.

\subsection{Metastable $\mathrm{O}\left({ }^{\mathrm{i}} \mathrm{D}\right)$ atoms}

Sources and sinks of $O\left({ }^{1} D\right)$ have been studied in detail by HAys et al. (1978) using AE data. Interest 


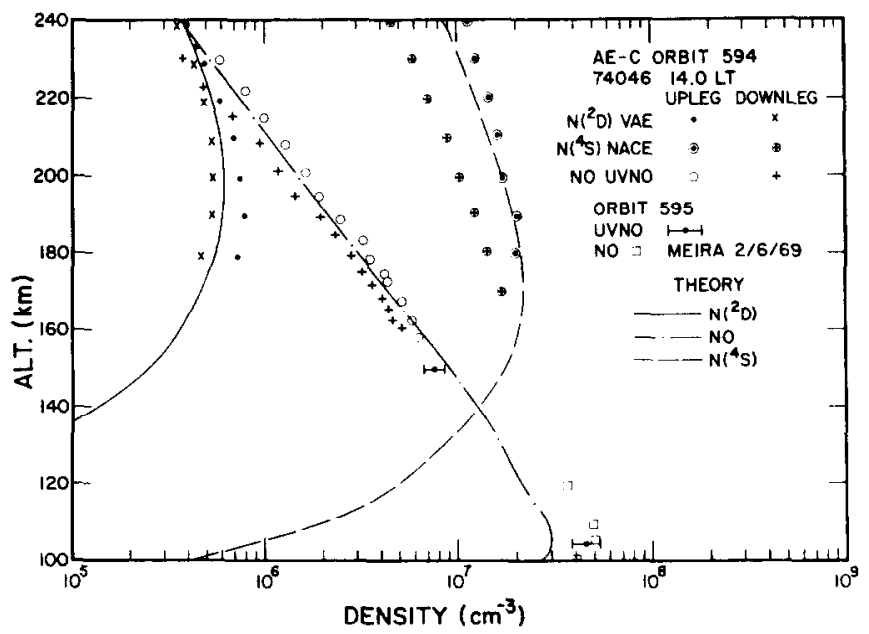

Fig. 33. Measured and theoretical concentrations of odd nitrogen as a function of altitude on AE-C orbit 594. The $\mathrm{N}\left({ }^{2} D\right)$ densities were measured by VAE (HAYs et al., 1973), the $\mathrm{N}\left({ }^{4} S\right)$ by NACE (CARIGNAN and Rusch, 1978), the NO by the UVNO instrument (BARTH et al., 1973). (cf. CARIGNAN and RuSCH, 1978).

in the photochemistry of $O\left({ }^{1} D\right)$ has increased recently because of its importance in the stratosphere (CADLE, 1964) and in stratospheric odd nitrogen chemistry (NicOlet, 1971; Crutzen, 1970), and because of interest in the ultraviolet neutral heating efficiency and the thermospheric energy budget (Chandra and Sinka, 1973; Stolarski et al., 1975).

4.3.1 Sources of thermospheric $\mathrm{O}\left({ }^{1} \mathrm{D}\right)$. Ground state $O\left({ }^{3} P\right)$ may be excited to the ${ }^{1} D$ state in collisions with electrons with energies greater than $1.96 \mathrm{eV}$.

$$
e(E>1.96)+O\left({ }^{3} P\right) \rightarrow O\left({ }^{1} D\right)+e .
$$

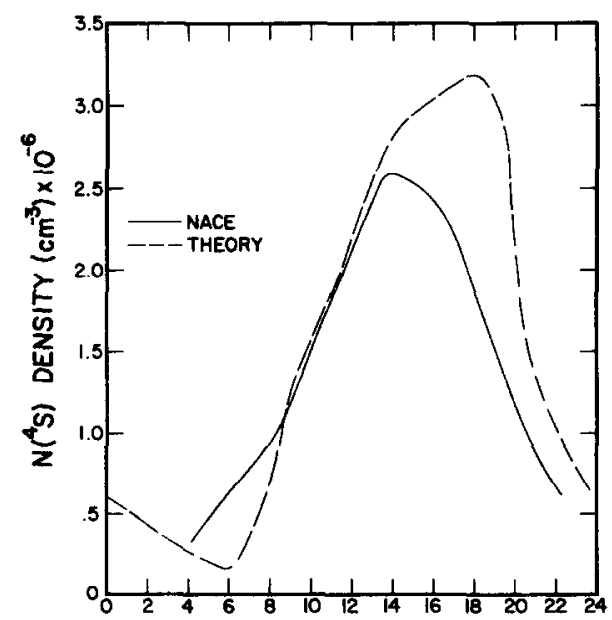

Fig. 34. The diurnal variations of $N\left({ }^{4} S\right)$ at $\sim 245 \mathrm{~km}$ altitude (CARIGNAN and RUSCH, 1978).
The classical nighttime source is dissociative recombination of $\mathrm{O}_{2}^{+}$(BATES, 1946):

$$
\mathrm{O}_{2}^{+}+e \stackrel{\beta_{5}^{\alpha} \alpha_{2}}{\longrightarrow} \mathrm{O}\left({ }^{1} \mathrm{D}\right)+\mathrm{O} \text {. }
$$

Photodissociation of $\mathrm{O}_{2}$ :

$$
\mathrm{O}_{2}\left(X^{3} \Sigma_{\mathrm{g}}{ }^{-}\right)+h \nu \stackrel{J_{02}}{\longrightarrow} \mathrm{O}\left({ }^{1} D\right)+\mathrm{O}\left({ }^{3} P\right) .
$$

4.3.2 Sinks of $O\left({ }^{1} D\right)$. The main sinks are:

$$
\begin{array}{r}
\mathrm{O}\left({ }^{1} D\right) \longrightarrow \mathrm{O}\left({ }^{3} P\right)+h \nu, \\
\mathrm{O}\left({ }^{1} D\right)+\mathrm{N}_{2} \stackrel{k_{30}}{\longrightarrow} \mathrm{O}\left({ }^{3} P\right)+\mathrm{N}_{2}, \\
\mathrm{O}\left({ }^{1} D\right)+\mathrm{O}_{2} \stackrel{k_{31}}{\longrightarrow} \mathrm{O}\left({ }^{3} P\right)+\mathrm{O}_{2} .
\end{array}
$$

With the exception of dissociation in the Schumann-Runge continuum of $\mathrm{O}_{2}$ where the cross section is well-known, there were many uncertainties in the cross sections and rates at which the above processes occur prior to AE.

Excitation cross sections for (4.13) had been derived by Henry et al. (1969). Rees (1967) had evaluated the excitation rate by hot thermal electrons and presented a simple expression for the ionization rate as a function of $T_{e}$. FourNIER and NAGY (1965) determined the source due to photoelectrons and hot thermal secondary electrons. However, significant discrepancies arose in the case of the photoelectron flux spectrum. Although the cross sections for photodissociation of $\mathrm{O}_{2}$ in the Schumann-Runge continuum are well-known (Metzer and Cook, 1964; Hudson, 1971) the absolute value of the solar flux was not well established $\left(2 \times 10^{-6}<J_{\mathrm{O}_{2}}(\infty)<6 \times 10^{-6} \mathrm{~s}^{-1}\right)$. The rates at which $O\left({ }^{1} D\right)$ is quenched by $\mathrm{O}_{2}$ and $\mathrm{N}_{2}$ were also 
uncertain prior to $\mathrm{AE}$, despite the fact that the rate had been extensively investigated (e.g. Peterson and VanZandt, 1969; Hernandez, 1972; Clark and Noxon, 1972; Heidner and Husain, 1973; SharP et al., 1975; Rusch et al., 1975b). Values derived for $k_{30}$ ranged from $2.2 \times 10^{-11}$ to $1 \times$ $10^{-10} \mathrm{~cm}^{3} \mathrm{~s}^{-1}$. The rate of $\mathrm{O}_{2}$ quenching is of the same order as $\mathrm{N}_{2}$, but the $\mathrm{O}_{2}$ concentration is much smaller.

Hays et al. (1978) effectively eliminated all the uncertainties discussed above in a comprehensive study of the $6300 \AA$ emission arising from the transition $O\left({ }^{1} S-{ }^{1} D\right)$. These measurements were made by the visible airglow experiment described by HAYs et al. (1973).

4.3.3 Nighttime results. HaYs et al. (1978) determined the yield of $\mathrm{O}\left({ }^{1} D\right)$ atoms due to dissociative recombination of $\mathrm{O}_{2}^{+}$at night (4.14) when the latter process constitutes the only significant source. Under these conditions the volume emission rate is given as

$$
\eta_{6300}=\frac{A_{6300} \beta_{5} \alpha_{2}\left[\mathrm{O}_{2}^{+}\right]\left[\mathrm{N}_{e}\right]}{A_{\mathrm{i}_{\mathrm{D}}}+k_{30}\left[\mathrm{~N}_{2}\right]}
$$

where $A_{6300}$ is the Einstein coefficient for the transition $O\left({ }^{1} S-{ }^{1} D\right)$ and $A_{1_{D}}$ is the inverse radiative lifetime. Equation (4.19) was rearranged to obtain a linear expression for which $\beta_{5}$ was determined from the intercept and $k_{30}$ from the slope. These results yielded the values

$$
\begin{gathered}
\beta_{5}=1.3, \\
k_{30}=3 \times 10^{-11} \mathrm{~cm}^{3} \mathrm{~s}^{-1} .
\end{gathered}
$$

The latter result is in agreement with earlier rocket determinations of $k_{30}$ (Rusch et al., 1975b; ShaRP et al., 1975). Most ground based determinations of $k_{30}$ however, have yielded values about a factor of two or more larger than this. M. TorR et al. (1975) identified the discrepancy as being due to effect of reactions of atomic nitrogen on the concentration of $\mathrm{O}_{2}{ }^{+}$, i.e. reaction (3.9). The $\mathrm{N}$ density is frequently large enough below $220 \mathrm{~km}$ to become a significant loss process for $\mathrm{O}_{2}{ }^{+}$. In determining $k_{30}$ from ground based measurements of $6300 \AA$ emission, the $\mathrm{O}_{2}{ }^{+}$density must be calculated. This has been done neglecting (3.9) and the density is overestimated resulting in an overestimation of $k_{30}$ or an under estimation of $\beta_{5}$. In the case of the rocket and satellite experiments, the $\mathrm{O}_{2}{ }^{+}$concentration was measured directly.

4.3.4 Daytime results. During the daytime the main sources of $O\left({ }^{1} D\right)$ are due to (4.13) (photoelectrons) and (4.15) (photodissociation of $\mathrm{O}_{2}$ ). HAYs et al. (1978) point out that despite considerable disagreement on the absolute magnitude of the photoelectron flux spectrum there has been reasonably good agreement on the shape of the theoretical source due to (4.15). They therefore evaluated the rate of $O\left({ }^{1} D\right)$ production by photoelectrons. This was found to agree with the theoretical results of Dalgarno and Lejeune (1971).

A comparison of the altitude profiles of the sources due to (4.13) and (4.15) shows that the photodissociation source predominates at lower altitudes, and could be studied independently of that due to photoelectrons. Figure 35 shows the $O\left({ }^{1} D\right)$

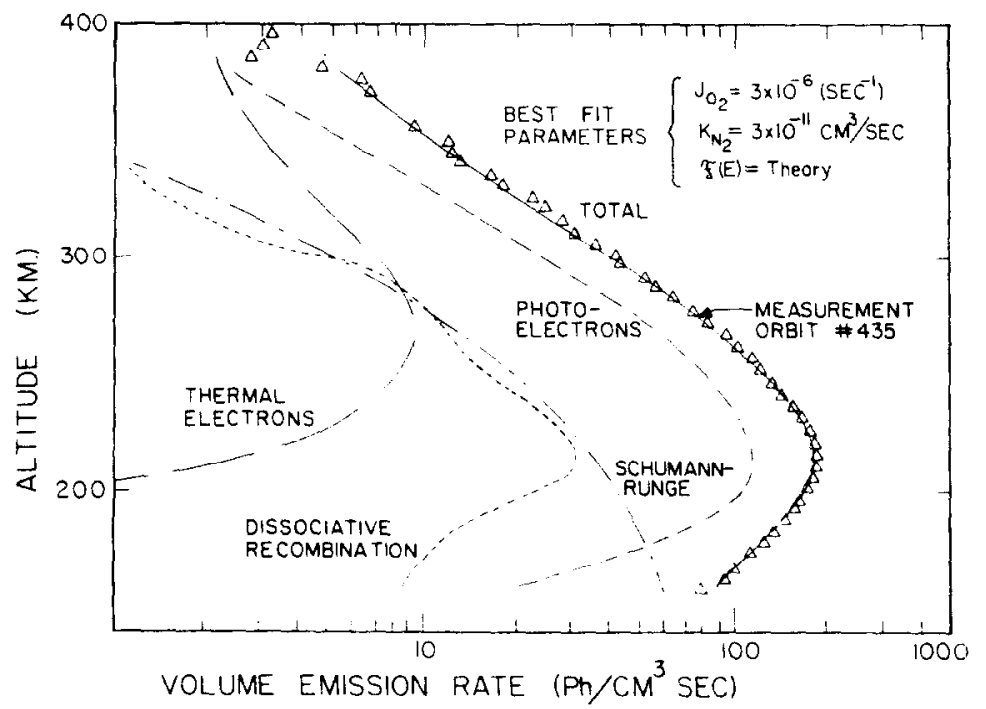

Fig. 35. The volume emission rate of OI (6300 $\AA)$ dayglow obtained on AE-C orbit 435 and the theoretical results of HAYs et al. (1978). 
sources on orbit 435 determined by HaYs et al. (1978). They found that $J_{02}(\infty)=2 \times 10^{-6} \mathrm{~s}^{-1}$. Recent measurements including those done on $\mathrm{AE}$ support the lower value for $J_{02}(\infty)$. However, the derivation discussed above involved a factor $\sim 2$ uncertainty in the $\mathrm{O}_{2}$ density.

Figure 36 shows the diurnal variations of the $6300 \AA$ volume emission at $170 \mathrm{~km}$ altitude observed and calculated by HAYs et al. (1978). The agreement between experiment and theory is good.

\subsubsection{Summary.}

(1) The conventional theory of the $6300 \AA$ dayglow including direct electron excitation of $O\left({ }^{3} \mathrm{P}\right)$, photodissociation of $\mathrm{O}_{2}$ and dissociative recombination of $\mathrm{O}_{2}^{+}$explains the measured $6300 \AA$ dayglow.

(2) The quenching rate of $O\left({ }^{1} D\right)$ by $N_{2}$ is about a factor of 2 lower than that deduced from ground based measurements. This is due to neglect of destruction of $\mathrm{O}_{2}^{+}$by $\mathrm{N}$ in ground based studies.
The rate coefficient was found to be $3 \pm 1 \times$ $10^{-11} \mathrm{~cm}^{3} \mathrm{~s}^{-1}$.

(3) The efficiency for the production of $O\left({ }^{1} D\right)$ atoms by dissociative recombination of $\mathrm{O}_{2}{ }^{+}$is $1.3 \pm$ 0.3 .

\subsection{Metastable ('S) atoms}

Investigations prior to $\mathrm{AE}$ established the following possible sources of $O\left({ }^{1} S\right)$ in the thermosphere

$$
\begin{gathered}
e+\mathrm{O} \longrightarrow \mathrm{O}\left({ }^{1} S\right)+e . \\
\mathrm{O}_{2}{ }^{+}+e \stackrel{\beta_{b^{\alpha}} \alpha_{2}}{\longrightarrow} \mathrm{O}\left({ }^{1} S\right)+\mathrm{O} .
\end{gathered}
$$

Investigations by WALLACE and MCELROY (1966), Feldman et al. (1971) Schaefer et al. (1972) and HAYS and SHARP (1973) established processes (4.22) and (4.23) as significant sources of $O(' S)$ atoms above $140 \mathrm{~km}$, but considerable conflict existed as to their relative importance. Laboratory measurements by Meyer et al. (1969,

\begin{tabular}{|c|c|c|}
\hline Reaction & Rate coefficient $\left(\mathrm{cm}^{3} \mathrm{~s}^{-1}\right)$ & \\
\hline $\mathrm{NO}^{+}+e \stackrel{\boldsymbol{\beta}_{1} \boldsymbol{\alpha}_{1}}{\longrightarrow} \mathrm{N}\left({ }^{2} D\right)+\mathrm{O}$ & $\beta_{1} \approx 1.0$ & FREDERICK and RUSCH (1977) \\
\hline $\mathrm{N}_{2}^{+}+e \stackrel{\alpha_{8 \times n 3}}{\longrightarrow} \mathrm{N}\left({ }^{2} D\right)+\mathrm{N}$ & $\beta_{1} \approx 1.0$ & Frederick and Rusch (1977) \\
\hline $\mathrm{N}_{2}^{+}+\mathrm{O} \stackrel{\beta_{3} k_{3}}{\longrightarrow} \mathrm{N}\left({ }^{2} D\right)+\mathrm{NO}^{+}$ & $\beta_{1} \approx 1.0$ & FREDERICK and RUSCH (1977) \\
\hline $\mathrm{N}^{+}+\mathrm{O}_{2} \stackrel{k_{z f \rightarrow}}{\rightarrow} \mathrm{N}\left({ }^{2} \mathrm{D}\right)+\mathrm{O}_{2}^{+}$ & $4 \times 10^{-10}$ & HUNTREsS and ANICICH (1976) \\
\hline $\mathrm{N}\left({ }^{2} D\right)+\mathrm{O} \stackrel{k_{2 b}}{\longrightarrow} \mathrm{N}\left({ }^{4} S\right)+\mathrm{O}$ & $4 \pm 2 \times 10^{-13}$ & FREDERICK and RUSCH (1977) \\
\hline $\mathrm{N}\left({ }^{2} D\right)+\mathrm{O}_{2} \stackrel{k_{25}}{\longrightarrow} \mathrm{NO}+\mathrm{O}$ & $6 \pm 1 \times 10^{-12}$ & FRFDFRICK and RUSSH (1977) \\
\hline $\mathrm{N}\left({ }^{2} D\right)+e \stackrel{k_{2 b \rightarrow}}{\longrightarrow} \mathrm{N}\left({ }^{4} S\right)+e$ & $3.6-6.5 \times 10^{-10}\left(T_{e} / 300\right)^{1 / 2}$ & FREDERICK and RUSCH (1977) \\
\hline $\mathrm{N}\left({ }^{2} D\right)+\mathrm{O} \stackrel{k_{2 a}}{\longrightarrow} \mathrm{NO}^{+}+e-0.37 \mathrm{eV}$ & $<2 \times 10^{-13}$ & M. TORR and TORR (1979b) \\
\hline $\mathrm{N}\left({ }^{4} S\right)+\mathrm{O}_{2} \stackrel{k_{23}}{\rightarrow} \mathrm{NO}^{+}+\mathrm{O}$ & $2.4 \times 10^{-11} \mathrm{e}^{-3075 / \mathrm{T}}$ & WILSON (1967) \\
\hline $\mathrm{N}\left({ }^{4} S\right)+\mathrm{NO} \stackrel{\mathrm{k}_{23}}{\longrightarrow} \mathrm{N}_{2}+\mathrm{O}$ & $1.5 \times 10^{-12} T^{1 / 2}$ & PHILLIPS and SCHIFF (1962) \\
\hline $\mathrm{O}_{2}{ }^{+}+e \stackrel{\beta_{5} \alpha_{2}}{\longrightarrow} \mathrm{O}\left({ }^{1} D\right)+\mathrm{O}$ & $\beta=1.3 \pm 0.3$ & HAYs et al. (1978) \\
\hline $\mathrm{O}_{2}\left(X^{3} \Sigma_{\mathrm{g}}{ }^{-}\right)+h \nu \stackrel{\mathrm{J}_{3}}{\longrightarrow} \mathrm{O}\left({ }^{1} D\right)+\mathrm{O}\left({ }^{3} P\right)$ & $J_{\mathrm{O}_{2}}=2 \times 10^{-6} \mathrm{~s}^{-1} \pm 50 \%$ & HAYs et al. (1978) \\
\hline $\mathrm{O}\left({ }^{1} D\right)+\mathrm{N}_{2} \stackrel{k_{30}}{\rightarrow} \mathrm{O}\left({ }^{3} P\right)+\mathrm{N}_{2}$ & $3 \pm 1 \times 10^{-11}$ & HAYs et al. (1978) \\
\hline $\mathrm{O}_{2}++e \stackrel{\beta_{6} \alpha_{2}}{\longrightarrow} \mathrm{O}\left({ }^{1} S\right)+\mathrm{O}$ & $\beta_{6} \approx 0.8$ & FREDERICK et al. (1976) \\
\hline $\mathrm{O}_{2}^{+}+\mathrm{N} \stackrel{k_{33}}{\longrightarrow} \mathrm{NO}^{+}+\mathrm{O}\left({ }^{1} \mathrm{~S}\right)$ & $\begin{aligned} \beta_{6} \alpha_{2}= & 7.4 \pm 0.8 \\
& \times 10^{-9}\left(T_{e} / 1150\right)^{-0.17} \\
& \approx 2.5 \times 10^{-11}\end{aligned}$ & FreDERICK et al. (1976) \\
\hline
\end{tabular}

Table 4. Thermospheric rate coefficients 


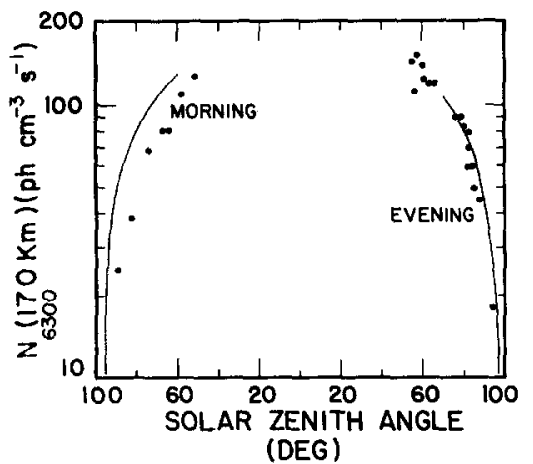

Fig. 36. Plot of the theoretical and experimental $6300 \AA$ volume emission rates at $170 \mathrm{~km}$ vs solar zenith angle for morning and evening twilight. The circles are the VAE data; the solid lines are the model results of HAYs et al. (1978).

1970) indicated that the charge transfer reaction

$$
\mathrm{N}_{2}\left(A^{3} \Sigma^{+}\right)+O \stackrel{k_{32}}{\longrightarrow} \mathrm{N}_{2}+\mathrm{O}\left({ }^{3} P,{ }^{1} D,{ }^{1} S\right),
$$

yields a significant fraction of $O(' S)$ atoms. Radiative loss at $5577 \AA$ constitutes the only significant sink for $O\left({ }^{1} S\right)$ above $140 \mathrm{~km}$. The radiative lifetime is $0.75 \mathrm{~s}$ (GARSTUNG, 1956).

Freiderick et al. (1976) analyzed the AE VAE measurements of the $5577 \AA$ green line which arises from the transition $O\left({ }^{1} D-{ }^{1} S\right)$. Their approach was similar to that of HAYs et al. (1978) for $O\left({ }^{1} D\right)$. They used nighttime measurements to determine $\beta_{6}$, i.e. when the photoelectron source of $O\left({ }^{1} S\right)$ (4.22) is negligible. They found that $\beta_{6} \simeq 0.8$. Figure 37 shows a comparison of the theoretical and measured $5577 \AA$ volume emission rates on one orbit at night.

Analysis of the daytime VAE measurements clearly indicated that nearly all of the observed emission above $200 \mathrm{~km}$ could be accounted for by reactions (4.22) and (4.23) (Frederick et al., 1976). Results for AE-C orbit 2744 are shown in Fig. 38. It was evident that a significant additional source is required below $200 \mathrm{~km}$. Frederick et al. (1976) identified this as the reaction

$$
\left.\mathrm{O}_{2}^{+}+\mathrm{N} \stackrel{k_{33}}{\longrightarrow} \mathrm{NO}^{+}+\mathrm{O}^{1} \mathrm{~S}\right)
$$

from the scale height characteristics required. The source due to (4.24) $\left(\mathrm{N}_{2}-A+O\right)$ was rejected because it was not large enough. The upper limit that Frederick et al. used arose mainly from an efficiency of $10 \%$ adopted for the $O\left({ }^{1} S\right)$ yield. This was based on auroral rocket measurements. An analysis of the diurnal variation of the green line emission by Kopp et al. (1977a) provided convincing evidence that (4.25) accounted for the broad features of the observed temporal variations in $\left[O\left({ }^{1} S\right)\right]$ adequately. The $O\left({ }^{1} S\right)$ emission exhibits a slow rise in the morning which builds up during the day and then decreases gradually as sunset approaches. This variation is not consistent with the temporal behavior of $\mathrm{N}_{2} A$ which is excited primarily by photoelectron impact. Atomic nitrogen, however, exhibits just the right kind of diurnal variation required to account for the observed green line emission. Unfortunately, measurements of $[\mathrm{N}]$ were not available over a diurnal cycle and hence the comparison was not strictly quantitative.

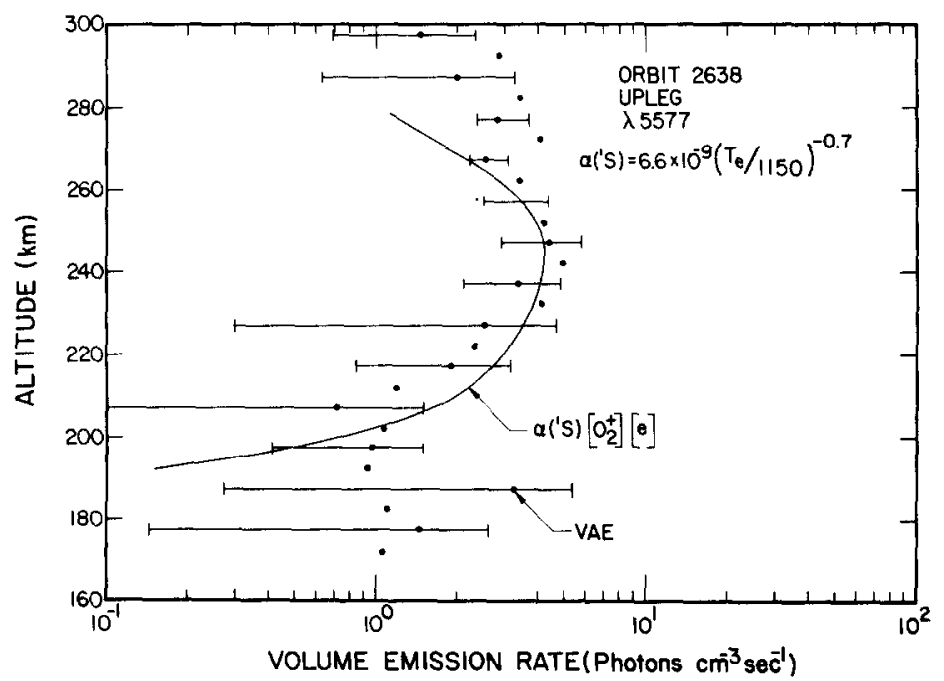

Fig. 37. $5577 \AA$ volume emission rate for nighttime orbit 2638 upleg (3 August 1974). The solid line is a theoretical fit to the VAE data using $\mathrm{O}_{2}{ }^{+}$measured by BIMS and electron densities from the CEP experiment (FrEDERICK et al., 1976). 


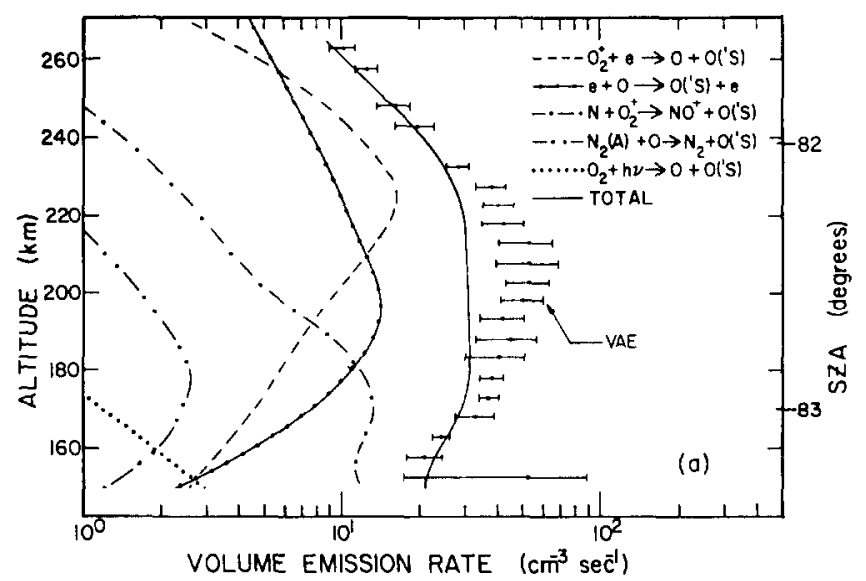

Fig. 38. The twilight $5577 \AA$ volume emission rate for the downleg of AE-C orbit 2744,11 August 1974 (Frederick et al., 1976).

Kopp et al. (1977a) deduced that $k_{33}=$ $2.5 \times 10^{-11} \mathrm{~cm} \mathrm{~s}^{-1}$ and

$$
\beta_{6} \alpha_{2}=7.4 \pm 0.8 \times 10^{-9}\left(T_{e} / 1150\right)^{-0.7} .
$$

It should be noted that the temperature dependence is an assumed laboratory value which applies to cases for $T_{e} \leq 1200 \mathrm{~K}$. Frederick et al. (1976) found the temperature dependence above $1200 \mathrm{~K}$ to agree with the laboratory measurements of MEHR and BIONDI (1969). They also investigated several other possible sources of $O\left({ }^{1} S\right)$ which were all rejected as insignificant.

4.4.1 Summary. There are three main sources of $O\left({ }^{1} S\right)$ in the thermosphere above $150 \mathrm{~km}$. These are photoelectron impact on $\mathrm{O}$, dissociative recombination of $\mathrm{O}_{2}{ }^{+}$and the reaction of atomic nitrogen with $\mathrm{O}_{2}^{+}$.

\subsection{The second positive system of $\mathrm{N}_{2}$}

The $\mathrm{N}_{2}(2 P)(0-0)$ transition at $3371 \AA$ was measured by VAE. The primary reason for monitoring this emission, which is excited by electron impact was to provide a monitor of the photoelectron flux. In view of the controversy that has arisen over the absolute values of the fluxes measured by the photoelectron spectrometer of DOERING et al. (1973), the $3371 \AA$ measurement has provided valuable additional information to modelers.

The dayglow emission was first identified by Barth and Pearce (1966). The volume emission rate was first calculated by NAGY and FOURNIER (1965). The relationship between the measured $3371 \AA$ volume emission rate and that calculated using measured photoelectron flux cross section data was established by Doering et al. (1970).
Figure 39 shows the measured volume emission rates observed on AE-D orbit 1788 (D) with the theoretical calculations of KopP et al. (1977b). The theoretical values were derived using two model calculations of the photoelectron flux spectrum. The 'Roble model' is essentially the same as that used by NAGY et al. (1977).

Kopp et al. (1977b) observed a sharp dependence of the emission on the $[\mathrm{O}] /\left[\mathrm{N}_{2}\right]$ ratio. This was attributed to competition by $\mathrm{O}$ in the attenuation of the primary photoelectrons. Also atomic oxgyen and molecular nitrogen have different photoionization cross sections and produce different primary photoelectron energy distributions for a given strong solar line. Although this does average out to

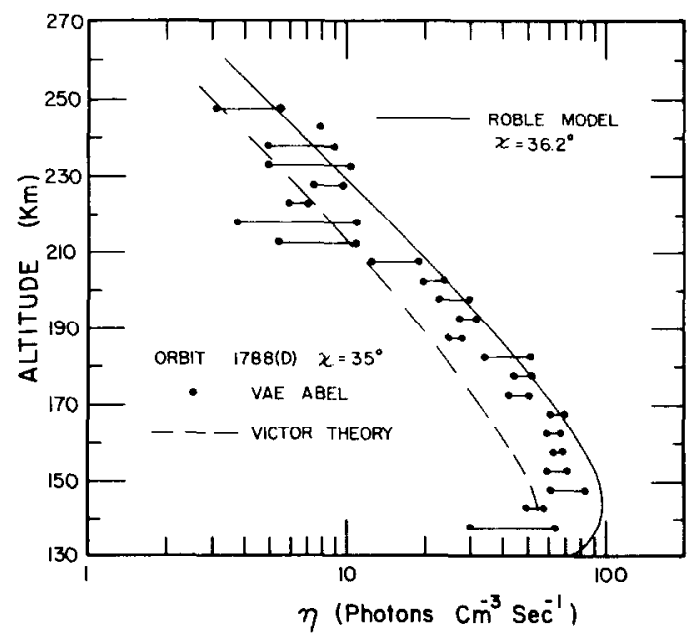

Fig. 39. Comparison of VAE $3371 \AA \mathrm{N}_{2}\left({ }^{2} P\right)(\mathrm{O}-\mathrm{O}-\mathrm{O})$ data (solid circles) with calculations (broken line, G. VICTOR; solid line, R. ROBLE) (KOPP et al., 1977b). 
some extent, if the $\mathrm{N}_{2}(2 P)$ dayglow emissions are used to monitor the photoelectron flux, these effects must be taken into consideration.

\section{DISCUSSION AND CONCLUSION}

We have reviewed highlights of the Atmosphere Explorer program involving studies of the chemistry of the ionosphere and thermosphere. Results from the program have exceeded the design goals. Significant results reviewed include the following.

The extreme ultraviolet spectrophotometers have revealed unexpected variations in the EUV flux and in the response of the thermosphere. A longstanding uncertainty concerning the absolute magnitude of the EUV flux has been resolved, and tables of EUV absorption and ionization cross sections and fluxes are presented. Complete references are cited in the text.

The discrepancy between measured and the calculated photoelectron flux is reviewed. No universally acceptable answer to this problem has yet been found. Comparison of theoretical and measured values of several atmospheric emissions excited by electron impact strongly suggest that the measurements are high. The question of the importance of photoelectrons as a source of $\mathrm{O}^{+}(2 \mathrm{D})$ and $O^{+}(2 P)$ ions is reviewed. The conclusion is drawn that an upper limit for the photoelectron source is about $15 \%$ of the EUV source for $\mathrm{O}^{+}(2 P)$.

Recent developments in the detection of nocturnal mid- and low-latitude sources of ionization are briefly reviewed. Ground based results by TinsLeY (1978) point to the existence of an equatorial aurora which could involve an energy deposition rate as large as the polar aurora during magnetic storms. The energy is distributed over a much larger area, however, and the fluxes are low.

The AE data have been used to study many ionospheric and thermospheric processes and numerous rate coefficients have been determined. Major developments in this area are reviewed in some detail, and the most recent results available have been presented. Discrepancies with laboratory results are investigated and reasons for these discrepancies sought.

The photochemical results of the AE program demonstrate that with the data base provided by the three spacecraft it has become possible to use the atmosphere as a laboratory to study atomic and molecular processes.

Only a limited number of studies have been covered in this review. For example, we have omitted results on minor ions and neutrals, such as $\mathrm{H}$, $\mathrm{H}_{e}, \mathrm{H}^{+}, \mathrm{H}_{e}^{+}, \mathrm{O}^{2+}$. Work on $\mathrm{N}_{2}^{+}, \mathrm{H}$ and $\mathrm{M}_{\mathrm{q}}$ emissions have been omitted. Very little space is devoted to variations in the major neutral constituents including the neutral temperature. No discussion is devoted to the energy balance of the thermosphere, and this list is not complete. The results that we present serve to illustrate the broad areas of progress that have been achieved with the AF system. We believe that excellent opportunities exist in space science for rigorously testing theoretical predictions pertaining to many areas of the Physical and Natural sciences.

Acknowledgements-The data used in the studies reviewed in this paper were provided by the AE team. Their collaborative efforts are gratefully acknowledged. This work was supported by NASA grant NAS5-24331, NSF grant ATM75-03986A01 and AF grant F19628-77C-0007. We thank Dr J. C. G. WALkER for reading the manuscript.

\section{REFERENCES}

Albritton D. L., DOtAN I., LINDINGer W., MCFarland M., Tellinghuisen J. and Fehsenfeld F. C.

Banks P. M., Schunk R. W. and Raitt W. J. Bardusley J. N.

Barth C. A. and Pearce J. B.

Barth C. A., Rusch D. W. and Stewart A. I.

BAtes D. R.

Benson R. F., Bauer P., Brace L. H., Carlson H. C., hagen J., Hanson W. B., HOEgY W. R., TORR M. R., WAND R. H. and WICKWAR V. B.

Black G., Slanger T. C., St John G. A. and Young R. A.

Brace L. H., Theis R. F. and Dalgarno A.

Breig E. L., Torr M. R., Torr D. G., hanson W. B., Hoffman J. H., Walker J. C. G. and Nier A. O.
1977 J. chem. Phys. 66, 410.

1974 Geophys. Res. Lett. 1, 239.

1968 J. Phys. B. 1, 365.

1966 Space Res. 6, 381.

1973 Radio Sci. 8, 379.

1946 Mon. Not. R. astr. Soc. 106, 509.

1977 J. geophys. Res. 82, 23.

1969 J. chem. Phys. 51, 116.

1973 Radio Sci. 8, 341.

1977 J. geophys, Res. 82, 1008. 
Brinton H. C., Scott L. R., Pharo III M. W. and Coulson J. T. C.

Brinton H. C., Grebowsky J. M. and BRACE L. H.

Burnside R., Torr D. G., Meriwether J. W. and TORR M. R.

Cadle R. D.

Carignan G. R. and Rusch D. W.

Chandra S. and Sinka A. K.

Clark I. D. and Noxon J, F.

Crutzen P. J.

DALGARNo A. and LeJEUNE G.

Dalgarno A., Hanson W. B., Spencer N. W. and SCHMERLING E. R.

Davenport J. E., Slanger T. G. and Black G.

Doering J. P., Fastie W. G. and Feldman P. D.

Doering J. P., Bostrom C. $\mathrm{O}$. and Armstrong J, C.

Donahue T. $M$.

Donahue T. M., Zipf E. C. and Parkinson T. D.

Engebretson M. J., Mauersberger K. and PotTer W. E.

Engebretson M. J., Mauersberger K., Kayser D. C. and Nier A. O.

Feldman P. D. and Takacs P. Z.

Feldman P. D., Doering J. P. and ZIPF E. C.

FOURNIER J. P. and NAGY A. F.

Frederick J. E. and Rusch D. W.

Frederick J. E., Rusch D. W., Victor G. A. Shakp W. E., Hays P. B. and Brinion H. C.

GARSTANG R. H.

Gerard J, C.

Ghosh S. N., Hinton B. B., Jones L. M., Lette R. J., Mason C. J., Schaefer E. J. and WALTERS $M$

Goldan P. D., Schmeltekopf A. F., Fehsenfeld F. C., SCHIFF I. and FERGuSON E. E.

Hanson W. B., Zuccaro D. R., Lippincott C. R. and SANATANI $S$.

HaYs P. B. and Sharp W. E.

Hays P. B., Carignan G. R., Kennedy B. C., ShepIIERD G. C. and Walker J. C. G.

Hays P. B., Rusch D. W., TORR D. G., Sharp W. E. and Swenson G. R.

Hays P. B., Rusch D. W., Roble R. G. WALKER J. C. G.

Hedin A. E., Mayr H. G., Reber C. A., SPEncer N. W. and Carignan G. R.

Hedin A. E., Spencer N. W., Hanson W. B. and BAUER $P$.

Hedin A. E., Salah J. E., Evans J. V., Reber C. A., Newton G. P., Spencer N. W., Kayser D. C., Alcayde D., Bauer P., Cogger L. and McClure J. P.

Hedin A. E., Reber C. A., Newton G. P., Spencer N. W., Brinton H. C., Mayr H. G. and Potter W. E.

Heidner R. F. and Husain D.

HENRY .R. J. W.

HenRY R. J. W. and WILliams R. E.

Henry .R. J. W., Burke P. G. and Sinfailam A. L.

HERNANDEZ G.

Hernandez G. and Turtle J. P.

HINTEREGGER $\mathrm{H}$. E.

Hinteregger H. E., Bedo D. E. and Manson J. E.
1973

1978

1978

1964

1978

1973

1972

1970

1971

1973

1976

1970

1973

1968

1970

1977 a

$1977 b$

1974

1971

1965

1977

1976

1956

1975

1968

1966

1973

1973

1973

1975

1978

1974

1976

$1977 a$

$1977 \mathrm{~b}$

1973

1970

1968

1969

1972

1969

1976

1973
Radio Sci. 8, 323.

J. geophys. Res. 83, 4767.

Paper presented at the Spring Meeting of the Am. geophys. Un., Miami, Florida.

Discuss. Faraday Soc. 37, 66.

Abstract in EOS 59, 339.

Planet. Space Sci. 21, 593.

J. chem. Phys. 57, 1033.

Q. Il R. met. Soc. 96, 320.

Planet. Space Sci. 19, 1653.

Radio Sci. 8, 263.

J. geophys. Res. 81, 12 .

J. geophys. Res. 75, 4787.

Radio Sci. 8, 387 .

Science, N.Y. 159, 489.

Planet. Space Sci. 18, 171.

J. geophys. Res. 82, 3291.

J. geophys. Res. 82, 461.

Geophys. Res. Lett. 1, 169.

J. geophys. Res. 76, 3087.

J. atmos. Sci. 22, 732.

J. geophys. Res. 82, 3509.

J. geophys. Res. 81, 3923.

The Airglow and the Aurora. Pergamon Press, London.

Geophys. Res. Lett. 2, 179.

J. geophys. Res. 73, 4425.

J. chem. Phys. 44, 4103.

Radio Sci. 8, 333.

J. geophys. Res. 78, 1153.

Radio Sci. 8, 369.

EOS 56, 405.

Rev. Geophys. Space Phys. 16, 225.

J. geophys. Res. 79, 215.

Geophys. Res. Lett. 3, 469.

J. geophys. Res. 82, 2139.

J. geophys. Res. 82, 2148.

Nature, Lond. 241, 10.

Astrophys. J. 161, 1153.

Publs. astr. Soc. Pacif. 80, 669.

Phys. Rev. 178, 218.

J. geophys. Res. 77, 3625.

Planet. Space Sci. 17, 675.

J. atmos. terr. Phys. 38, 791.

Radio Sci. 8, 349. 
Hinteregger H. E., Bedo D. E., Manson J. E. and SkILLMAN D. R.

HoEgy W. R. and BRace L. H.

Hofmman J. H., Hanson W. B., Lippincott C. R. and FERGUSON E. E.

Hoffman R. A., Burch J. L., Janetzke R. W., MCChesney J. F., Way S. H. and Evans D. S.

Huang C. M., Biondi M. A. and JoHnsen R.

HUDSON R. D.

Huntress W. T. and Anicich V. G.

JASPERSE J. R.

Keneshea T. J., Narcisi R. S. and Swider W.

Kirby-DOCKEN K. and OPPENHEIMER $M$.

Kopp J. P., Frederick J. E., Rusch D. W. and VICTOR G. A.

Kopp J. P., Rusch D. W, Roble R. G., VICTOR G. A. and Hays P. B.

Lin C. L. and Kaufman F.

Lindinger W., Fehsenfeld F. C., SCHMEltekopf A. L. and Ferguson E. E.

Lindinger W., Albritton D. L., Fehsenfeld F. C. and Ferguson E. E.

Maufrsafrgar K., Fngfirtison M., Potter W. E., Kayser D. C. and Nier A. O.

MCFARI.AND M., AlbritTon D. L., Fehsenfeld F. C., Ferguson E. E. and SCHMELTEKOPF A. L.

MCFari.AND M., Albritton D. L., Fehsenfeld F. C., Ferguson E. E. and SCHMELTEKOPF A. L.

Mehr F. J. and Biondi M. A.

Meriwether J. W. and Walker J, C. G.

Meriwether J. W. and Walker J. C. G.

Meriwether J. W., Torr D. G. and Walker J. C. G.

Metzer P. A. and Cook G. R.

Meyer J. A., Setser D. W. and Stedman D. H

Meyer J. A., Setser D. W. and Stedman D. H.

NAGY A. F. and Fournier J. P.

Nagy A. F., Doering J. P., Peterson W. K., TORR M. R. and BANks P. M.

NiCOLET $M$.

Nier A. O., Potter W. E., Hickman D. R. and MAUERSBERGER $\mathrm{K}$. M.

Nier A. O., Potter W. E., Kayser D. C. and Finstad R. G.

Norton R. B. and Barth C. A.

Oppenheimer M., Dalgarno A. and Brinton H. C.

Oppenheimer M., Constantinides E. R. KIRBY-DOCKEN K., BRINTON H. C. and HOFFMAN J. H.

Oppenheimer M., Dalgarno A., Trebino F. P., Brace L. H., Brinton H. C. and HOFFMAN J. $\mathbf{H}$.

Oppenhemmer M., Babeu S., Hoffman J. $\mathbf{H}$. and Breig $\mathbf{E}$.

Oran E. S., Julienne P. S. and Strobel D. F.

Orsini N., TORR D. G., TORR M. R.,

Brinton H. C., Brace L. H., Nier A. O. and WALker J. C. G.

Orsini N., Torr D. G., Brinton H. C., Brace L. H., Hanson W. B., Hoffman J. H. and Nier A. $O$.
1977

1978

1973

1973

1975

1971

1976

1978

1970

1977

$1977 \mathrm{a}$

$1977 \mathrm{~b}$

1971

1974

1975

1975

1973

1974

1969

1977

1978

1978

1964

1969

1970

1965

1977

1971

1973

1974

1970

1976

$1977 \mathrm{a}$

$1977 b$

J. geophys. Res. 82, 191.

1978 Geophys. Res. Lett. 5, 773.

$1975 J$ J geophys. Res. 80, 3068.

1977 a J. geophys. Res. 82, 4829.

1977b Geophys. Res. Lett. 4, 431.

Geophys. Res. Lett. 5, 269.

Radio Sci. 8, 315.

Radio Sci. 8, 393.

Phys. Rev. A11, 901.

EOS 59, 333.

J. geophys. Res. 75, 845 .

J. geophys. Res. 82, 3503.

J. geophys. Res. 82, 4715.

J. geophys. Res. 82, 555.

J. chem. Phys. 55, 3760.

J. geophys. Res. 79, 4753.

J. geophys. Res. 80, 3725 .

Geophys. Res. Iett. 2, 337.

J, chem. Phys. 59, 6620.

J. geophys. Res. 79, 2925.

Phys. Rev. 181, 264.

J. geophys. Res. 82, 1855.

$J$. geophys. Res (in press).

Astrophys. J. 157, 1023.

J. geophys. Res. 70, 5981.

J. geophys. Res. 82, 5099.

Geophys. Res. Lett. 1, 197.

J. geophys. Res. 75, 3903.

J. genphys. Res. 81, 4678.

J. geophys. Res. 82, 5485.
Rev. Geophys. Space Phys. 9, 305.

atmos. terr. Phys. 83, 3311

I. quantum Spectrosc. Radiat. Transfer 4, 107.

J. phys. Chem., Ithaca 74, 2238.

Mesosphere Models and Related Experiments. D. Reidel, Hingham, Massachusetts. 
Paulikas G. A.

Pelz D. R., Reber C. A., Hedin A. E. and Carignan G. R.

Petersen W. L., Doering J. P., Potemsa T. A. and Bostrom C. $O$.

Peterson V. L. and VanZandt T. E

Phmlips J. F. and SChifF H. I.

Prather M. J., McElroy M. B. and Rodrigues J.

Prölss G. W.

REES M. H.

RoBle R. G.

Rusch D. W.

RUSCh D. W., STEWART A. I., HAYS P. B. and HoFfMaN J. H.

Rusch D. W., Sharp W. E. and Hays P. B.

Rusch D. W., Torr D. G., Hays P. B. and TORR M. R.

Rusch D. W., Torr D. G., Hays P. B. and Walker J. C, $\mathrm{G}$.

Rusch D. W., Cravens T. E., Carignan G. R., Stewart A. I. and Gerard J.-C.

RUTherford J. A. and VRoom D. A.

Schaeffer R. C., Feldoman P. D. and Zipf E. C. SCHUNK R. W. and Walker J. C. G.

SChunk R. W., Banks P. M. and RaITT W, J.

SEATUN M. J.

Sharp R. D., Johnson R. G. and Shelley E. E. SHARP W. E.

Sharp W. E., Rusch D. W, and Hays P. B.

Slanger T. G., Wood B. J, and Black G.

Spencer N. W., Niemann H. B. and Carignan G. R.

Spiro R. W., HeElis R. A. and Hanson W. B.

Stebrings R. F., TuRner B. R. and RUTHERFORD J. A.

Stolarski R. S., Hays P. B. and Roble R. G.

St-Maurice J. P. and TorR D. G.

Strobel D. F., Hunten D. M. and MCELROY M. M.

Strobel D. F, Young T. R., Meier R. R., COFFEY T. P. and AuI A. W.

Strobel D. F., Oran E. S. and Feldman P. D.

TINSLEY B. A.

Torr D. G. and OrsinI N.

TORr D. G. and OrsinI N.

Torr D. G. and Torr M. R.

TORR D. G., TORR M. R. and Laurie D. P.

TORR D. G., RUSCH D. W., TORR M. R.

Walker J. C. G., Hoffman J. H., Hays P. B. and OPPENHEIMER $M$.

TORR D. G., TORR M. R., HOFFMAN R. A. and WALKER J. C. G.

TORR D. G., TORR M. R., WALker J. C. G., Brace L. H., Brinton H. C., Hanson W. B., HOFFMAN J. H., NiER A. O. and OPPENHEIMER $\mathrm{M}$.

TORr D. G., TORR M. R., Walker J. C. G., Nier A. O., Brace L. H. and Brinton H. C.

TORR D. G., TORR M. R., RUSCH D. W., HaYs P. B., Mauersberger K.,

Walker J. C. G., Spencer N. W., Hedin A. E., Brinton H. C. and Theis R. F.

TORR D. G., OrsinI N., TORR M. R., HANSON W. B., HOFFMAN J. H. and WALKer J. C. G.
1975 Rev. Geophys. Space Phys. 13, 709.

1973 Radio Sci. 8, 277.

1977 JHA/APL Preprint 77-05, NATO Advd Study Insts Ser., D. Reidel.

1969 Planet. Space Sci. 17, 1725.

1962 J. chem. Phys. 36, 1509.

1978 Planet. Space Sci. 26, 131.

1975 Annls geophys. 29, 503.

1967 Planet. Space Sci. 15, 1097.

1975 Planet. Space Sci. 23, 1017.

1973 J. geophys. Res. 78, 5676.

1975 a J. geophys. Res. 80, 2330.

1975b J. geophys. Res. 80, 1832.

1976 Geophys. Res. Lett. 3, 537.

$1977 \mathrm{a}$

$1977 b$

J. geophys. Res. 82, 719.

1971

1972

1973

1976

1956

1976

1978

1975

1971

1973

1978

1966

1975

1978

1970

1974

1976

1979

1977

1978

1978

1972

1974

EOS 58, 1198.

J. chem. Phys. 55, 5622.

J. geophys. Res. 77, 6828 .

Planet. Space Sci. 21, 1875.

J. geophys. Res. 81, 3271.

The Airglow and the Aurorat. Pergamon Press, New York, p. 289.

J. geophys. Res. 81, 3292.

J. geophys. Res. (in press).

J. geophys. Res. 80, 2876.

$J$. geophys. Res. 76, 8430 .

Radio Sci. 8, 284.

J. geophys. Res. 83, 4255 .

J. geophys. Res. 71, 771 .

J. geophys. Res. 80, 2266.

$J$ geophys. Res. 83, 969.

J. geophys. Res. 75, 4307 .

J. geophys. Res. 71, 3171.

J. geophys. Res. 81, 3745.

J. atmos. terr. Phys. (to appear).

Planet. Space Sci. 25, 1171.

Geophys. Res. Lett. 5, 657.

Rev. Geophys. 16, 327.

J. geophys. Res. 77, 203.

EOS Trans. Am. geophys. Un., 56, 1159.

$1976 a$

Geophys. Res. Lett. 3, 305.

$1976 \mathrm{~b}$

Geophys. Res. Lett. 3, 209.

$1976 \mathrm{c} J$ Jeophys. Res. 81, 5578 .

1976d Geophys. Res. Lett. 3, 1.

1977

J. geophys. Res. 82, 1631. 
Torr D. G., Donahue K., Rusch D. W., TORR M. R., NIER A. O., KAYER D.,

HANSON W. B. and HofmMan J. H.

TORR M. R., WALker J. C. G. and TORR D. G.

TORR M. R., TORR D. G., WALker J. C. G., hays P. B., Hanson W. B., Hoffman J. H. and KAYSER D. C.

TorR M. R., Hays P. B., Kennedy B. C. WALKER J. C. G

TORr M. R., St-Maurice J. P. and Torr D. G.

VICTOR G. A., KJRBY-DOCKEN K. and DALGARNO $A$.

WALker J. C. G., TORR D. G., HAYs P. B., Rusch D. W., KIRBY-DOCKEN K., VICTOR G. and OPPENHEIMER $M$.

Waldace I. and McElroy M. B.

WALLS F. L. and DUNN G. H.

WEILI Cr. M.

WILSON W. E.

ZIPF E. C.
1978

J. geophys. Res. (in press).

1974

1975

J. geophys. Res. 79, 5267.

Geophys. Res. Lett. 2, 395.

$1977 \mathrm{a}$

Planet. Space Sci. 25, 173.

1977b J. geophys. Res. 22, 3287.

1976 Planet. Space Sci. 24, 679.

1975 J. geophys. Res. 80, 1026.

1966 Planet. Space Sci. 14, 667.

$1974 J$ J. geophys. Res. 79, 1911.

1969 Atmospheric Emissions. Van Nostrand Reinhold, New York.

1967 J. chem. Phys. 46, 2017.

1978 EOS 59, 336.

Reference is also made to the following unpublished material:

Heroux L. and Hinteregger H. E.

HinTEREGGer H. E.

HINTEREGGER H. E.

Kirby-Docken, K., Constantinedes R., Babeu S.
Oppenheimer M. and Victor G. A.

MICHELS H. H.

\section{ORSINI N.}

SWENSON G. R.

Takanayagi $\mathrm{K}$.

TORR D. G.

TORR D. G., TORR M. R., BRINTON H. C.,

Brace L. H., Spencer N. W., Hedin A. E.,

Hanson W. B., Hoffman J. H., Nier A. $O$. and WALKer J. C. G.

TORR M. R. and TORR D. G.

TORR M. R. and TORR D. G.
1978 Submitted to J. geophys. Res.

1978a Submitted to J. geophys. Res.

1978b Submitted to Rev. Geophys. Space Phys.

1978 Submitted to Atomic Data.

1974 Report AFWL-TR-73-288, Air Force Weapons Laboratory, Kirtland Air Force Base, Unpublished.

1977 PhD Thesis, University of Michigan.

1976 PhD Thesis, University of Michigan.

1964 JILA Rept. 7, University of Colorado.

1979 J. geophys. Res. (in press).

1979 J. geophys. Res. (in press).

1979a J. geophys. Res. (in press).

1979 b Planet. Space Sci. (in press). 